San Jose State University

SJSU ScholarWorks

Master's Theses

Master's Theses and Graduate Research

Fall 2015

\title{
Movements, Habitat Use, and Demography of Western Pond Turtles in an Intermittent Central California Stream
}

Joseph Paul Belli

San Jose State University

Follow this and additional works at: https://scholarworks.sjsu.edu/etd_theses

\section{Recommended Citation}

Belli, Joseph Paul, "Movements, Habitat Use, and Demography of Western Pond Turtles in an Intermittent Central California Stream" (2015). Master's Theses. 4624.

DOI: https://doi.org/10.31979/etd.b9sq-ak47

https://scholarworks.sjsu.edu/etd_theses/4624

This Thesis is brought to you for free and open access by the Master's Theses and Graduate Research at SJSU ScholarWorks. It has been accepted for inclusion in Master's Theses by an authorized administrator of SJSU ScholarWorks. For more information, please contact scholarworks@sjsu.edu. 


\title{
MOVEMENTS, HABITAT USE, AND DEMOGRAPHY OF WESTERN POND TURTLES IN AN INTERMITTENT CENTRAL CALIFORNIA STREAM
}

\author{
A Thesis \\ Presented to \\ The Faculty of the Department of Biological Sciences \\ San José State University \\ In Partial Fulfillment \\ of the Requirements for the Degree \\ Master of Science
}

By

Joseph P. Belli

December 2015 
(C) 2015

Joseph P. Belli

ALL RIGHTS RESERVED 
The Designated Thesis Committee Approves the Thesis Titled

\section{MOVEMENTS, HABITAT USE, AND DEMOGRAPHY OF WESTERN POND TURTLES IN AN INTERMITTENT CENTRAL CALIFORNIA STREAM}

by

Joseph P. Belli

APPROVED FOR THE DEPARTMENT OF BIOLOGICAL SCIENCES

SAN JOSÉ STATE UNIVERSITY

December 2015

Dr. Jerry J. Smith

Dr. Paula Messina

Stephanie Trewhitt, MS
Department of Biological Sciences

Geology Department

Department of Biological Sciences 


\begin{abstract}
MOVEMENTS, HABITAT USE, AND DEMOGRAPHY OF WESTERN POND TURTLES IN AN INTERMITTENT CENTRAL CALIFORNIA STREAM
\end{abstract}

By Joseph P. Belli

Western Pond Turtles, Emys (Actinemys) marmorata, were captured $(\mathrm{n}=173)$ in 2011 (wet year) and 2012-2013 (successively drier drought years) along upper Coyote Creek, an intermittent stream in central California. Males outnumbered females 2.8:1, juveniles less than $120 \mathrm{~mm}$ long made up $26 \%$ of captures, growth rates varied among individuals, and little growth occurred in turtles older than 10 years. I radio-tracked turtles from May 2011 through August 2013 to ascertain movements and seasonal habitat use. Males had much larger home ranges than females (means of $2281 \mathrm{~m}$ for males and $501 \mathrm{~m}$ for females in 2012), and males moved extensively in April and May, during the apparent breeding season. Turtles preferred deep and complex pools, complex runs, and backwaters. Turtles left the stream for upland habitats in late spring and summer as stream flow ceased and pool connectivity was broken. There was substantial variation in departure dates among individuals and between wetter and drier reaches. Mean departure date was 16 August in 2011, but decreased to 20 July in 2012 and 28 June in 2013, as the drought intensified. Upland sites were mostly within $100 \mathrm{~m}$ of the stream, beneath dried leaves and/or thatch, and on slopes varying from flat to over $40 \%$. Turtles remained upland for almost seven months in 2011-2012, although there was much variation. Mean return to stream dates were 27 February (males) and 16 March (females). 


\section{ACKNOWLEDGMENTS}

This work could not have been completed without the efforts and support of many people. I'll begin with my family. My late grandparents, Joey and Florence Franco, introduced me to the outdoors and instilled in me a lifelong love of learning and exploring. My parents, Lee and Joy Belli, have been unwavering in their support of my academic goals, and my sons Joe and Ryan have always been ready to help in a multitude of ways.

On an institutional level, I am grateful to the Santa Clara County Open Space Authority for allowing access to the study area, and to the California Department of Fish and Wildlife for issuing the necessary permits. I thank Arthur and Karin Nelson for establishing the scholarship that provided much of the funding for this study.

Academically, I give thanks to Rey Morales at Gavilan Community College in Gilroy for all his encouragement and guidance when I first entered his biology department prior to my acceptance at SJSU. At San José State, I was fortunate to have learned from a number of fine instructors, especially those teaching field courses, Dr. Jerry Smith, Dr. Susan Lambrecht, and Professor Stephanie Trewhitt.

A number of people gave of their time to assist in the field work- a big thanks to Ymer Bjornson, Rachel Roberts, Kumi Soichi, Ruth Sundermeyer, and Wendy TubbsChase.

If not for Earl Gonsolin, I would never even have thought of pursuing a degree. It was he who encouraged me, and more importantly gave me the confidence I needed to do so. 
Dr. Paula Messina and Professor Stephanie Trewhitt deserve huge thank-you's for serving on my committee and providing comments, corrections, and suggestions that made this thesis much better than it would otherwise have been.

Some labs contain a number of students. I had just one labmate. If you're going to have just one, you couldn't possibly do better than Neil Keung. Neil spent many long days in the field, always bringing a smile, gentle demeanor, and a great work ethic. He was even more valuable in helping format the thesis and navigate the labyrinthine set of rules and requirements necessary to complete this thesis.

Finally, the biggest thank-you of all goes to Dr. Jerry Smith, who took a chance on me when 99 teachers out of 100 would have passed. His guidance, dedication, and hard work made the study as good as it could be, and while I truly appreciate his contribution to this study, I am equally appreciative of his dedication to his students, his insistence on doing things the right way, his passion for teaching, and living by an ethos that sees conservation biology as something far more than data and figures, but a set of values placing the preservation of biodiversity as its fullest expression. 


\section{Table of Contents}

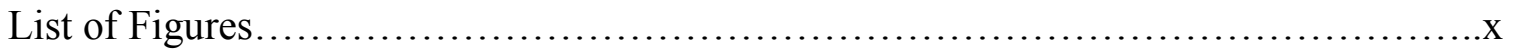

List of Tables..................................................................

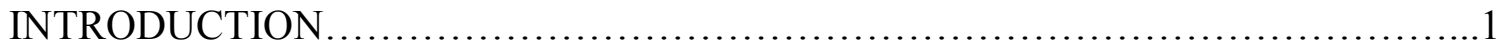

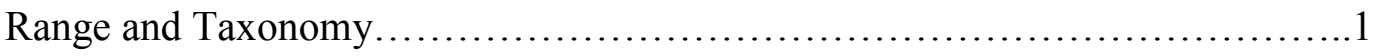

Description.........................................................

Habitat.................................................................

Life history.....................................................4

Nesting............................................................6

Growth...........................................................

Diet............................................................. 9

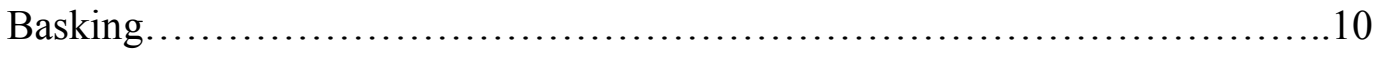

Seasonal Habitat Use.................................................11

Movements and Home Range....................................... 14

Population Density and Structure.....................................14

Historical Decline and Conservation Status.............................. 16

Research Objectives................................................18

STUDY AREA .......................................................... 19

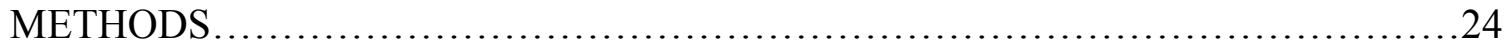

Turtle Location.....................................................24

Stream Flow and Air and Water Temperatures...........................26

Capture Methods..................................................26 
Data obtained from Captured Turtles...................................28

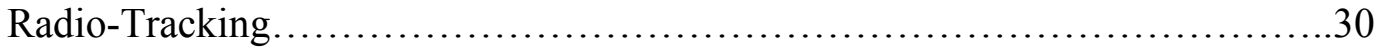

RESULTS............................................................. 36

Stream Flows and Air and Water Temperatures..............................36

Stream flow............................................... 36

Air temperatures.................................................39

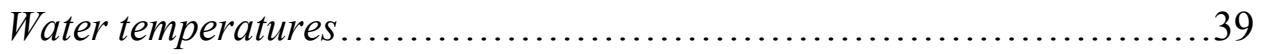

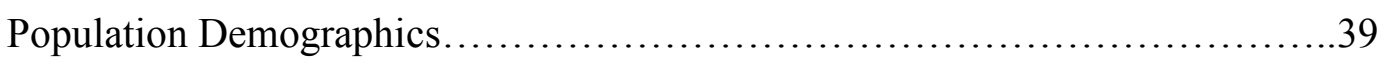

Gender composition...........................................41

Size...................................................41

Age structure................................................41

Growth rate................................................43

Female reproductive status....................................45

Home Ranges....................................................46

Seasonal Movement....................................................49

Return dates......................................................49

In-stream movements.......................................50

Response to spring storms...................................53

Movement to upland sties......................................53

Upland activity .............................................54

Spring/Summer Meso Habitat Use ..................................6 60

Microhabitat Use...................................................6 62 


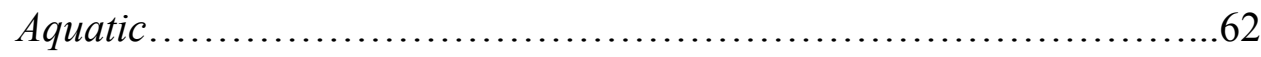

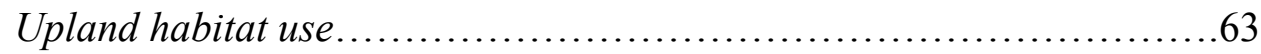

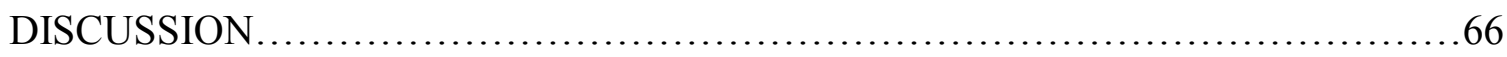

Population Demographics...............................................66

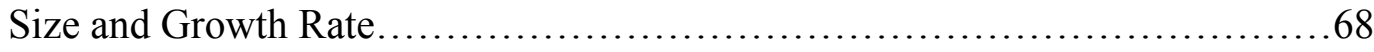

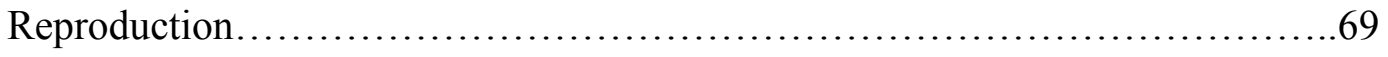

Home Range.......................................................... 71

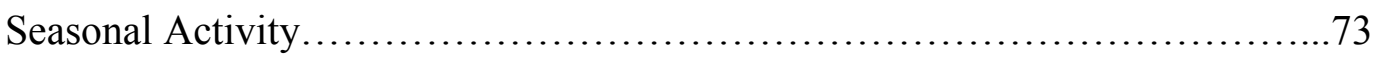

Spring/Summer Aquatic Habitat Use....................................... 81

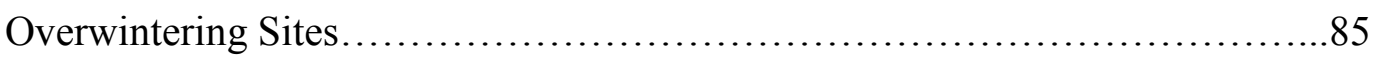

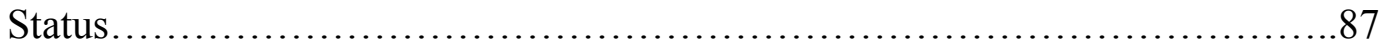

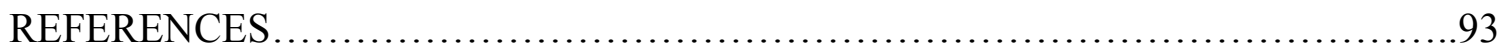




\section{List of Figures}

Figure 1. Location of Western Pond Turtle study area on upper Coyote Creek 20112013. Numbers refer to pool numbers.

Figure 2. More perennial core of Western Pond Turtle study area (Pools \#1-9) in 20112013, showing denser vegetation on north-facing slopes and sparser vegetation on

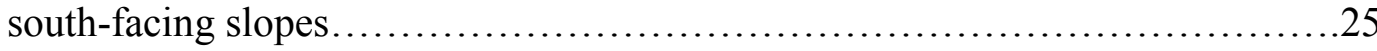

Figure 3. Stream flow at the USGS gage at the upper Coyote Creek turtle study site in

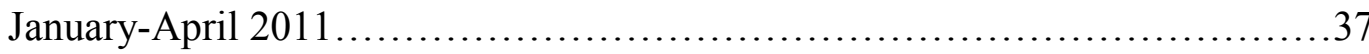

Figure 4. Stream flow at the USGS gage at the upper Coyote Creek turtle study site in

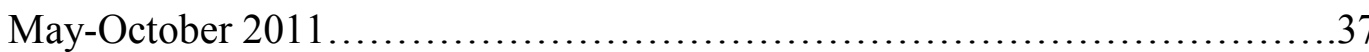

Figure 5. Stream flow at the USGS gage at the upper Coyote Creek turtle study site in

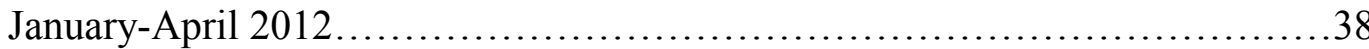

Figure 6. Stream flow at the USGS gage at the upper Coyote Creek turtle study site in

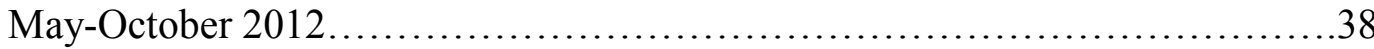

Figure 7. Stream flow at the USGS gage at the upper Coyote Creek turtle study site in

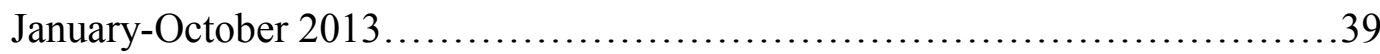

Figure 8. Air Temperatures at the upper Coyote Creek turtle study site (USGS gage) in

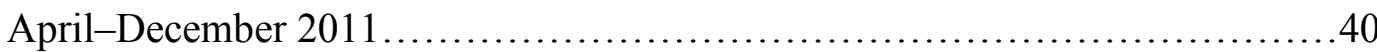

Figure 9. Water temperatures at the upper Coyote Creek turtle study site (USGS gage) in

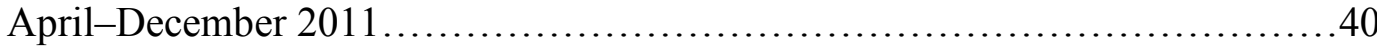

Figure 10. Distribution of carapace lengths and sexes of Western Pond Turtles $(n=173)$ at first capture at upper Coyote Creek, Santa Clara County, California, 20112012. Shaded bars represent males $(n=94)$, striped bars represent females $(n=34)$, open bars represent juveniles of unknown gender $(n=45) \ldots \ldots \ldots \ldots \ldots \ldots \ldots .42$

Figure 11. Age distribution of Western Pond Turtles $(n=173)$ at fist capture at upper Coyote Creek, Santa Clara County, California, 2011-2012. Shaded bars represent males $(n=94)$, striped bars represent females $(n=34)$, open bars represent juveniles of unknown gender $(n=45)$. 42

Figure 12. Ranges (m) of individual Western Pond Turtles radio-tracked in a) 2011 $(n=23)$ and b) $2012(n=26)$ along upper Coyote Creek, Santa Clara County, California. Solid bars represent males, striped bars represent females, and the open bar represents a juvenile, gender unknown. 
Figure 13. Ranges (m) of recaptured non radio-tracked Western Pond Turtles $(n=81)$ on upper Coyote Creek, Santa Clara County, California, 2011-2012. Shaded bars represent males $(n=45)$, striped bars represent females $(n=10)$, open bars represent juveniles of unknown gender $(n=27)$.

Figure 14. Return-to-stream dates in 2012 among Western Pond Turtles ( $n=15)$ radiotracked from winter refugia in 2011 along upper Coyote Creek, Santa Clara County, California. Dark bars represent males, striped bars represent females

Figure 15. Weekly mean movement (m) of radio-tracked Western Pond Turtles in a) 2011 and b) 2012 on upper Coyote Creek, Santa Clara County, California. Shaded diamonds represent male movements, and striped squares represent female movements.

Figure 16. Stream departure dates in a) $2011(n=18)$, b) $2012(n=21)$, and c) $2013(n=15)$ for Western Pond turtles radio-tracked along upper Coyote Creek, Santa Clara County, California. Dark bars represent males, striped bars represent females....

Figure 17. Monthly upland movements of Western Pond Turtles along Coyote Creek from July 2011-Februrary 2012; a) number of movements and b) mean distance moved

Figure 18. Duration of upland habitat occupancy of radio-tracked Western Pond Turtles $(n=15)$ in upper Coyote Creek, Santa Clara County, California, summer 2011spring 2012. Dark bars represent males $(n=8)$, striped bars represent females $(n=7)$.

Figure 19. Habitat available (black bars) and habitat used (white bars) in pools -10 to 25 in the Western Pond Turtle study area in upper Coyote Creek from 2011-2012. Dry Channel habitat availability was not calculated.

Figure 20. a) Distance from stream and b) percent canopy of upland sites used by Western Pond Turtles on upper Coyote Creek in summer 2011-spring 2012

Figure 21. a) Aspect and b) slope of upland sites used by Western Pond Turtles on upper Coyote Creek in summer 2011-spring 2012. .65 


\section{List of Tables}

Table 1. Age (years), sample size (n), mean size ( $\mathrm{mm})$, and size range (mm) of carapace lengths of Western Pond Turtles initially captured at upper Coyote Creek, Santa Clara County, California, 2011-2012 .....................................43

Table 2. Age classes (years), sample size (n), and mean growth ( $\mathrm{mm}$ ) of Western Pond Turtles $(n=44)$ initially captured in 2011 and recaptured in 2012 in upper Coyote Creek, Santa Clara County, California........................................44

Table 3. Carapace length (mm), sample size (n), and mean growth (mm) of Western Pond Turtles $(n=44)$ initially captured in 2011, and recaptured in 2012 in upper Coyote Creek, Santa Clara County, California..............................45 


\section{INTRODUCTION}

\section{Range and Taxonomy}

Emys (Actinemys) marmorata, the Western Pond Turtle (WPT), is found along the Pacific Coast of North America from Washington to Baja California Norte, primarily west of the Sierra Nevada and Cascade ranges (Stebbins 2003; Ernst and Lovich 2009). Isolated populations exist in the vicinity of Puget Sound, the Columbia River Gorge, the Mojave River, and the Carson and Truckee rivers of western Nevada. The Truckee and Carson river populations may have been introduced, and the Truckee population may no longer be extant (Ernst and Lovich 2009). Historical accounts from Vancouver Island and mainland British Columbia may represent transplanted individuals, and there have been no reports of the species from either region since the 1960s (Ernst and Lovich 2009). A single record from southwestern Idaho probably represents a transplant (Ernst and Lovich 2009). Its status and distribution in Baja California is poorly documented. Throughout most of its range, it exists as the only native turtle species (Germano and Rathbun 2008).

The earliest fossil record for the species dates back to the Pliocene Epoch (Ernst and Barbour 1972). During the Pleistocene Epoch, the species enjoyed a more extensive distribution, occurring throughout the western Great Basin, but in the aftermath of climatic warming and drying, its range contracted to the Pacific Coast (Brattstrom and Sturn 1959). In 1841, the first specimen was collected for science, and in 1852 Baird and Girard authored the first scientific description of the species, which they named Emys marmorata (Bury and Germano 2008; Ernst and Lovich 2009). The genus was later 
changed to Clemmys, and Seeliger (1945) proposed two subspecies based on morphological characteristics. Clemmys marmorata marmorata was the northern subspecies, occurring north of San Francisco Bay, while C. m. pallida was found to the south. A large intergrade zone was identified in central California. Morphological characteristics of C. m. marmorata included prominent triangular inguinal scutes and throat color paler than the sides of the head. In contrast, C. m. pallida featured reduced or absent inguinal scutes and similar coloration between the throat and sides of the head (Ernst and Barbour 1972; Stebbins 2003). Also on the basis of morphological features, Holland (1994) suggested that Clemmys marmorata actually consisted of three separate species: the two subspecies proposed by Seeliger, and the population inhabiting the Columbia River Gorge.

Molecular analyses for the species were first conducted in the 1990s. The results generally supported Seeliger's long-held subspecies designations but suggested a more complex situation. The Columbia River population and isolated populations in southern California and Baja California are genetically unique and could represent different taxa (Janzen et al. 1997; Ernst and Lovich 2009). In 2005 Spinks and Shaffer analyzed mitochondrial DNA from specimens throughout the range and, given the lack of support, the traditional two subspecies designation was recommended to be dropped. The WPT was considered a single species with no recognized subspecies by Ernst and Lovich (2009), and was moved from the genus Clemmys into the genus Actinemys, in which it was the sole member. Most recently, Spinks et al. (2014) used nuclear DNA, and the 
genetics supported two clades that matched Seeliger (1945) but differed sufficiently to be considered separate species within the genus Emys.

\section{Description}

The WPT is a medium-sized turtle, with adults typically ranging between 160-180 mm carapace length (CL; Bury and Germano 2008). The largest specimen recorded attained a length of $241 \mathrm{~mm} \mathrm{CL}$ (Lubcke and Wilson 2006). The WPT is cryptically colored with a carapace varying in tone from olive to nearly black (St. John 2002; Stebbins 2003; Ernst and Lovich 2009). The shell is low and may be subtly mottled or it may exhibit numerous dark flecks. The plastron is light in color, from whitish to pale yellow, and often contains dark blotches. The head is sometimes plain but frequently reticulated with dark markings. Throughout the range, individual variation appears high (Bury et al. 2012).

\section{Habitat}

The WPT is associated with a wide variety of aquatic habitats, from the still waters of lakes and ponds to flowing rivers and streams. In addition to natural habitats, it also utilizes man-made aquatic features such as reservoirs, canals, stock ponds, and even sewage treatment ponds (Holland 1994; Bury and Germano 2008; Germano 2010). Besides freshwater habitats, it has also been recorded in the brackish waters of coastal lagoons. Although most populations are found at elevations below $1500 \mathrm{~m}$, the species has been documented at $2048 \mathrm{~m}$ above sea level (Ernst and Lovich 2009). Aquatic habitat need not be perennial, for the WPT also occupies temporary ponds and seasonal streams (Holland 1994; Bury and Germano 2008). In streams, WPT are found in greatest 
concentrations in pool habitats (Bury 1972), while along the Trinity River, Reese and Welsh (1998) found optimal habitat features included deep waters with low velocity and suitable refugia such as boulders, root masses, and woody debris. Adequate basking sites are also key components of optimal habitat (Ernst and Lovich 2009). Despite its common name and its association with aquatic habitats, the WPT nevertheless relies heavily on terrestrial habitats for several crucial elements of its existence (Ernst and Lovich 2009). Females require upland habitat for nesting (Rathbun et al. 2002) while both genders utilize terrestrial sites in response to drought and stream drying (Rathbun et al. 2002; Bondi 2009). Turtles also seek refuge from floods by overwintering in upland habitat (Davis 1998; Rathbun et al. 2002). Although the timing and duration of terrestrial habitat usage vary, Reese and Welsh (1997) found that males in their Trinity River population utilized terrestrial habitat to some degree in 10 months out of the year, while females, due to nesting, used upland habitat at some point during all 12 months.

\section{Life History}

The WPT is a potentially long-lived species with a lifespan exceeding 40 or possibly 50 years under natural conditions (Holland 1994; St. John 2002; Bury and Germano 2008). Bury (2012) marked turtles that he estimated were at least 15 years old in 1968 along a tributary of the Trinity River. Some were recaptured 40 years later, suggesting that the maximum life span in the wild may exceed 55 years. The age of initial reproduction in females was believed to be between 8-10 years old (Holland 1994), but that figure is variable and may be due to geography and/or site-specific environmental conditions (Ernst and Lovich 2009). Bury and Germano (2008) suggested 
maturation ages of 7-10 years for northern populations and 4-8 years for southern populations. Females along Oregon's Rogue River began breeding at 10-12 years of age (Holland 1994). In contrast, Germano and Rathbun (2008) discovered four year old gravid females along the central California coast, as did Germano (2010) in the San Joaquin Valley. In terms of size, most females are thought to exceed $120 \mathrm{~mm}$ CL before breeding, although Goodman (1997a) documented a gravid female $110 \mathrm{~mm}$ CL in southern California. Very little is known about age or size among males at the onset of breeding. Holland (1994) found males with developed testes at $110 \mathrm{~mm} \mathrm{CL}$, and courtship behavior exhibited by a male of just $90 \mathrm{~mm}$ CL.

Mortality rates are highest among hatchlings and juveniles, with annual survivorship in the 1-3 year age class estimated at just 10-15\% (Holland 1994). Adult mortality rates are much lower, estimated at 3-5\% annually. Many species have been confirmed or suspected of being predators of WPT, especially upon eggs, hatchlings, and juveniles (Holland 1994; Ernst and Lovich 2009), including non-native species such as bass (Micropterus spp.) and bullfrogs (Rana catesbeiana; Holland 1994; Bury and Germano 2008). Adult turtles face fewer predators than hatchlings or juveniles but are nonetheless preyed upon. Raccoons (Procyon lotor) have been cited as predators upon all life stages, especially in or near urban areas (Holland 1994; Bury and Germano 2008). Besides predation and anthropogenic causes, information on additional mortality factors, particularly diseases, is lacking. Ernst and Barbour (1972) listed five species of trematode and two species of nematode parasites plaguing the species, but did not consider them as sources of mortality. 


\section{Nesting}

Females select nest sites and deposit eggs from late April through August (Ernst and Lovich 2009). Nesting activity may peak in summer. Reese and Welsh (1997) documented nesting along the Trinity River in June and July, while Holland (1985) found turtles nesting in central California from June to August. Nest sites require specific conditions including abundant sunlight and dry soils, and nests are usually dug in areas of scant vegetation (Holland 1994). Rathbun et al. (1992) found nest sites associated with open grassy areas and southern exposure. While nests are sometimes situated just above the water's edge near ponds, nests as distant as $400 \mathrm{~m}$ from water have been recorded (Holland 1994). Clutch size varies from 1-13 (Holland 1994), with larger females producing larger clutches (Goodman 1997a). Not all mature females reproduce annually. In a three year study in southern California, Goodman (1997a) found that only 2 of 15 females clutched in consecutive years. Scott et al. (2008) tracked 39 female turtles through 66 nesting seasons along coastal streams in central California and found a broad spectrum of nesting behavior. They found no clutches in 10 cases, 1 clutch in 27 instances, and 2 clutches on 29 occasions. Double clutching has been reported in several studied populations and may be common at some sites (Goodman 1997b; Rathbun et al. 2002). Double clutching may vary geographically and may be more prevalent in southern populations or warmer sites. At least one instance of triple clutching has been observed in the San Joaquin Valley (Bury et al. 2012). WPT gender is temperature dependent, with low development temperatures producing males and higher temperatures producing females (Ernst and Lovich 2009; Geist et al. 2015). The incubation period varies from 
80-122 days (Holland 1994). Hatching occurs in late summer or fall (Buskirk 1991). In some populations hatchlings remain in the nest throughout the winter and return to aquatic habitat in spring (Reese and Welsh 1997; Rathbun et al. 2002). Hatchling size ranges from 23-31 mm CL (Hill 2006).

\section{Growth}

Young exhibit accelerated growth rates. Holland (1994) calculated rates of 3.29 $\mathrm{mm} / \mathrm{month}$ during the first year and $1.95 \mathrm{~mm} / \mathrm{month}$ in the second year. Growth rates tapered off to $0.4 \mathrm{~mm} / \mathrm{month}$ during the fifth year. Growth rates described by Storer (1930) would result in turtles attaining lengths of 135-140 mm in 8-10 years (Ernst and Lovich 2009). A general trend for slower growth rates in the north versus the south has been postulated by Bury and Germano (2008). Growth rates, however, may be heavily influenced by environmental factors and thus subject to high variation. Cool air and water temperatures depress rates of food consumption, digestion, and growth in ectotherms (Germano and Bury 2009). Rapid growth rates are associated with larger body size, increased survivorship, early maturation, and enhanced reproductive success in WPT (Germano and Bury 2009; Bury et al. 2010). Several studies have examined the effects of temperature on growth rate in the WPT. On the Trinity River system in northern California, Ashton et al. (2006) found turtles growing faster and attaining larger sizes in the warmer waters of the South Fork than the main stem. However, Germano and Bury (2009) found no difference in growth rate or size of turtles occupying 6 pond habitats (warmer) and 4 stream habitats (cooler) in southern Oregon. Lubcke and Wilson (2007) studied the relationship between growth rate and habitat by measuring turtles in 
canal, slough, and stream habitats in the Sacramento Valley. They found the largest turtles occupying canals, while the smallest lived in streams. In the Mad River drainage, Bondi (2009) found turtles in a perennial stream to be significantly larger than those in an intermittent stream. Conditions associated with large size and rapid growth rate include warm water, perennial water, eutrophic conditions, abundant food supply, and good basking potential (Germano and Bury 2001; Lubcke and Wilson 2007; Germano and Rathbun 2008; Germano 2010). The fastest growth rates yet documented have come from turtles occupying sewage treatment ponds in the San Joaquin Valley, where Germano (2010) found turtles attaining lengths of $120 \mathrm{~mm} \mathrm{CL}$ in 2 years and $150 \mathrm{~mm} \mathrm{CL}$ in 4 years. In contrast, turtles along the central California coast took 4 years to reach 120 $\mathrm{mm} \mathrm{CL}$, while those in southern Oregon took between 5-9 years (Germano and Bury 2001).

Several studies have compared size and growth rate between the sexes. Most have shown either no significant difference or males growing larger and/or faster. Males grew faster and attained larger sizes at San Joaquin Valley sewage ponds (Germano 2010). Males also grew faster in ponds along the central California coast, but did not grow larger (Germano and Rathbun 2008). Males grew larger in the Klamath/Siskiyou region (Bury et al. 2010) as well as along the Russian River (Cook and Martini-Lamb 2004). Lubcke and Wilson (2007) did not measure growth rate but compared sizes of male and female turtles at three different habitat types (canals, sloughs, and streams) in the Sacramento Valley and found males significantly larger in sloughs and canals but no size difference between the sexes in streams. However, in the Mojave River, Lovich and 
Meyer (2002) found females to be significantly larger, $144 \mathrm{~mm}$ CL for females compared to $137 \mathrm{~mm} \mathrm{CL}$ for males.

\section{Diet}

The WPT is omnivorous, and a wide variety of items have been recorded in its diet (Bury and Germano 2008; Ernst and Lovich 2009). Animal matter may constitute a larger portion of its diet than plant material (Ernst 1972; Bury 1986). The most thorough dietary analysis was conducted in northern California by Bury (1986), who examined the stomach contents of 110 turtles. Although Bury confirmed omnivory, plant matter was less utilized, and algae, though readily available, constituted a small portion of the diet. Bury detected differences in diet between gender and age classes. Females consumed algae more than males, with algae present in $44 \%$ of the females but in only $10 \%$ of the males. Juveniles ate invertebrates almost exclusively and showed little use of plant material. Adult males took larger prey items, while juveniles had more but smaller prey items. Bury interpreted dietary differences between sexes and age classes as a means of avoiding intraspecific competition. Vertebrate prey was a small portion of the diet, and it could not be determined to what extent vertebrate prey was captured versus scavenged. An important aspect of WPT anatomy is that the species does not feed while on land, and must be in the water to swallow (Holland 1994; Rathbun et al. 2002). Although turtles have been documented carrying food from land to water to feed (Ernst 1972), the inability to feed on land may have profound implications for a species in which some populations typically spend over half the year occupying terrestrial habitat. 


\section{Basking}

Basking is an important mechanism for thermoregulation in WPT (Reese and Welsh 1998). WPT use at least two basking strategies, emergent (or aerial) basking and aquatic basking (Bury and Germano 2008). In emergent basking, turtles position themselves atop objects such as logs and boulders protruding above the water's surface or along the shore (Holland 1994). Stream microhabitats containing emergent basking features have been found to harbor more turtles than those without (Reese and Welsh, 1998). Emergent basking is terminated once a sufficient internal temperature has been attained, and turtles often respond by entering water (Ernst and Lovich 2009). Emergent basking may occur year round in mild climates (Bury and Germano 2008).

WPT engage in aquatic basking in habitats such as ponds where emergent basking objects are scarce or absent and warm water compensates for the lack of basking structures (Reese and Welsh 1998). Turtles may utilize floating mats of vegetation for aquatic basking and may also bask submerged beneath algal mats when such areas are warmer than surrounding waters (Holland 1994; Bury and Germano 2008; Germano and Rathbun 2008). WPT also bask in the warm, salty bottom layers of lagoons (Abel 2010). A third form of basking has been suggested by Rathbun et al. (2002), who identified terrestrial "resting" sites as possible basking locations. Such sites usually feature a combination of sunlight and vegetative cover, providing warmth, shade, and protective cover. 


\section{Seasonal Habitat Use}

Seasonal habitat use by the WPT varies geographically (Ernst and Lovich 2009) and is likely influenced by weather and hydrological conditions. While turtles are active in aquatic habitats throughout most of the spring and summer, turtles inhabiting streams may respond to drought and drying conditions by moving upland to terrestrial estivation sites (Rathbun et al. 2002). In perennial streams and rivers, turtles may remain active until fall/winter storms increase stream flows and reduce water temperatures. Turtles then move upland to seek refuge from flood conditions (Reese and Welsh 1997; Rathbun et al. 2002). Along California's central coast, Davis (1998) found turtles leaving a perennial stream in late fall in association with storms. Seasonal habitat use may vary within the same river drainage. Bondi (2009) found turtles estivating along an intermittent stream in the Mad River drainage, but not in a nearby perennial stream. Estivating turtles left stream habitats between early July and late August, coincident with the cessation of stream flow. Both populations overwintered upland. Some populations may remain active all year (Bury and Germano 2008). Lovich and Meyer (2002) found neither estivation nor overwintering behavior in turtles along the Mojave River.

Overwintering strategies may also vary between habitat types. Turtles inhabiting ponds and lakes often remain for the winter, burying themselves beneath the substrate (Holland 1994; Bury and Germano 2008), while turtles from rivers and streams overwinter at upland locations (Ernst and Lovich 2009). Along the central California coast, both Davis (1998) and Abel (2010) found turtles from a pond habitat overwintering on-site, while most turtles from an adjacent stream overwintered upland or moved to the 
pond. Several stream turtles moved to and overwintered in the pond, a phenomenon also noted by Reese and Welsh (1997). Once upland, WPT may remain sedentary or change locations frequently. Turtles along the Trinity River left the water in September, and changed sites up to four times before settling down in December (Reese and Welsh 1997). Rathbun et al. (2002) found stream turtles along the central California coast heading upland in October, with one using as many as nine different sites. Most moved far less often, with 51\% (22 of 43) moving once or not at all. Bondi (2009) found that estivating turtles often changed sites, although most movements were $10 \mathrm{~m}$ or less. Overwintering turtles showed less frequent movements, and upland sites showed considerable variation in distances from the stream. Davis (1998) found turtles at upland sites from 3-300 m away from the stream, although most were between 25-150 m from the stream. Rathbun et al. (2002) reported a similar finding, documenting distances ranging from 8-280 m (mean $49.7 \mathrm{~m}$ ). Both Holland (1994) and Reese and Welsh (1997) have found overwintering sites in excess of $500 \mathrm{~m}$ from streams, the longest such distances yet discovered.

The vegetation community at upland habitat sites varies. Reese and Welsh (1997) found turtles upland in both coniferous and oak forests. Rathbun et al. (2002) found 64\% overwintering in riparian plant communities, $18 \%$ in coastal sage scrub, and $18 \%$ in woodlands of oak or pine. Davis (1998) also found most turtles overwintering in a riparian plant community or seasonally flooded wetlands. While vegetation communities differed from site to site, open areas were avoided, and leaf litter was present at most sites (Reese and Welsh 1997; Davis 1998; Rathbun et al. 2002). Turtles typically buried 
themselves beneath leaf litter, usually between 5-10 cm deep (Rathbun et al. 2002). Another hallmark of upland sites was their position above flood level (Reese and Welsh 1997; Rathbun et al. 2002).

The duration of time spent at upland overwintering locations varied considerably between sites. Rathbun et al. (2002) documented periods ranging from 34-191 days (mean 111). Reese and Welsh (1997) characterized Trinity River turtles as being upland for 7 months annually, while Bondi (2009) found turtles from a perennial stream upland for an average of 207 days per year and turtles from an adjacent intermittent reach upland for an average of 241 days annually. The timing and duration of upland habitat usage may vary significantly with weather from year to year. One turtle tracked for 5 consecutive years had stream departure dates varying between 31 October and 9 January, with durations varying between 34-133 days (Rathbun et al. 2002).

Return dates from upland overwintering sites to stream habitats also show considerable flexibility, both within and among populations. Along the central California coast Rathbun et al. (2002) found most turtles returning to the stream in February, while Davis (1998) found them returning in April. In a comparison of perennial and seasonal streams in the Mad River drainage, Bondi (2009) found turtles along the intermittent stretch returning sooner (all by 20 April) than along the perennial stream (all by 13 May). Reese and Welsh (1997) noted a great degree of variation among turtles in the Trinity River, with some returning to the river as early as February, while others arrived as late as June. 


\section{Movements and Home Range}

Radio-tracking studies have documented movement and calculated home range areas for WPT in aquatic habitats. Movement studies have shown male turtles consistently traveling greater distances than females within the same stream system (Bury 1972; Reese 1996; Bondi 2009). Reese (1996) calculated male home ranges as twice as large as those of females, $1244 \mathrm{~m}$ for males versus $598 \mathrm{~m}$ for females, while Bury (1972) found male home ranges nearly 4 times larger than those of females, $976 \mathrm{~m}$ for males versus $248 \mathrm{~m}$ for females. While females were associated with smaller home ranges, there have been some notable exceptions. One female had a home range in excess of 4000 m (Goodman and Stewart 2000), while Abel (2010) documented a female moving $5000 \mathrm{~m}$ upstream. Individuals are also capable of covering considerable distances in a short period of time. Cook and Martini-Lamb (2004) found a male in the Russian River moving $762 \mathrm{~m}$ in 19 hours and $1241 \mathrm{~m}$ in 4 days.

\section{Population Density and Structure}

Typical population densities for WPT have been estimated between 23-214/ha (Ernst et al. 1994; Holland 1994), but densities exceeding 1000/ha may occur in favorable habitats (Holland 1994; Reese and Welsh 1998). Rathbun et al. (1992) estimated a population of 150-180 along a $6.2 \mathrm{~km}$ reach of stream $(24.2-29 / \mathrm{km})$ on California's central coast. Reese and Welsh (1997) estimated a population of 1210 along a $63 \mathrm{~km}$ stretch of the Trinity River and considered that density $(19.2 / \mathrm{km})$ to be low and indicative of suboptimal conditions for the species.

Sex ratios varied widely among studied populations (Ernst and Lovich 2009). 
While some populations show even gender distribution (Germano and Bury 2000; Lovich and Meyer 2002), others are male-biased, sometimes heavily so. Ratios of 2:1 or greater were found by Davis (1998) and Abel (2010) in California along a central coast stream, Lubcke and Wilson (2007) in a Sacramento Valley canal, and by Germano (2010) at sewage treatment ponds in Hanford in the San Joaquin Valley. The most extreme ratio to date was found in ponds at Vandenberg Air Force Base along the California coast near Lompoc, where males outnumbered females almost 4:1 (Germano and Rathbun 2008). While even ratios and male-biased populations are common, female-biased populations are not. Lubcke and Wilson (2007) reported a male/female ratio of 0.7:1 along a stream in the Sacramento Valley, while Bury and Germano (2010) noted more females than males in several sites in the Klamath/Siskiyou region.

Age structure of WPT populations is also subject to variation. Holland (1994) concluded that juveniles usually comprise $30-45 \%$ of a population. However, in a Willamette Valley, Oregon population juveniles accounted for only $10 \%$ of the population (Ernst and Lovich 2009), while along the Mojave River (Lovich and Meyer 2002), and in an urban waterway in the Sacramento Valley (Spinks et al. 2003) no juveniles were detected. Such situations suggest lack of recruitment and negative prospects for long-term survival of WPT. Some populations, however, show a preponderance of young turtles and relatively few older turtles (Germano and Bury 2001). Bury et al. (2010) cautioned against using size alone as an indicator of age structure, because productive habitats result in rapid growth rates. In such circumstances, 
juveniles may attain adult sizes and be classified inaccurately, leading to an erroneous assessment of age-related population structure.

\section{Historical Decline and Conservation Status}

The WPT has experienced substantial decline throughout most of its historical range since its formal scientific classification in the nineteenth century (Holland and Bury 1998; Stebbins 2003). This decline has been most severe in Washington, southern California, and the Central Valley of California. In the San Joaquin Valley alone, Stebbins (2003) estimated a historical population level exceeding 3 million. Today, the species persists there in fragmented populations and greatly reduced numbers (Stebbins 2003; Bury et al. 2010; Germano 2010). The population crash in southern California has been more recent but equally devastating. In 1960 the species was known from 87 localities from Ventura County south to the Mexican border. By 1987 that number had dropped to 53, and only 10 of those were considered viable populations (Brattstrom 1988). Today, northern California and southern Oregon comprise the stronghold for the species (Ernst and Lovich 2009).

There are a number of factors that have contributed to the decline of the WPT. Some have waned over time and are no longer considered significant threats, while others have emerged recently. In the late nineteenth and early twentieth centuries, commercial harvest of the WPT as a food source resulted in a substantial number of turtles being removed from the wild. In 1895 alone, the U.S. Bureau of Fisheries estimated the annual catch at 63,000 (Bury and Germano 2008). According to Storer (1930), they were sold in San Francisco markets for \$3-\$6 per dozen in the 1920s. Commercial trade continued 
until the 1930s (Bury and Germano 2008). Commercial exploitation of the WPT extended beyond its use as a food source. Collecting for the pet trade also resulted in the removal of WPT from wild populations. During the 1960s one dealer in southern California shipped 500 to Europe in a single year. Today, collecting WPT is no longer legal (Bury and Germano 2008), although some are undoubtedly removed from the wild each year. Recent increases in roads, vehicular traffic, and the fragmentation of habitat have left turtles vulnerable to road mortality, which may represent a substantial threat (Holland 1994). Another emerging threat may be the proliferation of non-native turtles in WPT habitat. This threat is most prevalent in and around urban and suburban areas (Germano 2010), where disinterested pet owners release captive turtles. Stebbins (2003) lists four species of non-native aquatic turtles that have established populations within the range of the WPT, while Spinks et al. (2003) documented eight exotic turtle species present with WPT within an urban waterway in Davis. While the effects of non-native turtles on WPT have yet to be analyzed, it is reasonable to speculate that non-native turtles represent competition for limited food resources and basking sites, as well as reservoirs for pathogens (Bury and Germano 2008). Groundwater depletion accelerated by exotic tamarisk (Tamarix spp.) threatens WPT in the Mojave River (Lovich and Meyer 2002).

The biggest and most pervasive threat to the WPT has been the loss and alteration of habitat (Bury and Germano 2008; Ernst and Lovich 2009; Germano 2010). Wetlands large and small have been drained and cleared for agricultural and urban expansion. Flood control projects and water developments, including dams, have altered and 
degraded habitats for the species throughout its range (Reese and Welsh 1997; Reese and Welsh 1998; Germano 2010). The end result has been a substantial decline in the overall abundance of the species and considerable fragmentation of remaining populations. In 1992, the WPT was petitioned for listing as a Threatened Species under the Federal Endangered Species Act of 1973, but that petition was denied in 1993 (USFWS 1993; Bury and Germano 2008). The WPT has been granted some level of protection in all three Pacific Coast states. In California, it has been designated a Species of Special Concern. This status affords some basic protections, such as a ban on collecting, but does not serve to protect habitat (Bury and Germano 2008). However, it does require that the WPT be addressed in Environmental Impact Reports, and mitigation of impacts often results.

\section{Research Objectives}

The past two decades have seen an increased amount of research devoted to the biology and ecology of the WPT. However, much remains to be learned about the species. The primary focus of this research was to determine movement and seasonal activity patterns of WPT along a seasonal stream. It addressed both spatial and temporal elements of turtle movement and habitat use. Prior research on WPT movement and seasonal habitat use has primarily focused on turtles inhabiting permanent streams, while movement data for intermittent streams have been lacking. Likewise, research efforts along coastal watersheds in California have been more extensive than those along the Inner Coast Ranges. This is especially true south of San Francisco Bay, where few if any studies have been initiated within the Diablo Range. 
In addition to movement and habitat use, this study also provided insight into the demographics of the population. While some studies have examined both movement and population structure, most have concentrated on one or the other. By integrating information on movement, habitat use, and population structure within a seasonal stream in a region where little research on behalf of the WPT has been conducted, this study will hopefully provide additional information useful in conserving and protecting this unique and interesting species.

\section{STUDY AREA}

The Coyote Creek watershed is an important feature of the San Francisco Bay Area. From its headwaters east of the Santa Clara Valley, it drains a portion of the Diablo Range before entering the valley northeast of the cities of Morgan Hill and Gilroy (Figure 1). It then flows north for over $40 \mathrm{~km}$ before emptying into the southern arm of the San Francisco Bay. Above the valley floor, two dams were constructed to harness its waters for residential, commercial, and agricultural needs, and to replenish an aquifer depleted from decades of groundwater pumping. Coyote Reservoir, completed in 1936, has a storage capacity of over 22,000 acre-feet, while farther downstream Anderson Reservoir, finished in 1948, has a 91,000 acre-feet capacity (Bousman 2007). Although those dams profoundly altered flow regimes, stream morphology, and ecological communities downstream, upstream of Coyote Reservoir upper Coyote Creek remained in a mostly natural state.

Upper Coyote Creek (UCC) originates at the confluence of the Middle Fork and East Fork of Coyote Creek in Henry W. Coe State Park (Coe Park), and terminates at the 


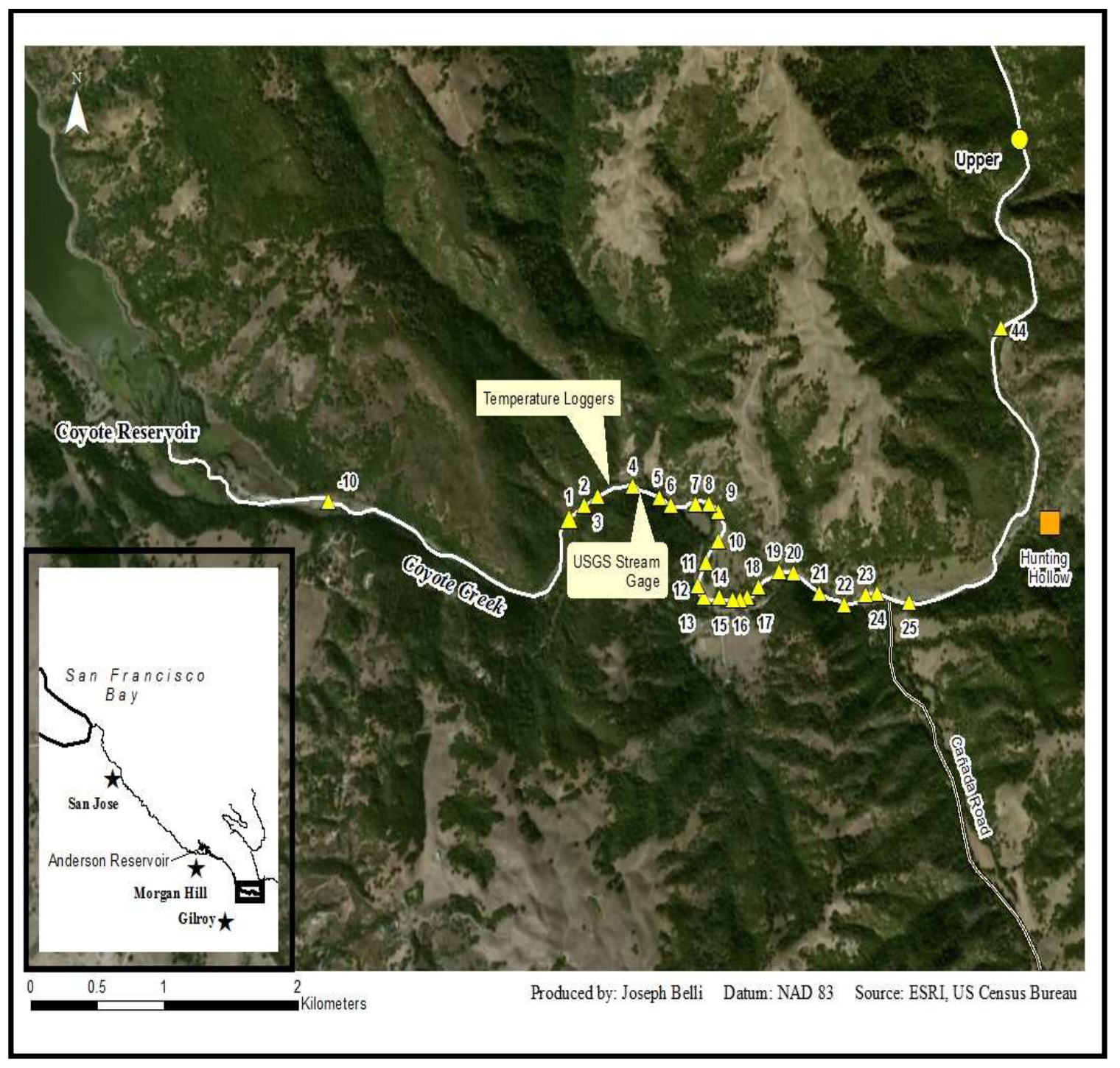

Figure 1. Location of Western Pond Turtle study area on upper Coyote Creek 2011-2013. Numbers refer to pool numbers.

inflow to Coyote Reservoir, a distance of roughly $20 \mathrm{~km}$. The creek initially flows south through a steep canyon separating Palassou Ridge and Mahoney Ridge. It then turns west, swinging widely before changing course and flowing north before emptying into Coyote Reservoir. 
The geophysical features of upper Coyote Creek include a low gradient $(<1 \%)$, low entrenchment, and moderate sinuosity, with a substrate consisting mostly of cobbles and gravels. Boulders are present but not prominent, and downed woody debris is uncommon. Some braided channels and backwaters are present, while long pools and runs dominate. Many of the pools are scour pools associated with western sycamores (Platanus racemosa) which grow along the bank.

Upper Coyote Creek is a mostly seasonal stream in which continuous flow ceases in some reaches in late spring or early summer. Thereafter, stream flow becomes increasingly restricted between pool complexes, and by fall connectivity is either nonexistent or greatly reduced. In fall, most pools have dried completely, and the few still containing water persist in areas with entrenched channels and substantial tree canopy and shading.

The climate of the study site is typical of the Mediterranean climate found throughout much of California: one of hot, dry summers and cool, wet winters. Most precipitation falls as rain between the months of December through March, while virtually no rain falls between the months of June through September (Bousman 2007). On the floor of the Santa Clara Valley west of the study site, mean annual precipitation ranges between 35.6-45.7 cm (Bousman 2007). At higher elevations in the watershed, such as the visitor center at Coe Park (approximate elevation $800 \mathrm{~m}$ ), precipitation is greater, with averages exceeding $63 \mathrm{~cm}$ (Pine Ridge Association 1997).

The topography adjacent to upper Coyote Creek consists of a series of north to south ridges rising to elevations approaching $800 \mathrm{~m}$. Many slopes are steep, exceeding 
50 degrees, and the varied topography results in a diverse assortment of vegetation communities. North and east facing slopes have closed canopy forests of coast live oak (Quercus agrifolia) and California bay (Umbellularia californica). Deciduous trees associated with more mesic conditions such as big leaf maple (Acer macrophylum) and black oak (Quercus kelloggii) are also present in smaller numbers. In contrast, south and west facing slopes contain two types of oak woodlands. Live oak woodlands predominate adjacent to drainages, while those of blue oak (Quercus douglasii) occupy drier slopes. The most xeric areas are dominated by coastal sage scrub, a community composed of shrubs such as California sagebrush (Artemisia californica), sticky monkeyflower (Mimulus aurantiacus), deerweed (Acmispon glaber), and poison oak (Toxicodendron diversilobum). Grasslands dominated by non-native species cover some of the slopes, ridgetops, and open areas above the stream terrace, where valley oaks (Quercus lobata) can also be found. The riparian community is dominated by western sycamore, several species of willows (Salix spp.), and mule fat (Baccharis salicifolia), although white alders (Alnus rhombifolia) are present at sites where surface water tends to persist (pools \#1-6 and at the upper sample site; Figure 1). Riparian areas often contain extensive stands of ground cover dominated by shrubs such as California blackberry (Rubus ursinus), snowberry (Symphoricarpos albus), and poison oak.

Historically, the UCC watershed was held in private ownership, with cattle ranching the primary land use (Goodrich 2005). Neither logging nor mining was conducted in the watershed, and there were no stream diversions or channel alterations. The stream modifications currently in place consist of scattered efforts to control and 
stabilize the slope below Roop Road, a paved public road which runs alongside the stream for much of its course in the study area.

Current land use practices differ little from those in the recent past. The landscape remains largely natural and undeveloped, although several rural-residential parcels have been built upon in recent decades. Vehicular traffic along Roop Road has increased slightly with the expansion of Coe Park in the 1990s and the opening of the park's Hunting Hollow entrance. While land use practices remain similar, ownership and management regimes are vastly different now than they were 25 years ago. Today, most of the watershed is in public ownership, with the portion upstream of the Gilroy Hot Springs bridge belonging to Coe Park and the downstream section owned by the Santa Clara County Open Space Authority. Both manage the watershed with common conservation goals, although there are operational differences between the two. Coe Park does not allow livestock grazing and is open to the public, while Open Space Authority lands have limited grazing but no public access. This study site was selected because it represents an example of a seasonal stream within protected habitat containing a population of WPT. In addition, restricted public access reduced the threats of tampering with field equipment (especially traps), and capturing, removing, or otherwise altering the behavior of turtles.

The study area for this project consisted of a stream section approximately $5 \mathrm{~km}$ in length beginning roughly $2 \mathrm{~km}$ upstream of Coyote Reservoir and continuing upstream $1 \mathrm{~km}$ above Hunting Hollow (Figure 1). Most research, however, was conducted within a 
$2.5 \mathrm{~km}$ stretch downstream of the intersection of Roop Road and Canada Road (Pools \#123).

\section{METHODS}

\section{Turtle Location}

The study area was divided into a series of pool complexes. Pool complexes varied widely in size and structure and often contained other, usually less extensive, habitat features besides pools. Thus, runs, riffles, backwaters, and secondary channels were all considered part of a single pool complex. Pool complexes were identified in the field, assigned a number, and labeled on maps of GoogleEarth satellite images (Figures 1 and 2). Pool \#1 was designated as the farthest downstream pool likely to survive drought, based upon the experience of Earl Gonsolin, who had previously studied Foothill Yellow-legged Frogs (Rana boylii) at UCC (Gonsolin 2010). Pool complexes upstream of Pool \#1 were numbered from 2 to 44 (Figure 1), but the most persistent pools were \#1-9 (Figure 2). Pool complexes upstream of pool \#44 were not assigned a number, being outside the main study area. Pool complexes downstream of Pool \#1 were assigned negative numbers, -1 through -10 . Pool complexes downstream of Pool \# -10 were not numbered, but were instead categorized as being adjacent to the reservoir, and during periods of high reservoir level were submerged. Lengths of each pool complex were measured using GoogleEarth images from the head of the pool (or the run immediately upstream) to the tail. Runs between pools were designated $n^{+}$, where $n$ was the downstream pool. Distances for total range and movements between trackings could be quantified from the maps and length data. 


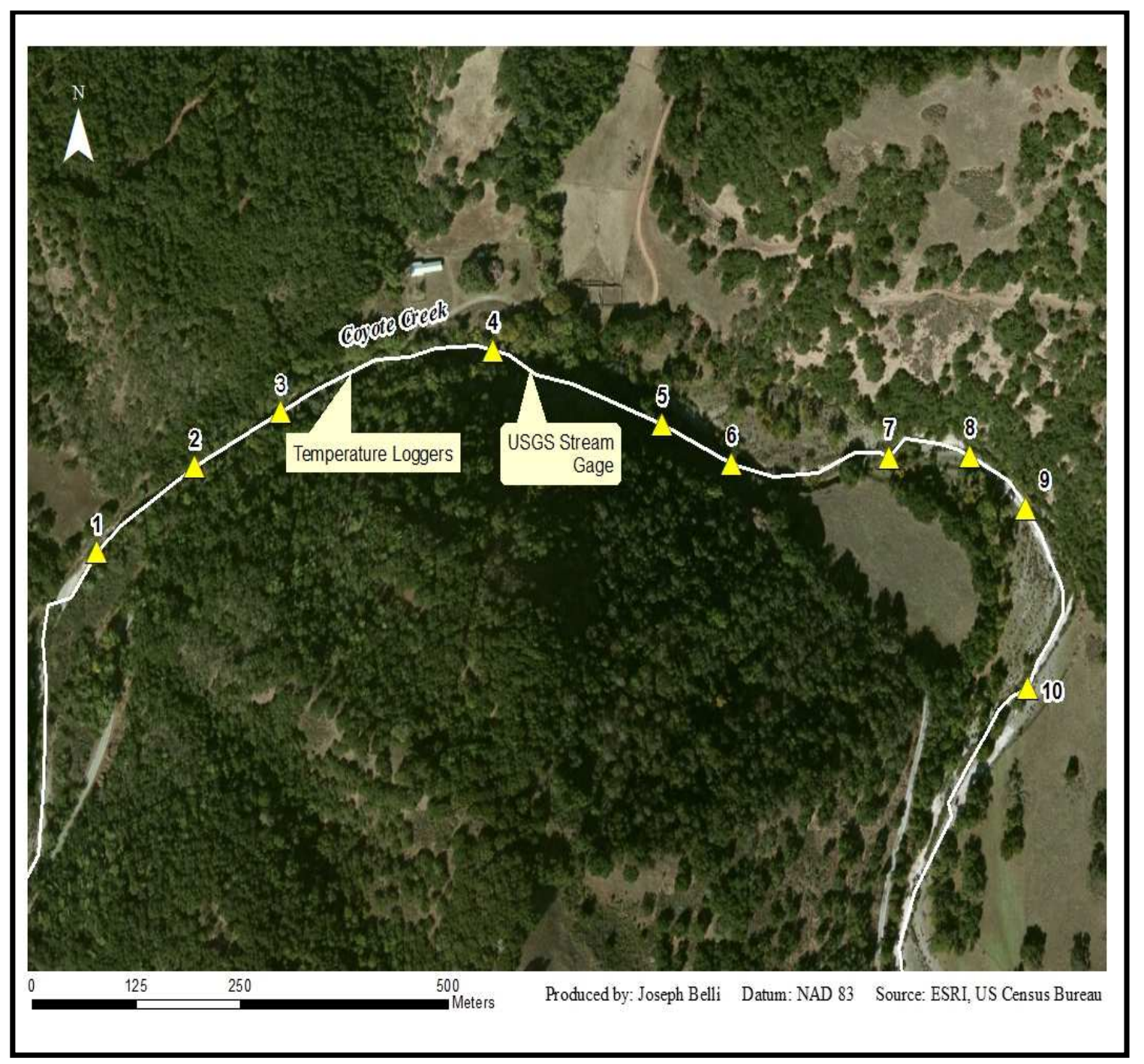

Figure 2. More perennial core of Western Pond Turtle study area (Pools \#1-9) in 2011-2013, showing denser vegetation on north-facing slopes and sparser vegetation on south-facing slopes.

To determine the total range of individual turtles, I included the complete length of both the farthest upstream and downstream pool complexes where the turtle had been detected. For example, if I tracked a turtle over time from Pool \#4 to Pool \#18, I would include the 
entirety of both pool complexes in my range calculation, instead of trying to pinpoint the precise farthest locations upstream and downstream.

To analyze meso habitat use, habitat within the stream was classified under the following categories: pools, runs, backwaters, secondary channels, and dry channels below bankfull. Pools were divided into three types: 1) simple and shallow; 2) simple or shallow; 3) complex and deep. Runs were divided into two types, simple and complex. GoogleEarth photos were used to calculate the percentages each habitat type comprised of the total habitat available.

\section{Stream Flow and Air and Water Temperatures}

A USGS stream gage is located in Pool \#4, and provided data on storm and base flows within the most perennial section of stream. Conditions of flow continuity between pools in the study area were recorded during turtle capture and tracking efforts. In AprilDecember 2011, air temperatures in the riparian shade of Pool \#3 and water temperatures in Pool \#3 were recorded at 15 minute intervals with Hobo Water Temperature Pro V2 loggers.

\section{Capture Methods}

Turtles were captured by hand or with a hand-held net, but most were captured in $1.6 \mathrm{~m}$ hoop traps made of nylon netting with wooden stretcher boards. Most of the trapping was conducted by Dr. Jerry Smith. The traps had two funnels so turtles could not exit, and were baited with canned sardines, with cans left partially open so turtles could feed. Traps were set in deep water (approaching or exceeding one $\mathrm{m}$ deep) adjacent to overhanging vegetation, roots, undercut banks, or other cover. A flotation 
device in the baited end of the trap allowed a portion of the trap to remain above the water's surface so that captured turtles could rise for air. Traps were set and maintained seasonally in 2011 and 2012, and more briefly in 2013. Trapping began in spring, when stream flows were relatively high and turtles had resumed stream activity after a period of dormancy, and continued into summer. Traps were removed in summer on a pool-bypool basis as stream levels declined and trapping success diminished. The number of traps deployed at any given time varied. The maximum number set at any given time was 12 , with no more than 1 per pool.

In 2011, trapping began on 30 April. During the course of the season, traps were placed at the following locations: Pools \#1, \#2, \#4 through \#7, \#11, \#15 through \#18, and \#25, as well as on a pond on private property across the road from the creek near Pool \# -5. Except for a hiatus between 26 May and 14 June, when traps were decommissioned, traps were checked two to three times weekly between 3 May and 9 September. By 12 August, traps in upstream pools had been removed due to channel drying, and remaining traps were in Pools \#1, \#4 through \#7, and \#11. On 31 August, the traps at Pools \#6, \#7, and \#11 were pulled, and the last three traps were removed from Pools \#1, \#4, and \#5 on 9 September.

In 2012, trapping began on 16 March. During the course of the season traps were placed at the following Pools: \# -5, \# -2, \#1, \#2, \#4 through \#7, \#11, \#15 through \#18, $\# 20$, \#22, \#25, and a site outside the main study area, $1 \mathrm{~km}$ upstream of Pool \#44, which was termed the upper site (Figure 2). That site was chosen to detect movement of marked turtles outside of the study area. Traps were removed on 19 May during a hiatus 
and reset between 10 June and 15 June. As in 2011, up to 12 traps at a time were used; in May one was stolen. Lower stream flows and declining water levels resulted in an earlier end to the trapping season in 2012. The first trap was pulled on 8 July, and the last traps on 5 August.

In 2013, a smaller scale trapping and tracking effort was conducted in response to increased drought conditions during the winter of 2012-2013. Trapping began 6 April. Traps were placed at various locations from Pool \#1 through Pool \#20. All traps were removed by 4 May.

\section{Data Obtained From Captured Turtles}

Turtles were handled and data were collected on shore, adjacent to the trap site or point of capture. When traps were found to contain more than one turtle, turtles were transferred to a nylon mesh bag and handled individually. Processing and data collection usually took less than 5 minutes per turtle, except when turtles were fitted with transmitters, which required about 15 minutes. On a standardized data sheet the following were recorded: location, date, capture method, turtle number, PIT tag number, sex, carapace length, annuli count, radio frequency, and additional comments. Location was described by pool number. Capture method was recorded as either by hand, net, or trap. Turtle number referred to the shell notch number used to identify individual turtles, which was modified from the method originally proposed by Cagle (1939). Triangular notches up to $5 \mathrm{~mm}$ deep were filed with a hand-held metal file in the center of the marginal scutes on the carapace. Marginal scutes frequently showed signs of wear or predator damage over time, making notch identification challenging. A second method 
of identification, a PIT (Passive Integrated Transponder) tag, was injected subcutaneously anterior to the right hind limb. To minimize the risk of infection, Neosporin was applied to the injection site. In addition, all PIT-tagged turtles received a second notch on the plastron in the center of the right femoral scute, to identify turtles that had PIT tags. Turtles too small $(<50 \mathrm{~mm} \mathrm{CL})$ to safely notch or PIT tag were left unmarked.

Gender was determined on the basis of two secondary sexual characteristics. Adult males possess a concave plastron, while adult females have a flat plastron. In adult males, the cloacal opening on the underside of the tail protrudes significantly beyond the rim of the carapace when the tail is extended, whereas in females it does not (Ernst and Lovich 2009). Male characteristics do not become apparent until the turtle approaches adult size. A carapace length of $120 \mathrm{~mm}$ has been recommended as sufficient to determine gender (Bury and Germano 1998), yet males as small as $110 \mathrm{~mm}$ CL have been documented with such features (Bury and Germano 2008). Therefore, almost all turtles under $120 \mathrm{~mm} \mathrm{CL}$, and every turtle under $110 \mathrm{~mm} \mathrm{CL}$, were classified as being of undetermined gender. Gender data also included information on the reproductive condition of adult females. Egg presence was determined by hand, by gently probing both sides of the body cavity anterior to the hind limbs. Females were periodically recaptured to check for egg presence and development.

Carapace lengths were measured in $\mathrm{mm}$. A home-made measuring board (Abel 2010) was used to measure all but the smallest turtles, which were measured with a ruler. Age was estimated by counting the number of annuli on plastron scutes. WPT exhibit growth rings which are usually deposited annually and are visible on the scutes of 
the plastron. This was first noted by Storer (1930) and was further developed and refined by Bury and Germano (1998), who found that annuli count matched age up to 15 or 16 years. Annuli were recorded by applying transparent tape to the most visible ringed scute and tracing the annuli beneath the tape in pencil. The tape was then transferred to a data sheet where annuli could be counted easily. On many older turtles the plastron was worn and all or some of the rings were gone, preventing aging.

\section{Radio-Tracking}

To provide data on movement, habitat use, and seasonal activity patterns, radio transmitters were attached to turtles. During 2011, 20 battery-powered transmitters were attached to turtles between 25 April and 24 June. The first 15 transmitters were Advanced Telemetry Systems model \#R1170 (ATS, Isanti, MN). This model featured a flat ribbon internal antenna and weighed $4 \mathrm{~g}$, was unobtrusive, but proved to have limited range (100-200 m) unless tracked from an elevated location. The limited range made locating turtles difficult, for many moved much more extensively than expected. The other five transmitters were the larger model, \#R1510, with a thin external antenna and a much stronger signal. They emitted a more directional signal, and it was sometimes more difficult to pinpoint exact locations. The transmitters were originally planned to be removed, and the study terminated, when turtles returned to the water in spring 2012. However, the study was extended, and in 2012, the number of transmitters was increased to 24 . In both years, adult males and females received transmitters in approximately equal numbers; one large (103 mm CL) juvenile also received a transmitter. In 2012, transmitters were swapped out on many of the turtles. Some turtles which moved little in 
2011 were replaced with turtles that trapping showed to be more mobile. Most males, which typically moved farther, received larger, more powerful transmitters, while smaller transmitters were used primarily on females, which moved relatively less. Used transmitters with some battery life remaining after 2011 were also used for brief periods in summer 2012. In order to extend battery life, larger transmitters were programmed to operate 12 hours per day, usually between 0800 through 2000 . In 2013,18 turtles were fitted with transmitters to compare dates of movement to upland sites in a severe drought year. In all, 37 turtles were fitted with transmitters during the course of this study, although never more than 24 at a time. On occasions when a tracked turtle was discovered dead, the transmitter was typically removed and attached to another turtle shortly thereafter.

Transmitters were attached in the field at the site of capture, immediately following data collection and marking. Transmitters were attached by Dr. Jerry Smith during trapping. Each transmitter was tested prior to application, and its actual field frequency, which varied with receiver, and its factory frequency were recorded on the data sheet. Transmitters were attached to the carapace, on to the side and near the center of the shell in females so as not to interfere with mating. Transmitter placement was less critical for males. Dental acrylic was used as a bonding and camouflage agent when attaching transmitters. The powdered acrylic and curing acrylic resin were mixed until a satisfactory consistency was obtained. Black toner was added to darken the mixture, to match the carapace. The mixture was placed on the shell, the transmitter pressed into the acrylic, and then molded over and around the transmitter. The package was then allowed 
to catalyze and harden. Once the acrylic hardened, the turtle was released at water's edge near the point of capture.

I radio-tracked turtles using a receiver (TRX 2000S, Wildlife Materials Inc., Carbondale, IL) and a hand-held metal antenna. Tracking began on 7 May 2011, after six turtles had been fitted with transmitters. I tracked twice weekly from 7 May 2011, until 1 August 2011. Intervals between tracking dates were usually 3-4 days. An exception arose during a hiatus in the study between 26 May and 14 June 2011, when I did not track. By August, stream flow and pool connectivity had declined, turtle movement had decreased, and some turtles had left the stream for upland habitat, where movement was further curtailed. As a result, beginning in August, I tracked less frequently, with intervals typically between 6-8 days, but occasionally as few as 4 and as many as 10 . Most tracking efforts commenced between 0930-1130, and ended between 1330 and 1730. In 2012, I continued tracking once a week until 25 October. My goal was to track each turtle to a precise location (within several $\mathrm{m}$ ) on each tracking day. Sometimes turtles were able to access habitats with impenetrable vegetation. In such cases turtles could be tracked by triangulation only to a general location. There were also turtles that could not be tracked at all during a tracking session, whether from having failed or weak transmitters, moving beyond the study area, or being removed from the area by people or predators. Most turtles, however, were successfully tracked to specific locations each tracking day. In 2013, transmitters were attached to 18 turtles, which I tracked weekly to determine movements to upland sites, from 19 April until 17 August. 
When turtles were radio-tracked to stream habitats, I collected data on location, habitat, activity, depth, canopy, complex cover, emergent basking potential, and previous location. I identified location by pool complex number and position within the pool. Locations of turtles tracked to runs were identified with a "+" following the number of the pool complex immediately downstream. I also noted whether a turtle was tracked to the head (h), tail (t), or backwater (bw) of a pool. Further description of location included whether or not the turtle was in water or on shore. I described turtles tracked to shore as being along the bank, on islands between split channels, or on raised terraces. I described turtles tracked to water as being in the middle of the stream or a given distance from either the right or left bank. Additional microhabitat information was often included here for specificity.

To compare turtle locations, general available habitat of Pools \#-10 through \#25 was classified as: pools (simple and shallow, simple or shallow, deep and complex), runs (simple or complex) and backwaters, later mapped and measured on GoogleEarth, and ground-truthed.

I also recorded activity, such as basking, swimming, or resting. Turtles under water that could not be seen were recorded as being submerged. I took two depth measurements for submerged turtles. One was the depth of the stream where the turtle was located. The other was the thalweg of the stream. I measured depths by entering the stream with gradations on my waders. Depths in excess of one meter were estimated. I visually estimated the percent of canopy cover. I also noted which tree or shrub species provided canopy cover at each site. I noted the amount and type of complex cover at each 
site, including deep water, boulders, root-wads, woody debris, and dense vegetation, including algae mats. When a turtle was tracked to a site lacking complex cover, I noted the nearest source of complex cover. I noted the presence or absence of emergent basking features at each site. I defined emergent basking areas as features allowing turtles to bask out of water while allowing ready access to water. Such features included in-stream or bank-side boulders, downed logs, and root systems hanging above the water. When I tracked turtles to locations lacking emergent basking sites the pool complex providing the nearest source of emergent basking was recorded.

I included data on the previous location each time I tracked a turtle in order to determine the distance between tracking locations. I estimated distances between locations within the same pool complex visually on-site. When the previous location involved a different pool complex I estimated distance later from scales provided by GoogleEarth maps.

I collected data for upland turtles including location, habitat, activity, canopy, vegetation, leaf litter, slope, distance from stream bank, and previous location. I categorized upland locations relative to the closest pool complex and stream bank, (e.g. "upland, pool \#6RB [right bank])". Due to the complexity of upland habitats I took detailed notes when describing each location, and marked upland locations with flagging inserted into the ground adjacent to each turtle. I recorded the date, turtle ID, and distance and direction to the turtle on the flags, in order to record movements. I also recorded the distance of each upland site to the nearest stream bank. I estimated distances by pacing when possible, but on steep, unstable, or heavily vegetated slopes I 
estimated distances visually. I also included data on the previous tracking location for upland turtles to ascertain distance traveled. Movement between upland locations tended to be less than in-stream movements, so distances between many upland sites were estimated by pacing. Those movements with challenging habitat features such as steep slopes were estimated visually.

I classified habitat of upland turtles by vegetation community or communities. I noted vegetation present at each upland site. In contrast to the vegetation community data recorded under habitat, I documented the prominent vegetation species in the surrounding microhabitat, typically listing 2-4 species. I identified trees and shrubs at the species level, but did not distinguish among grasses. I estimated the percent of canopy cover at upland sites, and noted the species composition of the trees and shrubs providing canopy. I noted the relative presence and abundance of leaf litter at all sites where I found turtles either completely or partially buried. The amount of leaf litter or other material covering buried turtles was not measured since doing so would increase the likelihood of disturbing turtles. If leaf litter was absent or sparse I noted other forms of cover used, such as thatch and twigs. I noted the activity level of upland turtles, and categorized activity level as being inactive/unalert (for buried turtles), inactive but alert (for sedentary turtles), or active. I estimated the degree of slope in the vicinity at all upland locations as well as the slope where the turtle was located. For example, a turtle might be tracked to a level microhabitat along an otherwise steep slope. In such instances, I estimated the steepness of the slope and mentioned the turtle was on level ground. 
Because I was not tracking on a daily basis, exact dates of movement and stream departure (when turtles left the stream for upland habitats in association with estivation/torpor) could not be determined. Instead, I chose to designate the first date I tracked turtles to a novel habitat as being the date of detection, when in reality it may have been 3-7 days earlier. Likewise, when turtles returned to the stream the following year, I designated the date when the turtle was first tracked back to the stream as the return date.

\section{RESULTS}

\section{Stream Flows and Air and Water Temperatures}

Stream flow.-In 2011, stream flows on upper Coyote Creek varied from 10008000 cfs during storms in February and March (Figure 3), with small storms (20-25 cfs) in May and early June (Figure 4). By mid-July, flow was $<1 \mathrm{cfs}$ (Figure 4), with loss of continuity in pools upstream of Pool \#10 and downstream of Pool \#1 in mid-July-early August.

In 2012, dry weather prevailed with low stream flows through early March, but two brief, large storms (750-1100 cfs) hit in mid-March and mid-April (Figure 5). Flows at the USGS gage dropped to $<1 \mathrm{cfs}$ by early June (Figure 6), and discontinuous flow occurred between Pools \#10 and \#25 and downstream of Pool \#1 by July.

In 2013, conditions were even drier with stream flows less than 48 cfs in January, less than $8 \mathrm{cfs}$ in February and March, and less than $1 \mathrm{cfs}$ by mid-April (Figure 7). Most pools from \#10-25 and downstream of Pool \#1 were disconnected by May. 


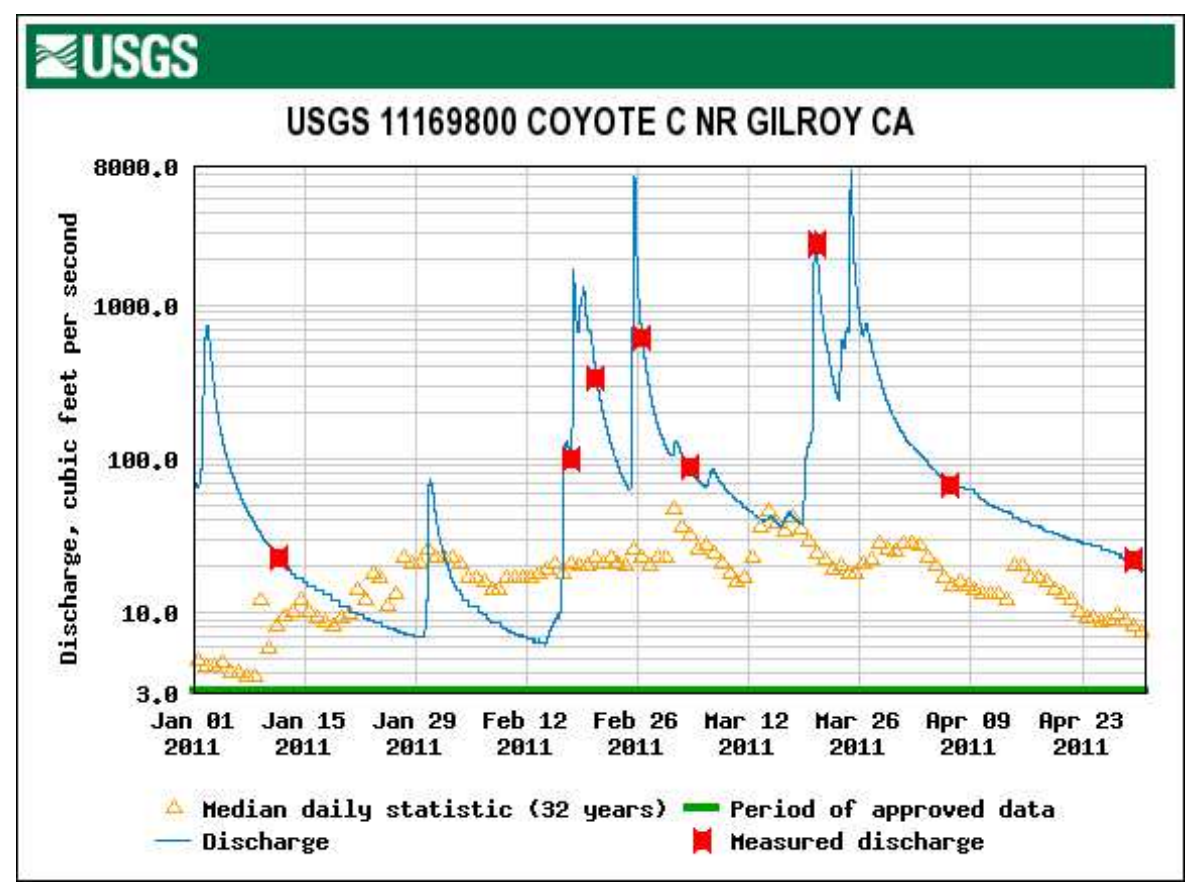

Figure 3. Stream flow at the USGS gage at the upper Coyote Creek turtle study site in JanuaryApril 2011.

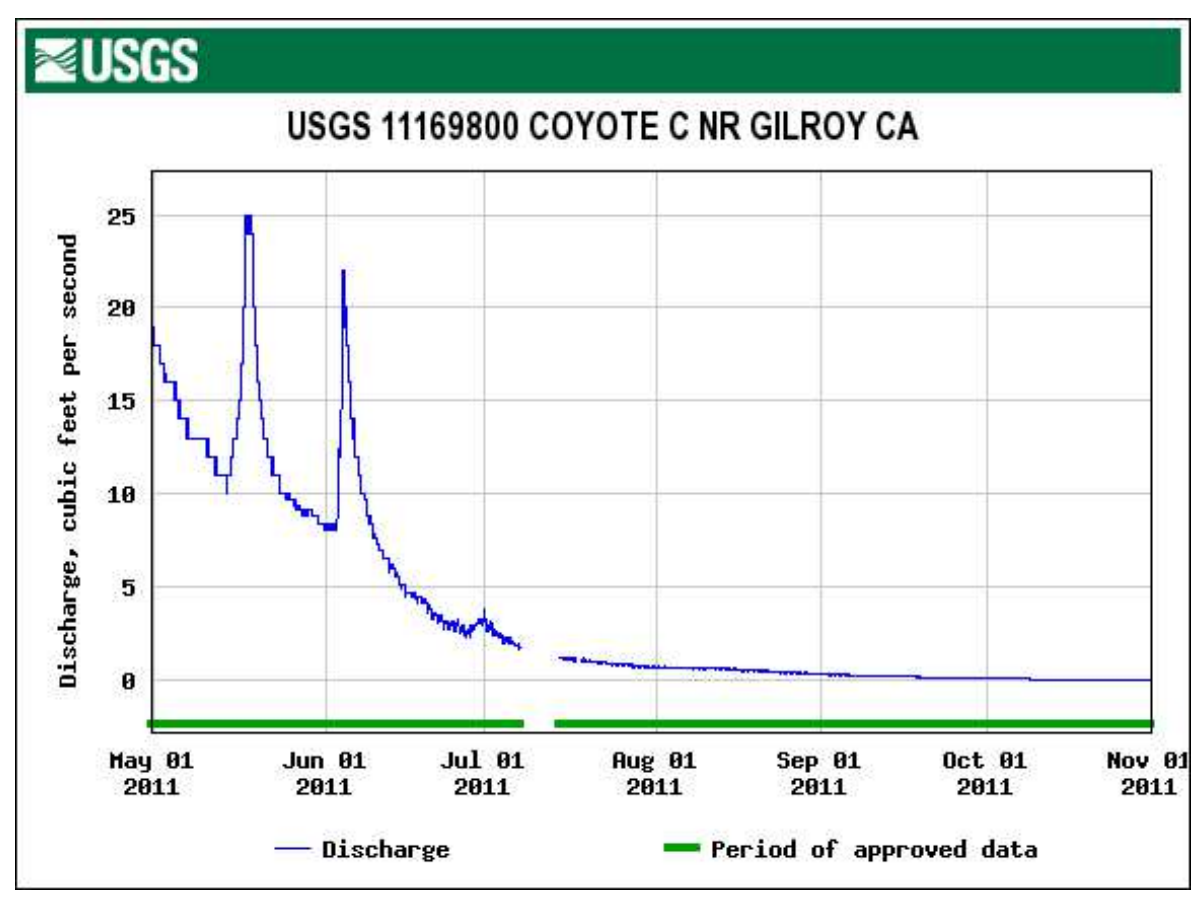

Figure 4. Stream flow at the USGS gage at the upper Coyote Creek turtle study site in MayOctober 2011. 


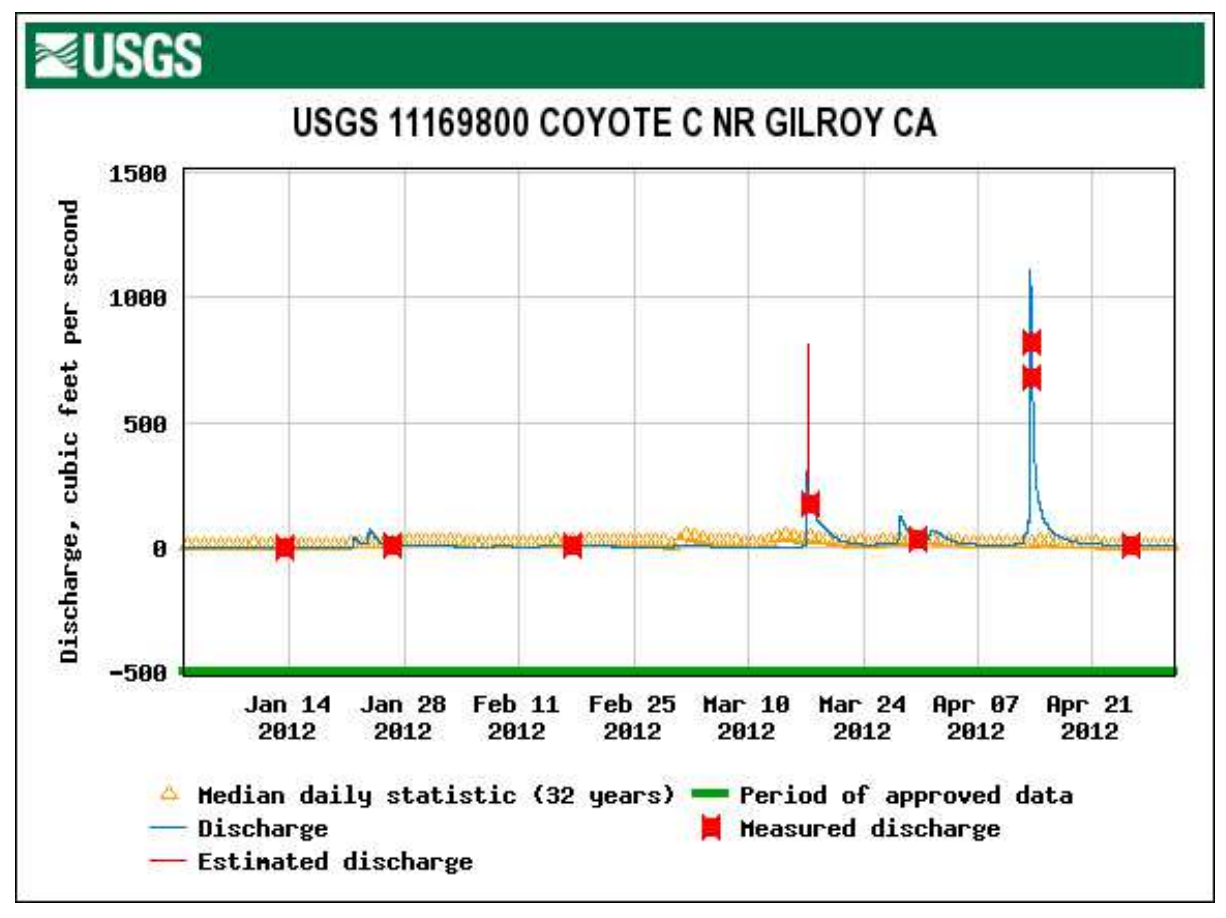

Figure 5. Stream flow at the USGS gage at the upper Coyote Creek turtle study site in JanuaryApril 2012.

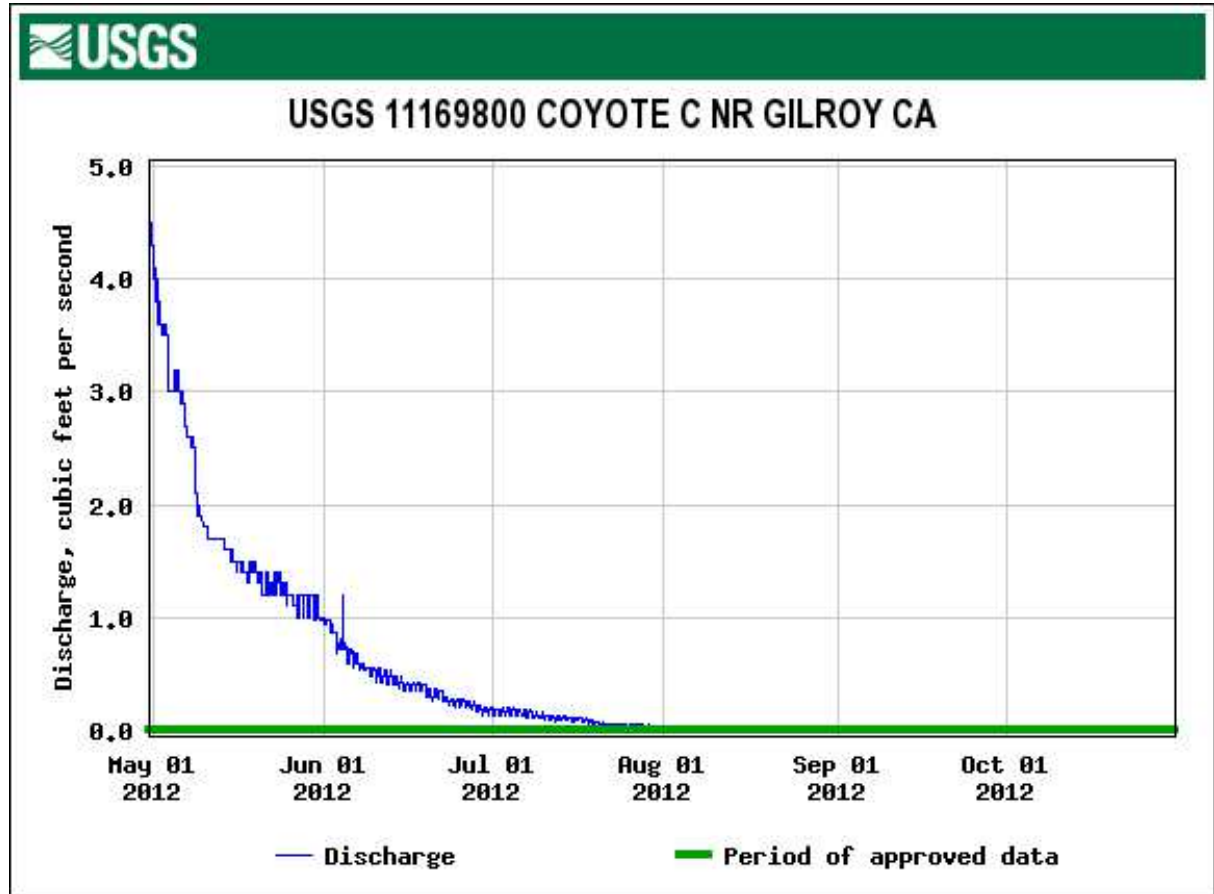

Figure 6. Stream flow at the USGS gage at the upper Coyote Creek turtle study site in MayOctober 2012. 


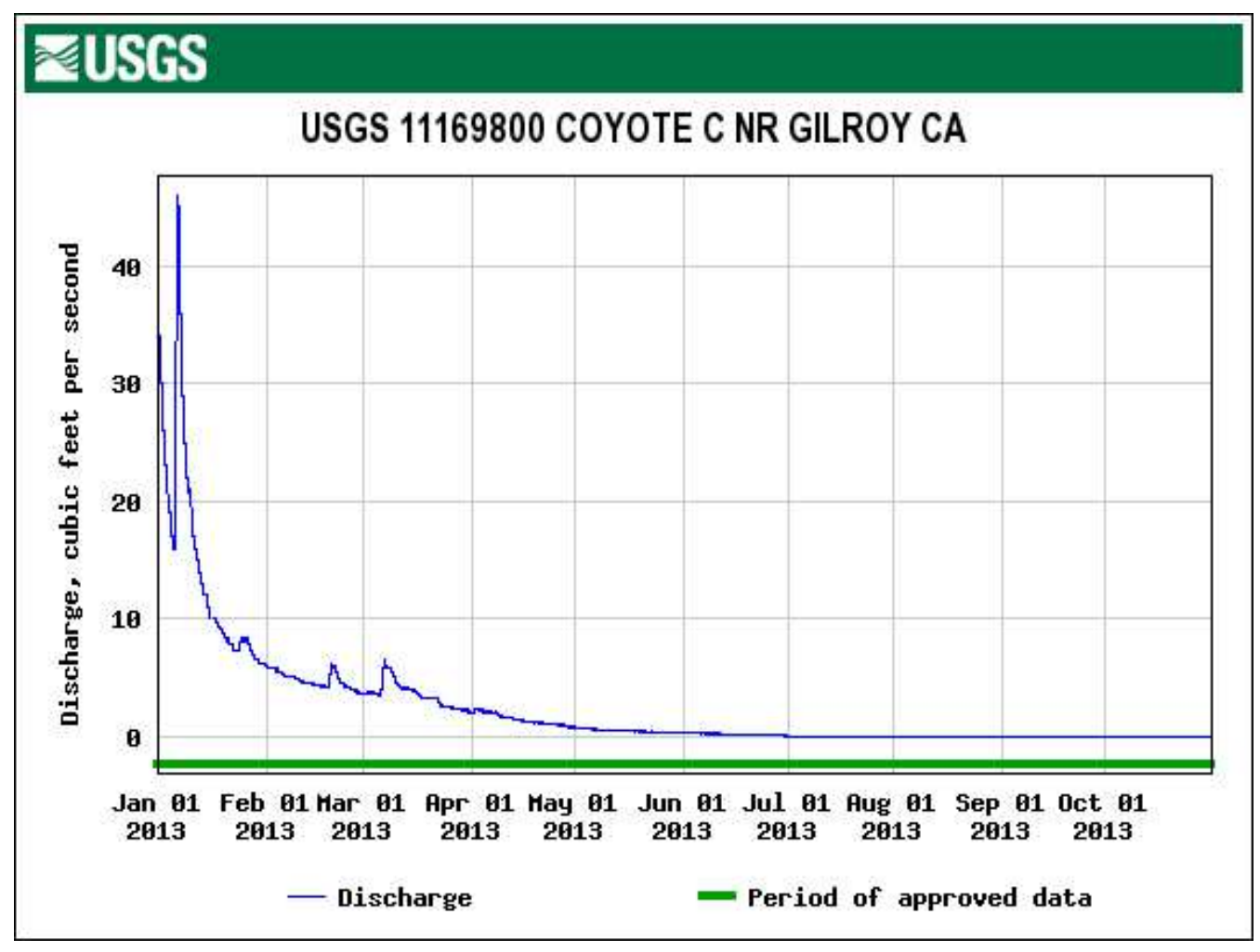

Figure 7. Stream flow at the USGS gage at the upper Coyote Creek turtle study site in JanuaryOctober 2013.

Air temperatures. - In 2011, air temperature increased from means of $10^{\circ} \mathrm{C}$ in May to $16^{\circ}$ by mid-June, with maximums regularly exceeding $30^{\circ} \mathrm{C}$ in mid-June through September (Figure 8).

Water temperatures. - Water temperatures in 2011 climbed from a mean of $12^{\circ} \mathrm{C}$ in mid-April to $18-20^{\circ} \mathrm{C}$ in mid-June, and they remained at that level through September (Figure 9). Maximums in mid-June through September reached 22.5-25 ${ }^{\circ} \mathrm{C}$.

\section{Population Demographics}

Between April 2011 and August 2012, 173 individual WPTs were captured, shell notched, and PIT-tagged, providing data on gender composition, age structure, and size. 


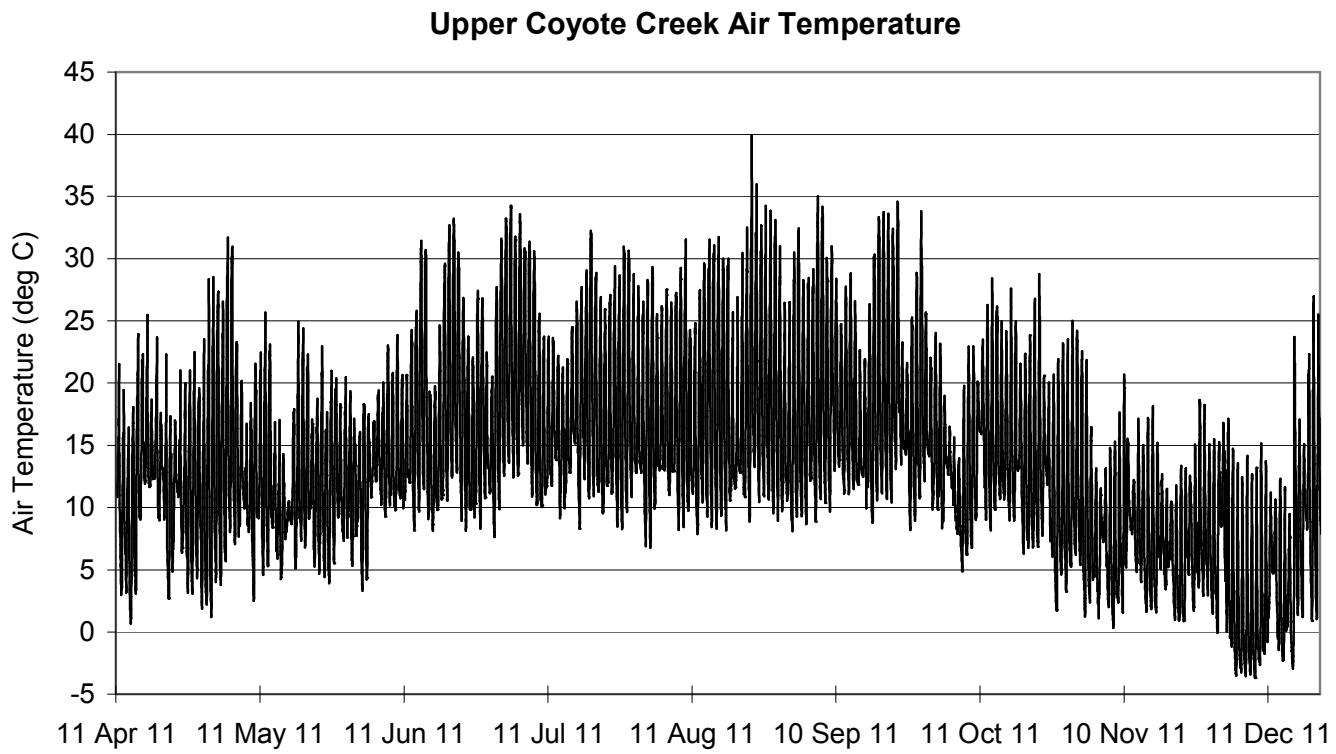

Figure 8. Air Temperatures at the upper Coyote Creek turtle study site (USGS gage) in AprilDecember 2011.

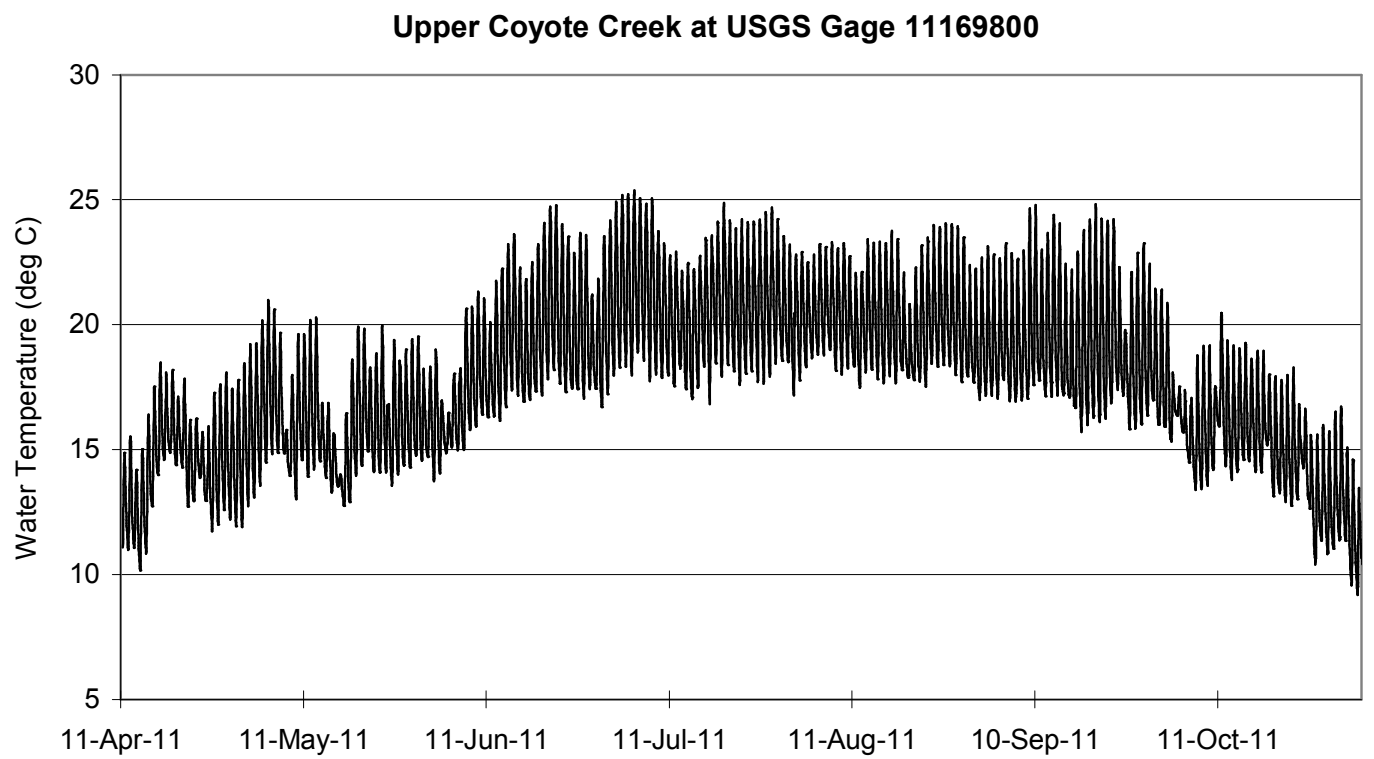

Figure 9. Water temperatures at the upper Coyote Creek turtle study site (USGS gage) in AprilDecember 2011. 
In addition, recaptured turtles provided information on growth rates.

Gender composition.-Of the 173 turtles captured, 94 (54.3\%) were male, 34 $(19.7 \%)$ were female, and $45(26 \%)$ were of unknown gender, being too small to exhibit the morphological traits used to determine gender (Figure 10). No turtles smaller than $110 \mathrm{~mm}$ were sexed, but all longer than $120 \mathrm{~mm}$ were (Figure 10). Five of nine turtles 110-119 mm were sexed with confidence, and four of those were males with concave plastrons. All sexed turtles were at least six years old (Figure 11). Of the turtles identified to gender, $73.4 \%(94 / 128)$ were males, a male/female ratio of $2.8: 1$.

Size.-Captured turtles ranged in size from 47-174 mm CL. Females were slightly larger than males, with a mean CL of 144.9 compared to 138.6 for males (Figure 10). Fourteen of $34(41.2 \%)$ females were $150 \mathrm{~mm}$ CL or larger, compared to only $23.4 \%$ (22/94) of males. In addition, 7 of the 11 turtles $160 \mathrm{~mm} \mathrm{CL}$ or larger were female, and $20.6 \%$ (7/34) of all females made up this largest size class, while only $4.3 \%$ (4/94) of males did (Figure 10).

Age structure.-Young adult and unsexed turtles 6-11 years old comprised the largest age class, accounting for $42.2 \%$ (73/173) of the total. Juvenile turtles $1-5$ years old constituted a far lesser percentage $(14.5 \%, 25 / 173)$, while adults $12-15$ years were even less common, occurring as just 2.3\% (4/173) of the population (Figure 11). However, 71 turtles $(41.0 \%)$ could not be aged due to the worn condition of the plastron. Those turtles ranged in size from 122-174 mm CL, and were adults, and most were probably more than 10 years old. 


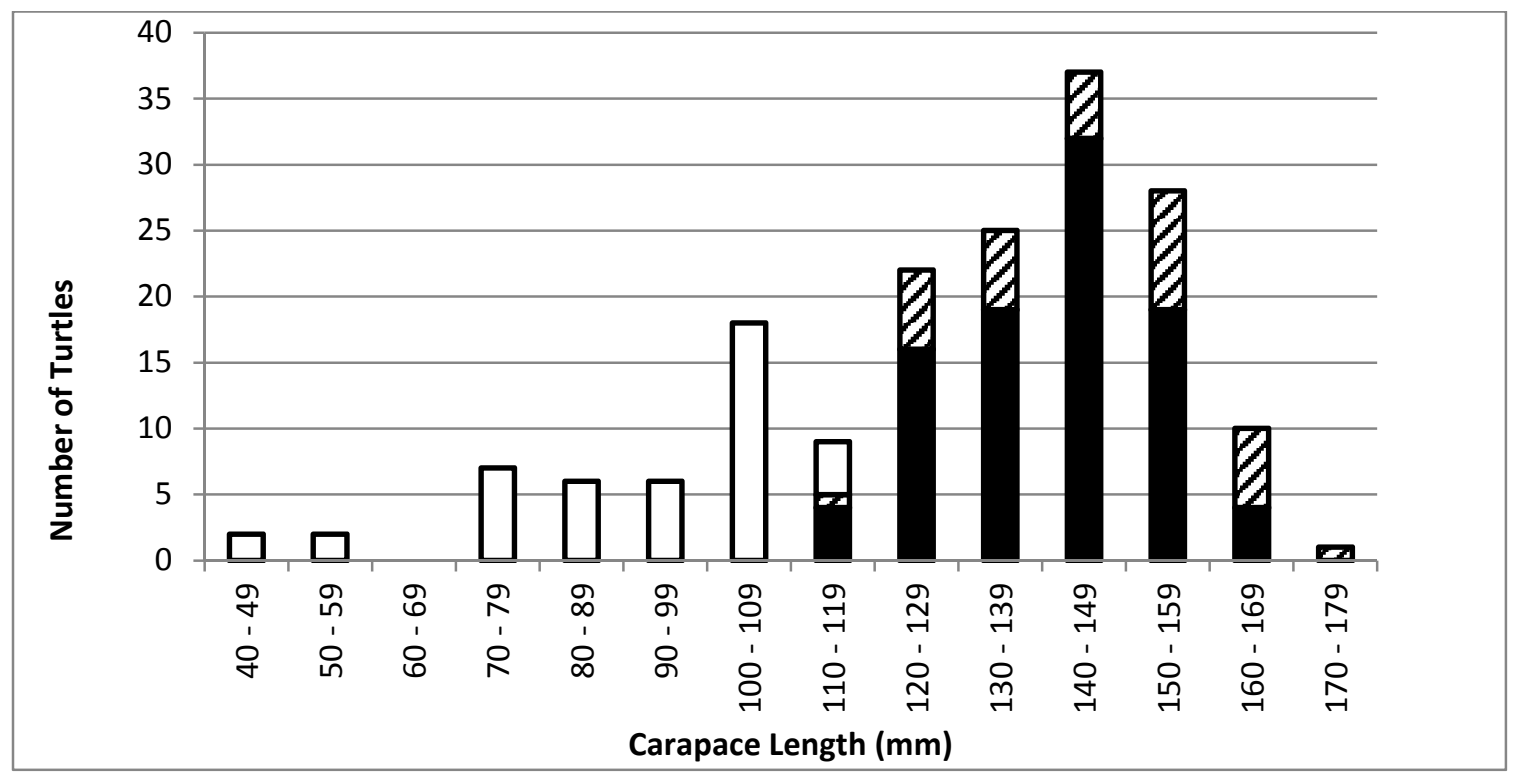

Figure 10. Distribution of carapace lengths and sexes of Western Pond Turtles $(n=173)$ at first capture at upper Coyote Creek, Santa Clara County, California, 2011-2012. Shaded bars represent males $(n=94)$, striped bars represent females $(n=34)$, open bars represent juveniles of unknown gender $(\mathrm{n}=45)$.

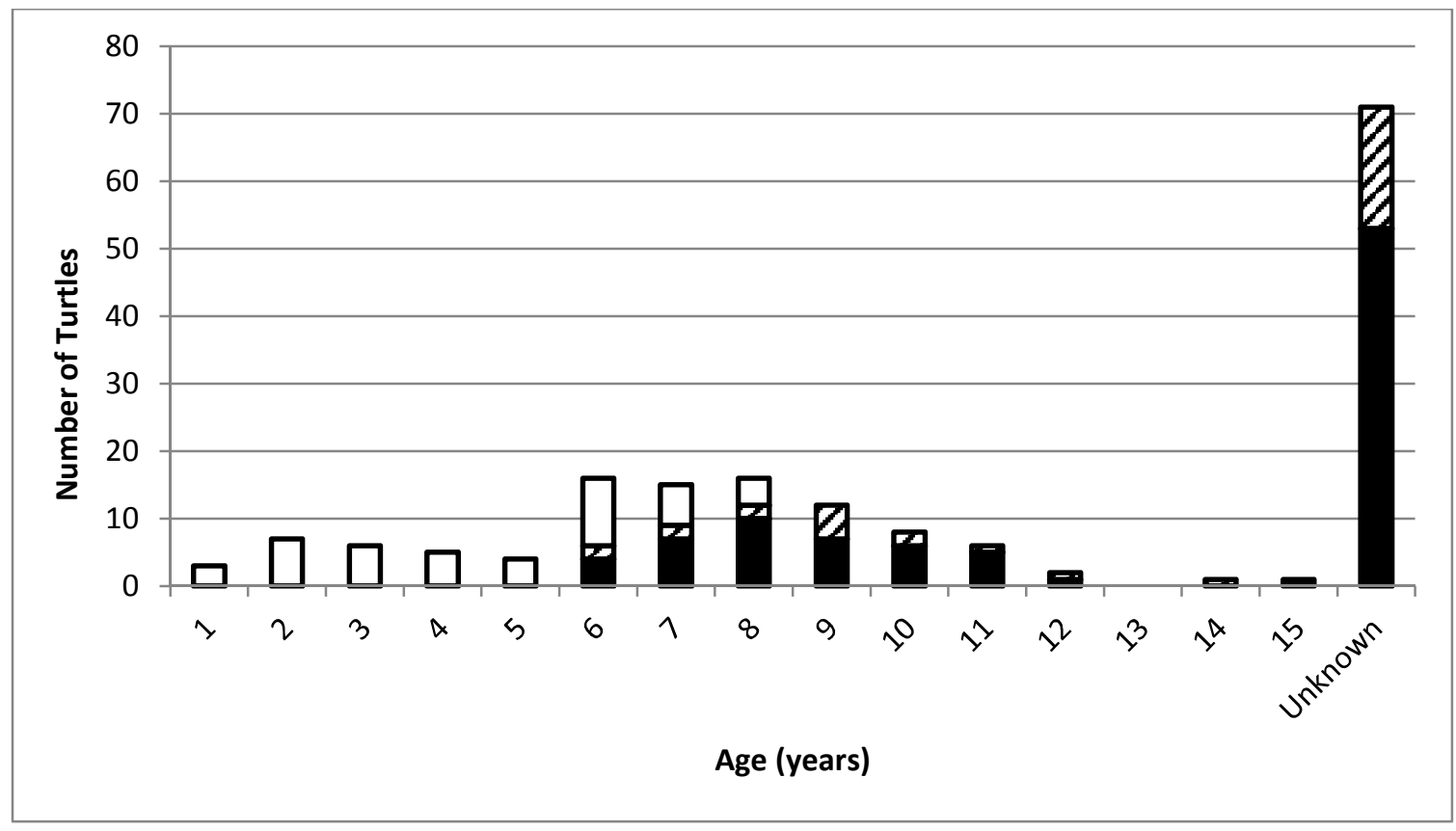

Figure 11. Age distribution of Western Pond Turtles $(n=173)$ at fist capture at upper Coyote Creek, Santa Clara County, California, 2011-2012. Shaded bars represent males ( $n=94)$, striped bars represent females $(n=34)$, open bars represent juveniles of unknown gender $(n=45)$ 
Growth rate.-Turtle size generally increased with age up to 10 years old, but there was wide variation in growth among individuals (Table 1). There was no apparent age/size relationship for turtles older than 10 years or for the presumably older turtles with worn plastrons.

Table 1. Age (years), sample size (n), mean size ( $\mathrm{mm})$, and size range ( $\mathrm{mm}$ ) of carapace lengths of Western Pond Turtles initially captured at upper Coyote Creek, Santa Clara County, California, 2011-2012.

\begin{tabular}{|c|c|c|c|}
\hline Age (years) & $\mathbf{n}$ & Mean Size $(\mathbf{m m})$ & Size Range $(\mathbf{m m})$ \\
\hline \hline 1 & 3 & 49.7 & \\
2 & 7 & 73 & $57-54$ \\
3 & 6 & 80.7 & $72-95$ \\
4 & 5 & 97 & $88-104$ \\
5 & 4 & 94.5 & $83-103$ \\
6 & 16 & 111.1 & $95-125$ \\
7 & 15 & 119.1 & $92-146$ \\
8 & 16 & 126.9 & $114-153$ \\
9 & 12 & 135.5 & $120-163$ \\
10 & 8 & 143.6 & $120-156$ \\
11 & 6 & 143.2 & $130-156$ \\
$12-15$ & 4 & 148.3 & $140-160$ \\
Unknown & 71 & 146.4 & $122-174$ \\
\hline
\end{tabular}

Turtles caught and measured in 2011 and recaptured in $2012(\mathrm{n}=44)$ provided data on growth rates. Intervals between 2011 and 2012 measurements ranged from 238-421 days, so the growth increment did not strictly represent annual growth. The amount of growth varied from 0-9 mm, with a mean of $2.6 \mathrm{~mm}$. Younger turtles exhibited greater 
growth than older turtles. Immature turtles in the 1-5 year age group $(n=5)$ grew a mean of $4.4 \mathrm{~mm}$ between 2011 and 2012 (Table 1). Turtles aged 6-11 $(\mathrm{n}=26)$ grew a mean of $2.9 \mathrm{~mm}$. The 12 turtles of unknown age, presumably old turtles, exhibited the least growth, a mean of $1.9 \mathrm{~mm}$ (Table 1). Some turtles age $7+$ in the driest reaches of the stream showed little or no growth when recaptured in 2012, and several failed to show a new growth ring. Most recaptures in 2013 failed to show new growth rings.

Similarly, smaller turtles tended to grow more than larger turtles, but with wide individual variation (Table 2). Turtles under $100 \mathrm{~mm} \mathrm{CL}$ in $2011(\mathrm{n}=7)$ had a mean growth of $3.9 \mathrm{~mm}$ (Table 3$)$. Turtles in the $100-119 \mathrm{~mm} \mathrm{CL}$ range $(\mathrm{n}=10)$ had a mean growth of $2.8 \mathrm{~mm}$, and turtles in the $120-139 \mathrm{~mm}$ CL range $(\mathrm{n}=11)$ had a mean growth of $3.3 \mathrm{~mm}$. Turtles $140 \mathrm{~mm} \mathrm{CL}$ and larger $(\mathrm{n}=16)$ exhibited the least annual growth, with a mean of $1.6 \mathrm{~mm}$.

Table 2. Age classes (years), sample size (n), and mean growth ( $\mathrm{mm}$ ) of Western Pond Turtles $(n=44)$ initially captured in 2011 and recaptured in 2012 in upper Coyote Creek, Santa Clara County, California.

\begin{tabular}{|c|c|c|c|c|}
\hline Age Class & $\mathbf{n}$ & $\begin{array}{c}\text { Mean Growth } \\
(\mathbf{m m})\end{array}$ & Standard Deviation (mm) & $\begin{array}{c}\text { Growth Range } \\
(\mathbf{m m})\end{array}$ \\
\hline \hline & & & & \\
$1-5$ & 5 & 4.4 & 1.3 & $3-6$ \\
$6-11$ & 26 & 2.9 & 2.2 & $0-9$ \\
$12+$ & 1 & 0 & 0 & 0 \\
Unknown & 12 & 1.8 & 2.2 & $0-7$ \\
\hline
\end{tabular}


Table 3. Carapace length ( $\mathrm{mm}$ ), sample size (n), and mean growth ( $\mathrm{mm}$ ) of Western Pond Turtles $(\mathrm{n}=44)$ initially captured in 2011, and recaptured in 2012 in upper Coyote Creek, Santa Clara County, California.

\begin{tabular}{|c|c|c|c|c|}
\hline $\begin{array}{c}\text { Carapace Length } \\
\text { (mm) }\end{array}$ & $\mathbf{n}$ & $\begin{array}{c}\text { Mean Growth } \\
\text { (mm) }\end{array}$ & $\begin{array}{c}\text { Standard Deviation } \\
(\mathbf{m m})\end{array}$ & $\begin{array}{c}\text { Growth Range } \\
\text { (mm) }\end{array}$ \\
\hline \hline & & & & \\
$<100$ & 7 & 3.9 & 2.1 & $2-6$ \\
$100-119$ & 10 & 2.8 & 7.5 & $0-9$ \\
$120-139$ & 11 & 3.3 & 3.6 & $0-7$ \\
$140+$ & 16 & 1.6 & 9.3 & $0-6$ \\
\hline
\end{tabular}

Female reproductive status.-Data on reproductive status were collected by capturing and examining females during late spring and summer. In 2011, 17 turtles were checked between 14 May and 12 August. Seven were examined once, while ten were checked 2-5 times. Nine of the $17(52.9 \%)$ were gravid, including 8 of the 10 that had been checked two or more times. The size range of gravid turtles was 131-161 mm CL (mean $147.8 \mathrm{~mm})$. Gravid turtles of known ages $(\mathrm{n}=4)$ ranged from 9-12 years old, but most females, including five gravid turtles, had worn plastrons. We confirmed double clutching in four turtles, and possibly a fifth in 2011. The earliest date we documented a gravid turtle was 26 May. The latest date was 26 July, when three turtles found to be gravid earlier were rechecked and gravid with a second clutch.

In 2012, when conditions were drier (Figures 4 and 6) 16 turtles were checked between 28 April and 19 August. Nine were checked once, and seven were checked 2-3 times. Four of the sixteen were gravid $(25 \%)$. The size range of gravid turtles was $134-$ $156 \mathrm{~mm}$ CL (mean $147 \mathrm{~mm}$ ). All four had worn plastrons. The earliest date confirmed for a gravid turtle in 2012 was 17 June. The latest date was 8 July. Double clutching was 
not detected in any of the gravid turtles in the drought-shortened period of surface flow in 2012 (Figure 6).

\section{Home Ranges}

In general, male turtles ranged over greater distances and exhibited greater movement than females. In 2011, I radio-tracked 12 males, 10 females, and 1 subadult, beginning in May. Mean male home range was $1166 \mathrm{~m}$, and the mean for females was $560 \mathrm{~m}$. Five of the males $(41.6 \%)$ had home ranges exceeding $1000 \mathrm{~m}$, with the highest exceeding $3000 \mathrm{~m}$ (Figure 12a). None of the female home ranges exceeded $1000 \mathrm{~m}$. The largest home range $(3423 \mathrm{~m})$ was that of the subadult, which moved from the study area downstream to Coyote Reservoir. In 2012, I radio-tracked 16 males and 10 females. Mean male home range was $2281 \mathrm{~m}$, and the mean for female home range was $501 \mathrm{~m}$. Seven of the males $(43.8 \%)$ had home ranges exceeding $1000 \mathrm{~m}$, four had home ranges exceeding $3000 \mathrm{~m}$, and one had a home range exceeding $5000 \mathrm{~m}$ (Figure 12b). As in 2011, none of the females had home ranges exceeding $1000 \mathrm{~m}$. Of 12 turtles tracked in both 2011 and 2012 (7 males, 5 females), the mean home range for males was $2656 \mathrm{~m}$, five times higher than the mean home range for females $(527 \mathrm{~m})$. Home ranges of males varied from $636 \mathrm{~m}$ to $5483 \mathrm{~m}$. Female mean home range varied from $316 \mathrm{~m}$ to $734 \mathrm{~m}$.

Minimum home ranges for turtles that were not fitted with transmitters $(n=82)$ were obtained through recapture efforts. The vast majority of recaptures (194/205, 94.6\%) came through trapping, while the rest were caught opportunistically by hand. Of the 82 recaptured turtles lacking transmitters, 41 (50\%) were recaptured just once, so just 


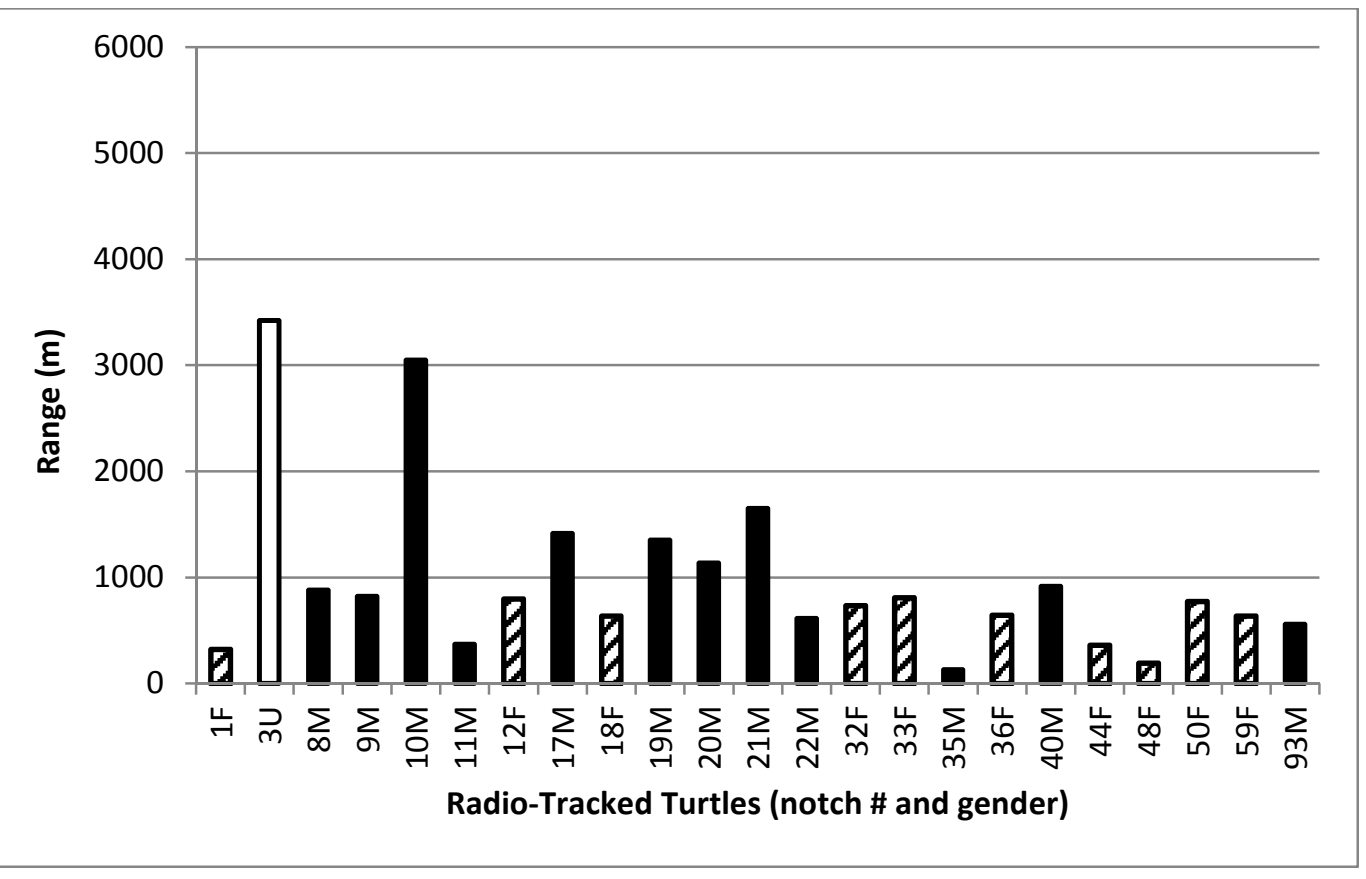

a)

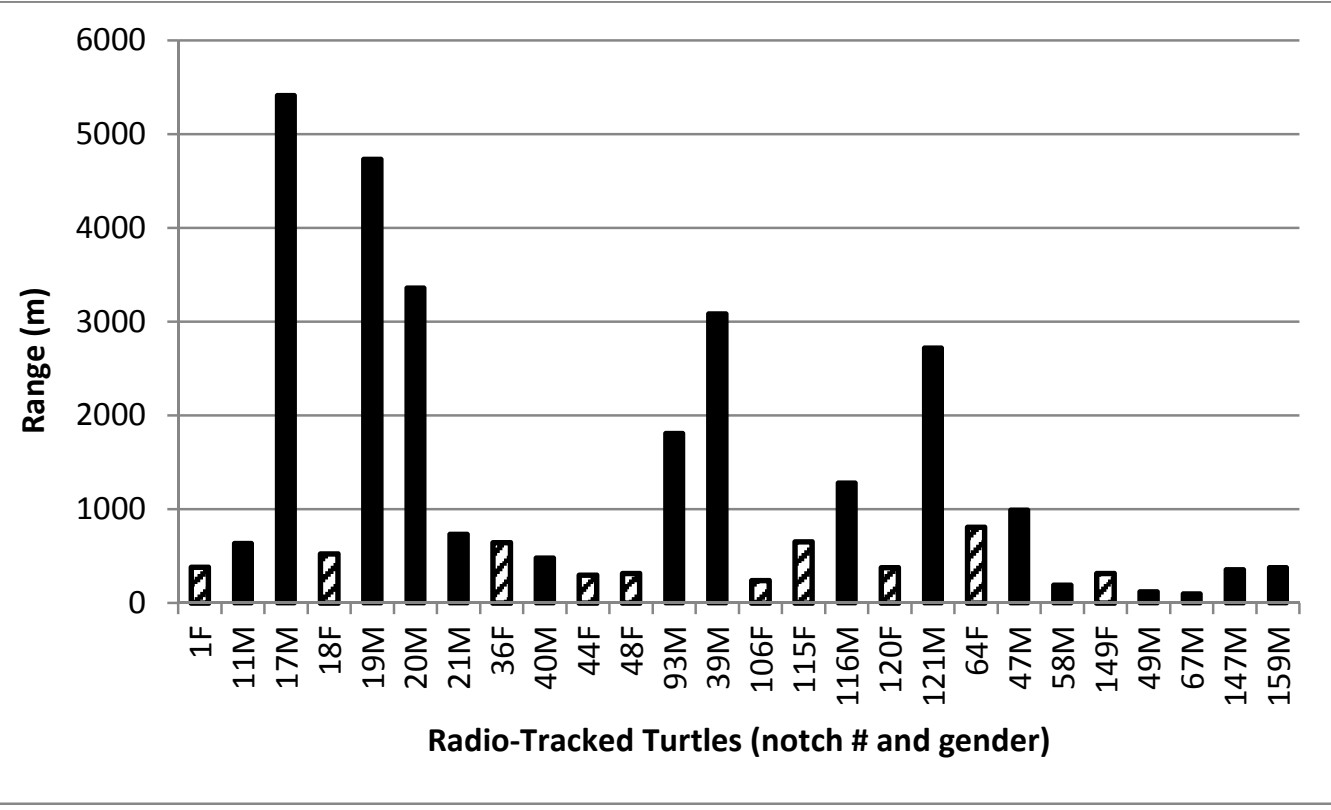

Figure 12. Ranges $(\mathrm{m})$ of individual Western Pond Turtles radio-tracked in a) $2011(\mathrm{n}=23)$ and $\mathrm{b})$ $2012(\mathrm{n}=26)$ along upper Coyote Creek, Santa Clara County, California. Solid bars represent males, striped bars represent females, and the open bar represents a juvenile, gender unknown. 
two locations (site of original capture and site of recapture) account for their home range. The rest were recaptured between 2 and 11 times. The gender composition for the 82 turtles recaptured without transmitters was 45 males, 10 females, and 27 juveniles of undetermined gender. In contrast to radio-tracking, where we selected a gender ratio close to even, recaptured turtles lacking transmitters had a 4.5 to 1 male/female ratio and also provided us with movement data for juvenile turtles, too small for radio-tracking.

Despite the limitations, almost half the recaptured males $(22 / 45,48.9 \%)$ had home ranges exceeding $500 \mathrm{~m}$, compared to $20 \%(2 / 10)$ of females and $18.5 \%(5 / 27)$ of juveniles. Of 13 turtles with home ranges exceeding $1000 \mathrm{~m}, 11$ were male, 1 was female, and 1 was a juvenile (Figure 13). The mean home range for males was $835 \mathrm{~m}$; the mean home range for females was $391 \mathrm{~m}$, and that of juveniles was $342 \mathrm{~m}$. These ranges were lower than the mean home ranges for radio-tracked turtles, for both females $(625 \mathrm{~m})$ and especially for males $(2325 \mathrm{~m})$. The largest home ranges documented for recaptured turtles were $4616 \mathrm{~m}$ for males, $1063 \mathrm{~m}$ for females, and $1088 \mathrm{~m}$ for juveniles.

Males showed a tendency to move greater distances than females over short periods of time. Radio-tracking documented 24 instances involving 8 males in which a turtle moved over $1000 \mathrm{~m}$ between tracking intervals (approximately one week). The maximum distance recorded for a male between tracking events was $4100 \mathrm{~m}$, while the maximum distance recorded for a female between tracking events was $640 \mathrm{~m}$. All but four of these long distance movements occurred in April through May, when breeding was apparently occurring. During this period traps containing females always contained several males as well. 


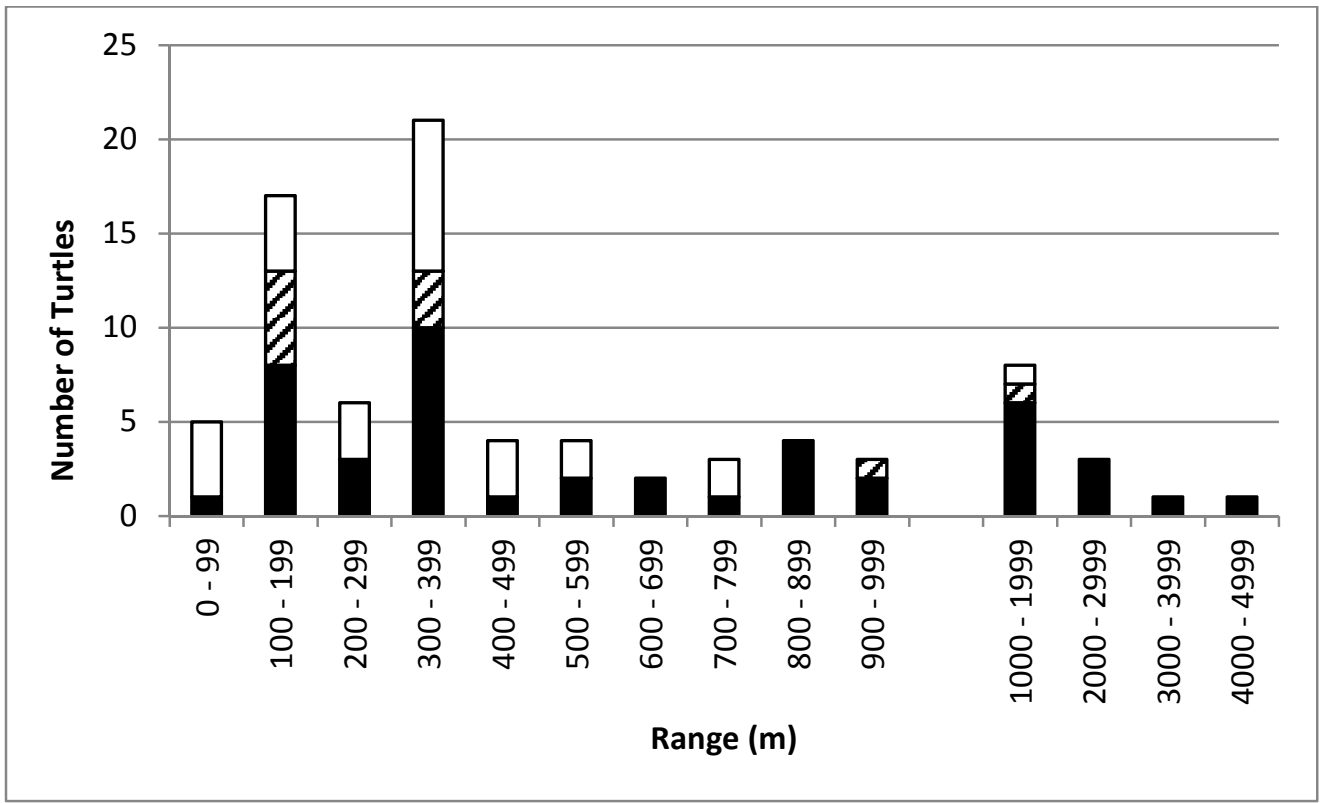

Figure 13. Ranges (m) of recaptured non radio-tracked Western Pond Turtles $(n=81)$ on upper Coyote Creek, Santa Clara County, California, 2011-2012. Shaded bars represent males ( $\mathrm{n}=45)$, striped bars represent females $(n=10)$, open bars represent juveniles of unknown gender $(n=27)$.

\section{Seasonal Movement}

Return dates.-Following a period of relative inactivity upland in summer 2011 through winter 2012, turtles returned to the stream in late winter through early spring, after winter rains had restored stream flow. I radio-tracked 17 turtles through the fall and winter of 2011-2012, but two apparently perished and never emerged from their inaccessible upland retreats. Thus, I was able to obtain return to stream data for 15 turtles (8 males, 7 females). The earliest date at which I tracked a turtle returning to stream habitat was 29 January (Figure 14). The latest date was 27 April, and the mean return to stream date was 6 March. Males tended to return to the stream earlier than females, with a mean arrival date of 27 February, and a range from 29 January-16 March (Figure 14). 


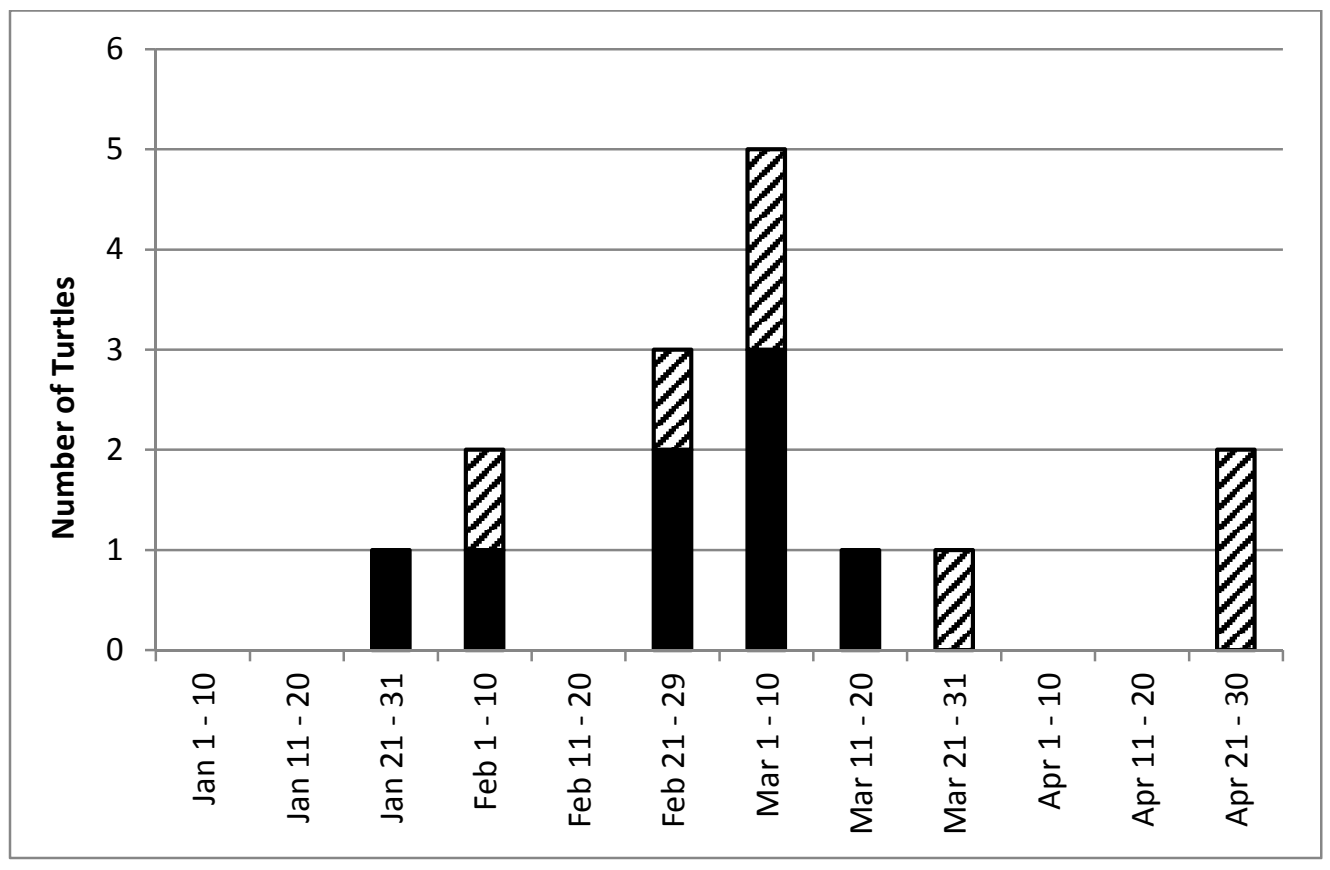

Figure 14. Return-to-stream dates in 2012 among Western Pond Turtles $(\mathrm{n}=15)$ radio-tracked from winter refugia in 2011 along upper Coyote Creek, Santa Clara County, California. Dark bars represent males, striped bars represent females.

The mean return to stream date for females was 16 March, and the range was from 3 February-27 April (Figure 14).

In-stream movements.- Turtles showed the greatest amount of movement in spring. In 2011, I did not begin tracking until May, so the month of April went unrepresented. In May, mean weekly movement for males ranged between 213-591 m per week, while that of females ranged from 0-148 m (Figure 15a). In June, mean male weekly movement was slightly less, between 188-560 m, while that for females increased, ranging from 154-243 m. In July, males moved slightly less, with mean weekly movements ranging from 239-464 m, while females ranged between 120-263 m. 
In August, movement for both sexes decreased substantially, and remained at low levels until turtles returned to the stream the following spring.

Radio-tracking in 2012 found limited movement in February for the first few turtles that had returned to the stream, followed by a modest increase in March in which mean weekly movements for males ranged from 197-243 m, and those for females ranged from 25-89 m (Figure 15b). The month of April showed a substantial increase, primarily by males, with mean weekly movements for males ranging from $367-775 \mathrm{~m}$ and those for females ranging from 34-119m. May showed the most extensive movement among males, with male mean weekly movements ranging from 421-1223 m; those for females ranged from 62-92 m, hardly different from April. Mean weekly movements for males declined sharply in June, ranging from 83-188 m, while those of females ranged from 53$86 \mathrm{~m}$, just slightly less than in May. In July, mean male weekly movement ranged from 12-210 m, while that for females ranged from 0-94 m. By August, in-stream movement was further curtailed, as many turtles had left the stream for upland habitats (Figure 15b). Male movement the week of 5 May-11 May 2012 was the highest documented in the study, with a mean movement of $1223 \mathrm{~m}$. I documented 24 instances in which a turtle moved in excess of $1000 \mathrm{~m}$ between weekly tracking efforts. All were by males, and all but four were in April or May. There were eight cases in which a turtle moved in excess of $2000 \mathrm{~m}$ between weekly tracking efforts, and all were in April or May.

With summer and reduced stream flows, turtle movement decreased, so there was a marked difference between 2011 and the much drier conditions in 2012. In 2011, movement in June and July tailed off but was still substantial, and male and female 


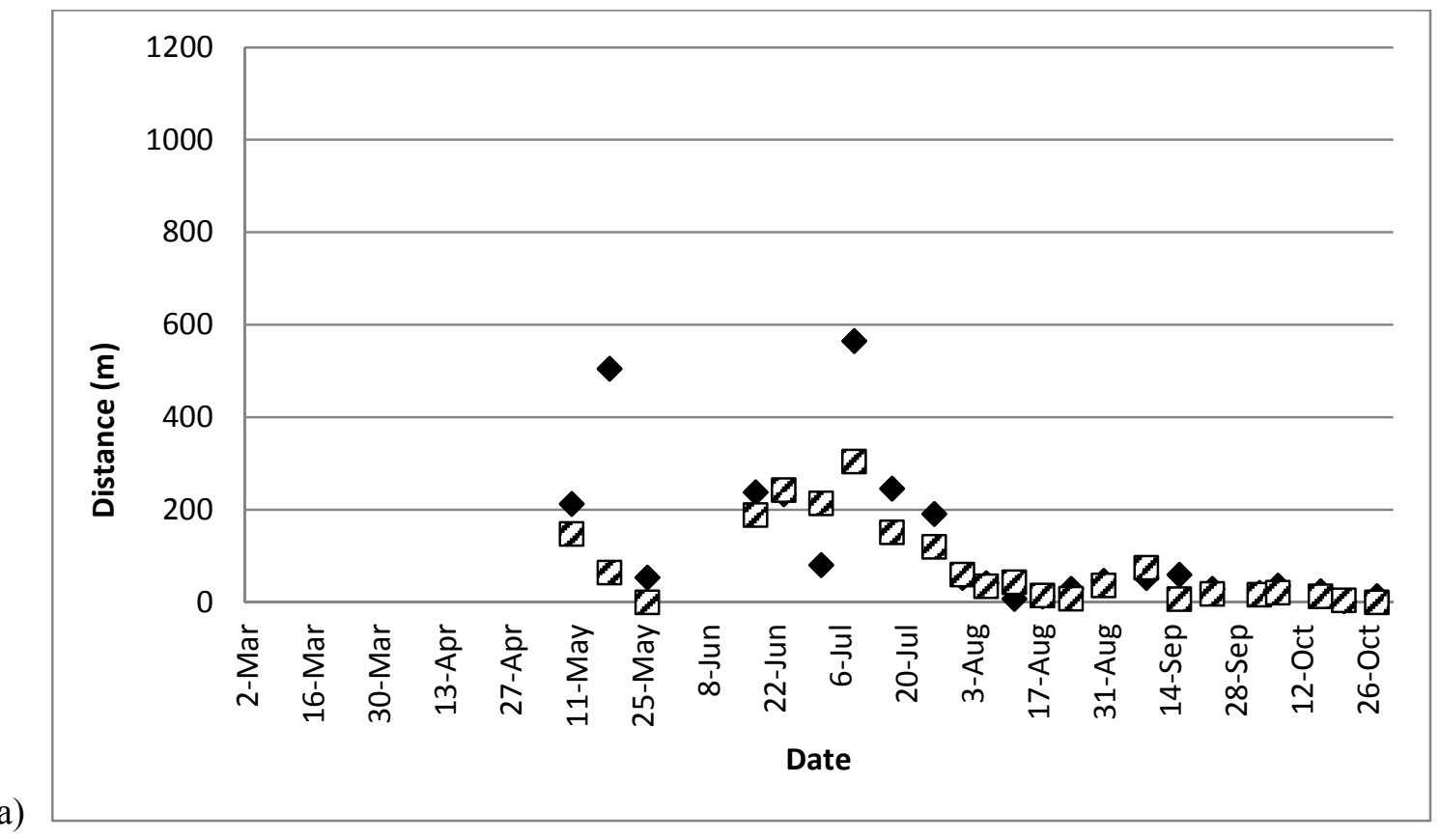

a)

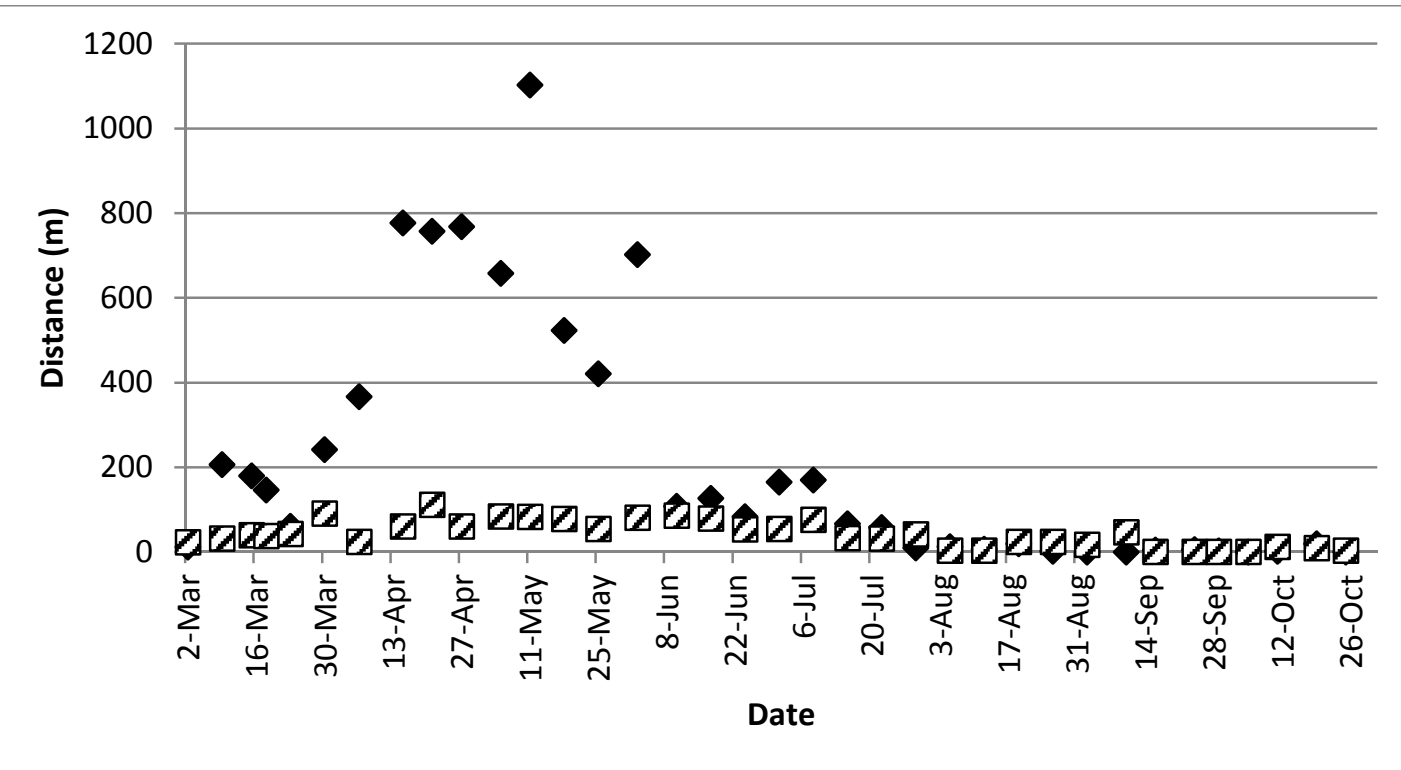

b)

Figure 15. Weekly mean movement (m) of radio-tracked Western Pond Turtles in a) 2011 and b) 2012 on upper Coyote Creek, Santa Clara County, California. Shaded diamonds represent male movements, and striped squares represent female movements. 
movement was similar (Figure 15a). In 2012, June and July movement was much less (Figure 15b). Throughout mid-June and July, 2011 movements were consistently 2-3 times higher than in 2012. I compared weekly mean movement data for 22 weeks in 2011 and 2012, from early May to late October, and 2011 figures were higher in 19 of 22 weeks. Despite the differences, the general pattern of heavy spring movement tapering off in summer remained constant.

Response to spring storms. - In March and April 2012, storms produced flood peaks of 800 and $1100 \mathrm{cfs}$ (Figure 5). Turtles were tracked to determine their response to the floods. In both cases, most ( 9 of 12, and 12 of 17) turtles remained in the stream under stream banks or within submerged shoreline or riparian vegetation. However, four turtles left the stream in response to the floods. Turtles moved $4 \mathrm{~m}, 10 \mathrm{~m}, 6 \mathrm{~m}$, and $15 \mathrm{~m}$ from the stream; the farthest movement included moving uphill more than $10 \mathrm{~m}$ above the flood level.

Movement to upland sites.-As summer progressed, turtles left the stream and moved to upland habitats. In 2011, the mean stream departure date for 18 radio-tracked turtles (9 males, 9 females) was 16 August, but with substantial variation (Figure 16a). The earliest date was 17 July, the latest date was 23 September. Males tended to depart slightly earlier (mean 10 August) than females (mean 22 August). The stream departure date range for males was 17 July-23 September. The range for females was 22 July-23 September. Departure generally started when stream flow continuity between pools ceased, and began in the driest stream reaches (upstream of Pools \#1-11) first. In 2012, the mean stream departure date for 21 turtles (12 males, 9 females) was 
20 July, 27 days earlier than in 2011. The earliest date was 1 July, and the latest was 2 September (Figure 16b). In 2012, there was very little difference between male and female stream mean departure dates. The mean date for males was 19 July, and the mean date for females was 21 July. The stream departure date range for males was 1 July-19 August, and the range for females was 1 July-2 September (Figure 16b). As in 2011, departures within reaches began when stream flow continuity was lost, although in 2012 there was a greater lag time in departure compared to dryback, especially for females. In 2013, the mean stream departure date for 15 turtles (10 males, 5 females) was 28 June, 22 days earlier than in 2012 and 49 days earlier than in 2011. The mean date for males was 30 June (Figure 16c). The mean date for females was 25 June.

I documented stream departure dates for 10 turtles in both 2011 and 2012. Of those, eight ( $80 \%$ ) left the stream earlier in 2012, with dates ranging from 14-72 days earlier (mean 29 days). The two turtles leaving later in 2012 did so 19 and 22 days later. I documented stream departure dates for eight turtles in both 2012 and 2013. All but one left the stream earlier in 2013 (mean 27 days), and that turtle did so only four days later. The greatest difference was 41 days. I recorded stream departure dates for five turtles for all three years. All left earlier in 2013 than 2011, with differences ranging from 16 to 72 days (mean 47 days).

Upland activity.-In 2011, I tracked 18 turtles to upland habitats after they left the stream, but one was found dead of unknown causes in October and two others were presumed to have died after failing to emerge by May 2012. Both were tracked to microhabitats that were virtually inaccessible to researchers (a poison oak thicket and a 
a)

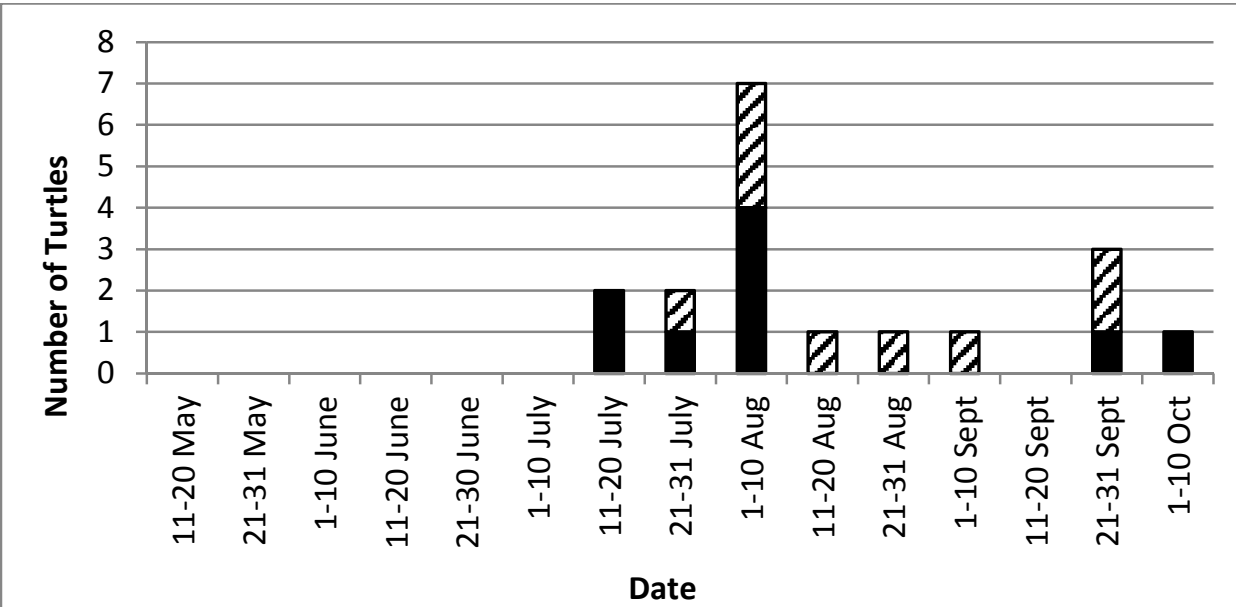

b)

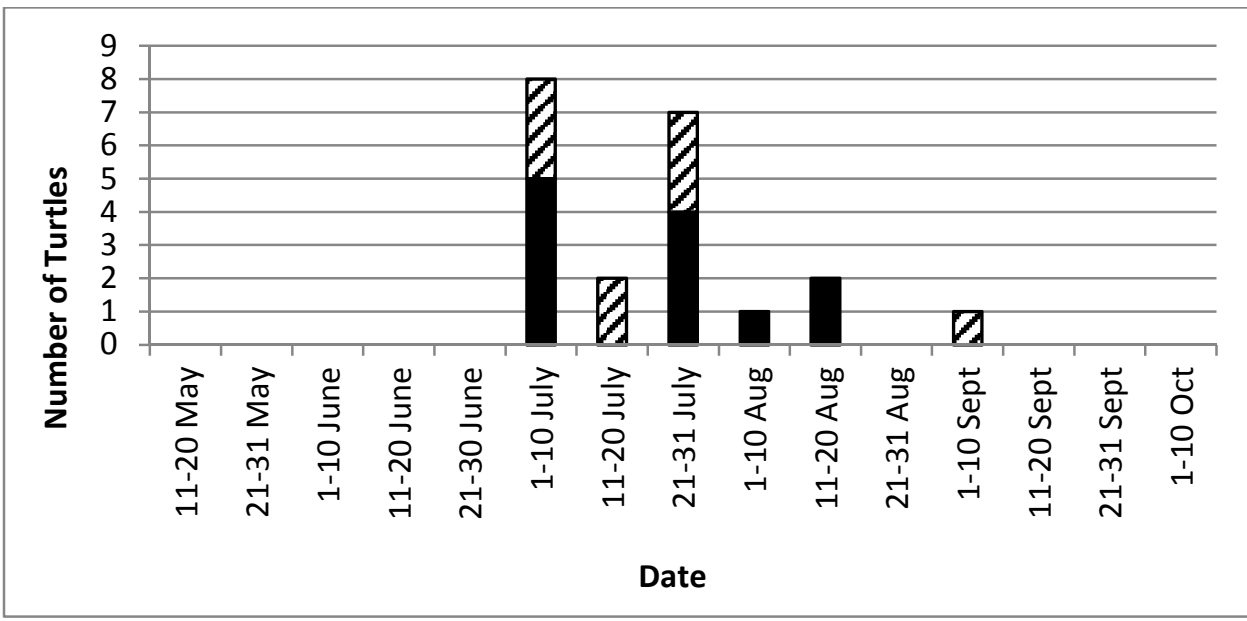

c)

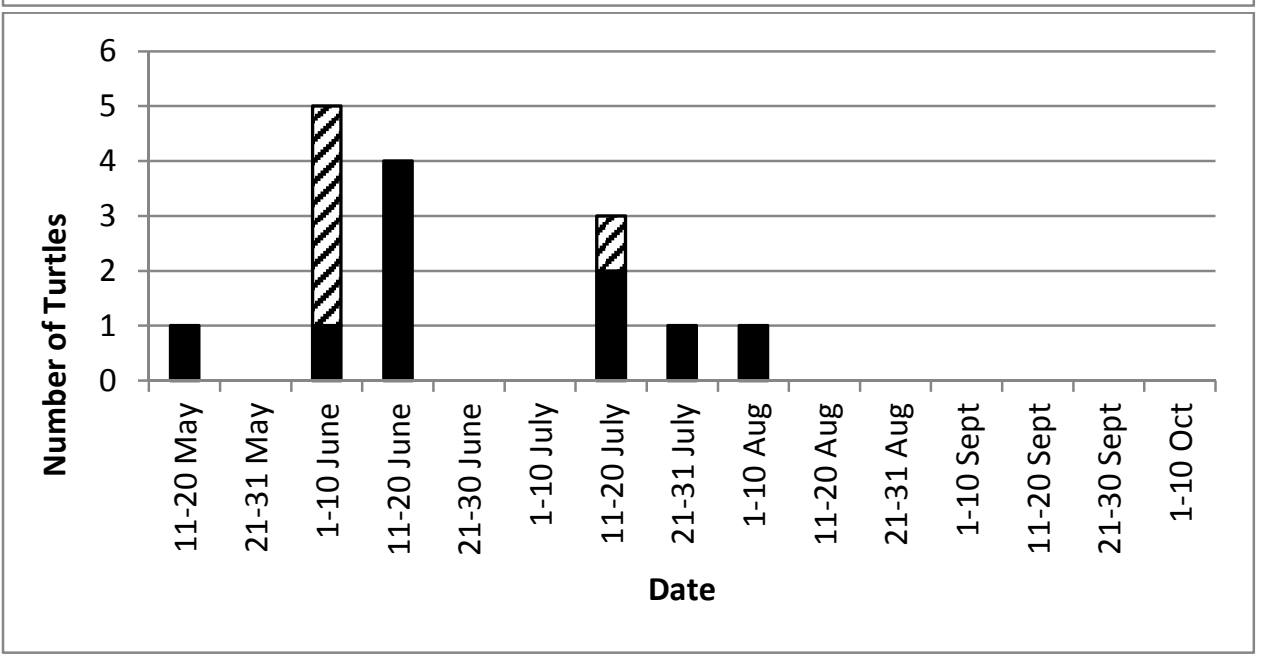

Figure 16. Stream departure dates in a) $2011(\mathrm{n}=18)$, b) $2012(\mathrm{n}=21)$, and c) $2013(\mathrm{n}=15)$ for Western Pond turtles radio-tracked along upper Coyote Creek, Santa Clara County, California. Dark bars represent males, striped bars represent females. 
small tree cavity). As a result, only 15 turtles ( 8 males, 7 females) were tracked from their 2011 stream departure dates until their return to the stream in 2012. During that time they provided data on upland and seasonal habitat use.

Once upland, turtle activity was somewhat complex and difficult to classify. No turtle left the stream, selected an upland site, and remained completely inactive until returning to the stream in 2012. The amount of upland movement varied substantially. I documented turtles moving anywhere from 2-18 times once they were tracked upland (I did not count the initial upland movement or the return to water in 2012). The mean number of movements was 5.8. One male was first tracked upland 1 August, made two minor movements over the next two weeks ( $4 \mathrm{~m}$ and $2 \mathrm{~m}$ ), then showed no further evidence of movement until he returned to the stream in late January 2012. A female was first tracked upland 6 August, moved $10 \mathrm{~m}$ the following week, remained stationary for about a month before being tracked to another site $20 \mathrm{~m}$ away, and showed no further evidence of movement until her return to the stream in February 2012. In contrast, one male was first tracked upland 17 July, and was constantly on the move. This turtle was tracked to an additional 18 locations before returning to the stream in February 2012. The next highest number of upland movements I recorded for an individual turtle was nine. Males moved from 2-18 times, with a mean of 6.9. Females moved from 2-9 times, and had a mean of 4.6. Upland movements included five turtles that briefly returned to the stream in late summer or fall. One turtle made three return trips to the stream before settling down upland. Most turtles that returned to water were tracked back in upland habitat the following week. The lone exception was a male that moved 
far upstream (Pool \#44), which was upland in August 2011, but tracked to Pool \#44 on 16 September 2011, where he remained for nearly a month. Overall, forays back to stream habitat occurred between 26 July and 7 October. Otherwise, no turtle was tracked to the stream again until 2012, after emerging from winter inactivity.

The general pattern of upland activity showed the most frequent (Figure 17a) and extensive (Figure 17b) movement occurring in late-summer through mid-fall. September had the most extensive movement (mean distance $70 \mathrm{~m}$; Figure 17b). Upland turtles moved in excess of $100 \mathrm{~m}$ between tracking intervals nine times, and four of those were in September, including the longest distance, $335 \mathrm{~m}$. The greatest number of movements regardless of distance was in October (24) and August (18; Figure 17a). September and November had 15 each. After November and the onset of cooler weather, movement declined substantially. There were only seven movements in December and six in January (Figure 17a). In addition, the mean distance for movements in both months was just $5 \mathrm{~m}$ (Figure 17b). The longest distance recorded for movement in December was 15 $\mathrm{m}$, and the longest for January was $11 \mathrm{~m}$. Most turtles had selected a spot and remained until returning to the stream and resuming activity in early 2012 .

The mean upland stay was 201 days (Figure 18). The shortest upland period was 154 days (23 September 2011-24 February 2012) by a female. The lengthiest upland stay was 274 days (22 July-21 April) by another female. Males showed a slightly shorter upland period, with a mean of 198 days, and a range from 159-231 days (Figure 19). Females had a mean upland stay of 206 days, and a range from 154-274 days. 

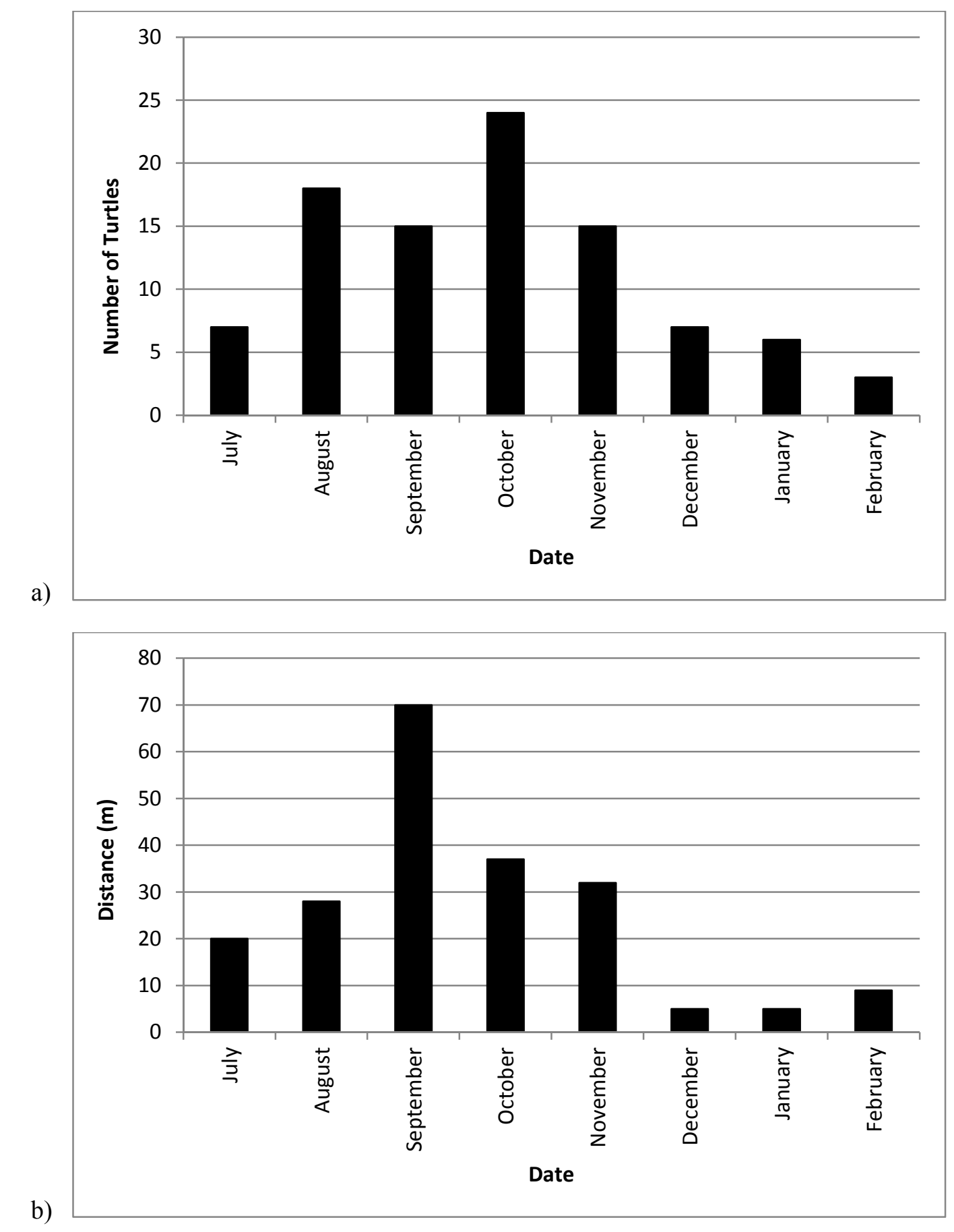

Figure 17. Monthly upland movements of Western Pond Turtles along Coyote Creek from July 2011-Februrary 2012; a) number of movements and b) mean distance moved. 


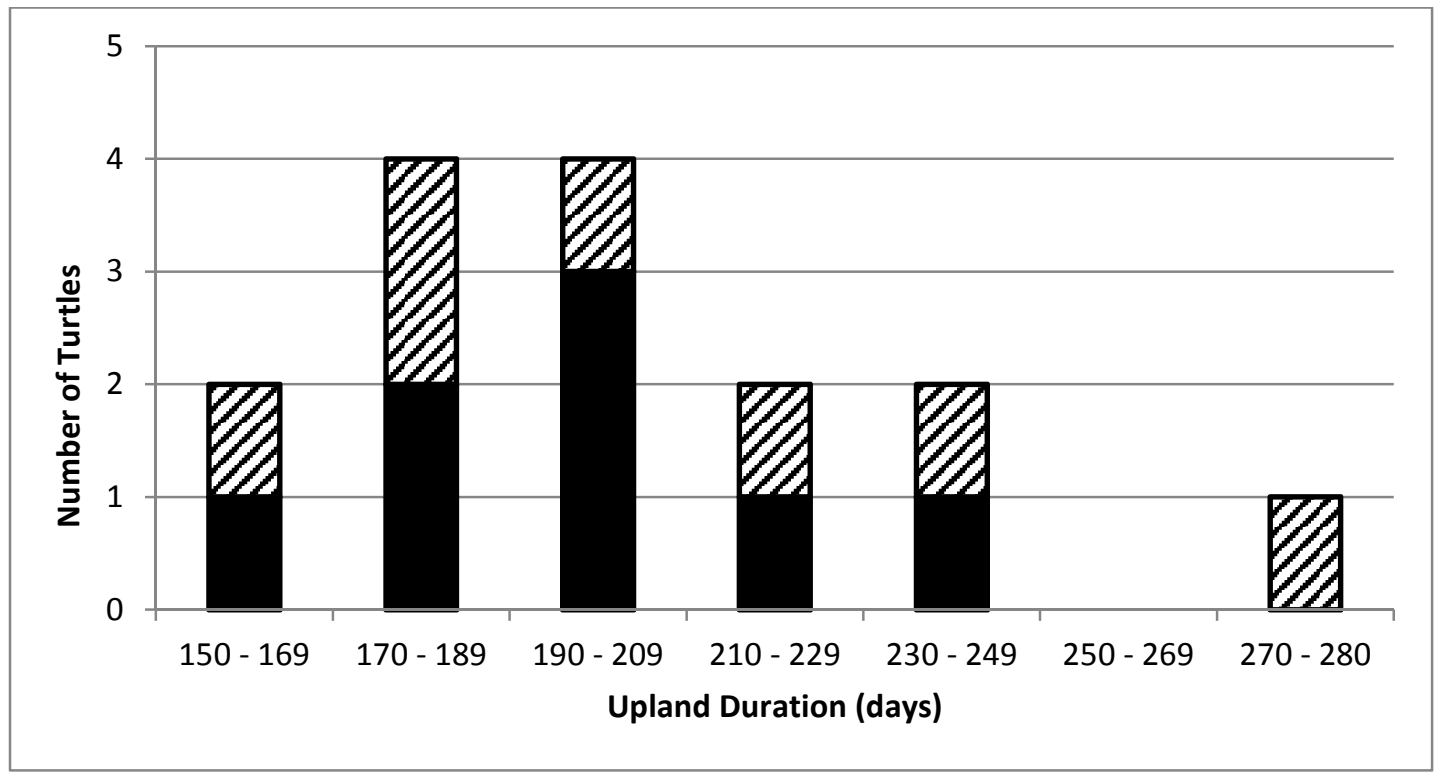

Figure 18. Duration of upland habitat occupancy of radio-tracked Western Pond Turtles $(n=15)$ in upper Coyote Creek, Santa Clara County, California, summer 2011-spring 2012. Dark bars represent males $(n=8)$, striped bars represent females $(n=7)$.

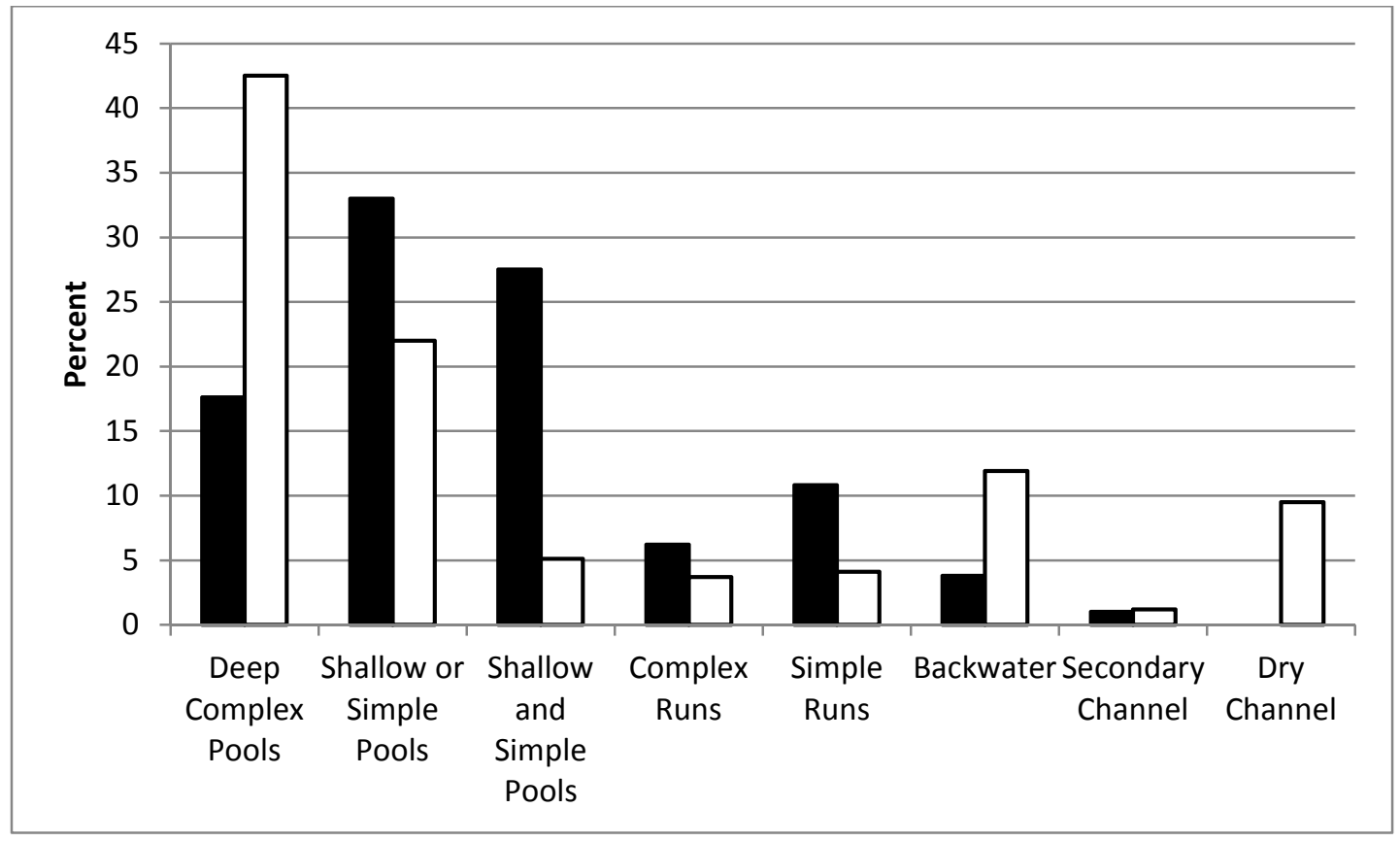

Figure 19. Habitat available (black bars) and habitat used (white bars) in pools -10 to 25 in the Western Pond Turtle study area in upper Coyote Creek from 2011-2012. Dry Channel habitat availability was not calculated. 


\section{Spring/Summer Meso Habitat Use}

I recorded 590 locations for radio-tracked turtles prior to their moving to upland sites. During that time, I found turtles associated with aquatic habitats far more frequently $(n=534,90.5 \%)$ than dry channels below bankfull $(n=58,9.5 \%$; Figure 19$)$. Pools were the preferred aquatic habitat $(78.3 \%)$, followed by backwaters $(13.1 \%)$, and runs $(8.6 \%)$. But while pools constituted the majority $(69.6 \%)$ of trackings, WPT pool use differed greatly among three pool types. Complex, deep pools constituted just $17.6 \%$ of available habitat, yet accounted for $42.5 \%$ of all trackings (Figure 19). In contrast, pools that were either simple or shallow constituted $33 \%$ of available aquatic habitat but accounted for $22 \%$ of all trackings, and pools that were both simple and shallow, while comprising $27.5 \%$ of available habitat, accounted for only $5.1 \%$ of trackings (Figure 19 ). Besides complex, deep pools, the only other aquatic habitat type to register disproportionally heavy usage were backwaters, which made up $3.8 \%$ of available habitat but accounted for $11.9 \%$ of trackings (Figure 19).

Among the deep, complex pools, Pool \#6 had the most tracking observations, with 70, followed by Pool \#11 (64), Pool \#5 (52), and Pool \#8 (50). In contrast, few turtles were tracked to shallower, simpler Pools \#10,\#12, and \#13, which also dried earlier. Pool \#7 had the highest number of turtles tracked to it, with a total of 14 , followed by Pool \#6 (13),Pool \#11 (13), Pool \#5 (11), and Pool \#8 (11).

Turtles tracked to other habitats similarly showed certain areas of more frequent occurrence. Within run habitats, I found turtles 46 times. Runs with complex escape cover, usually overhanging vegetation, were about twice as likely to be used compared to 
their availability than were simple runs (Figure 19). The most heavily frequented runs were those between Pools \#6 and \#7 (9 trackings of 4 turtles), and between Pools \#7 and \#8 (9 trackings of 5 turtles), all of which were complex runs. In contrast, 10 simple runs had 0-1 trackings.

The most prolific backwaters (45 trackings of 19 turtles) were associated with three large pools (\#11,\#17,\#18). A large, deep, isolated backwater adjacent to Pool \#15 was also heavily used (17 trackings of 2 turtles).

Like backwaters, secondary channels were relatively scarce components of the upper Coyote Creek stream system (Figure 19). However, the secondary channel of -1+ ( 5 trackings of four turtles) and the secondary channel adjacent to $7+$, Pool \#8 and $8+(6$ trackings of 2 turtles) were as large as the main channels, had good depth and complex cover and were heavily used. In 2011, one juvenile radio-tracked turtle moved downstream to Coyote Reservoir and remained until the battery died in March 2012. This was the only tracked turtle to use the reservoir extensively, although in 2012, several turtles briefly moved to the uppermost section of the reservoir where stream pools were backwatered by the reservoir.

The most prolific streambed terrace (below bankfull) site was at Pool \#8 and 8+, between the two channels, with 19 trackings of four turtles. Other heavily-used terrace locations included $-3+(7$ trackings of two turtles $), 6+(6$ trackings of 4 turtles $)$, and $-1+$ ( 5 trackings of 5 turtles). In comparison, the many other terrace sites had 0-1 trackings. 


\section{Microhabitat Use}

Aquatic. - Few $(<5 \%)$ tracked or non-transmittered turtles were readily visible during the surveys. Most tracked turtles were hidden and associated with cover provided by undercut banks, boulders, or overhanging vegetation. Fewer than $2 \%$ of tracked turtles were basking when located. Basking habitat on boulders and wood was more frequently used (including sightings of non-transmittered turtles) early in the year when water was cool. Use was relatively less after water had warmed by mid-June, and in summer basking was frequently observed in tracked turtles submerged beneath algal mats in shallow water; water temperature beneath the mats was normally $5^{\circ} \mathrm{C}+$ warmer than in the rest of the pool.

I examined specific microhabitats where individual turtles were tracked three or more times to document habitat use by individual turtles as well as areas frequently shared by numerous turtles. In contrast to the spring movements, I observed four cases in which a turtle was tracked to a specific location 10 times or more during the active period. A female was tracked 28 times to a dense willow thicket at the head of Pool \#5, by far the strongest microhabitat association found for any turtle in the study. Other instances included a male in the isolated backwater adjacent to Pool \#15 (12 times), a male in the backwater along the left bank at the tail of Pool \#11 (10 times), and a female submerged beneath a boulder along the left bank of Pool \#6 (10 times). I found six microhabitats used three times or more by more than one turtle. The willows along the right bank of Pool \#5 harbored four different turtles at least three times, as did the boulders at the head of Pool \#6. The other four locations (Pool \#11 left bank backwater, 
Pool \#15 isolated backwater, Pool \#18 backwater at head of pool, and 5+ run) all had two turtles with three or more trackings there.

Upland habitat use.-Overwinter sites ranged from $9 \mathrm{~m}$ to $110 \mathrm{~m}$ from the edge of the stream, with a mean distance of $54 \mathrm{~m}$ (Figure 20a). All overwinter sites had at least $40 \%$ canopy cover, while 13 of $15(86.7 \%)$ had $50 \%$ or more, and $7(46.7 \%)$ had $80 \%$ or more (Figure 20b). The vegetation community for 5 of the 15 sites consisted of edge habitats showing near equal representations of 2 plant communities, and 6 different plant communities were found in association with overwinter sites. Coast Live Oak Woodlands were associated with 14 of the 15 sites (93.3\%), and Coastal (Diablan) Sage Scrub was associated with 2 sites, the only other plant community with more than one. The other 4 plant communities recorded at overwinter sites were Sycamore Alluvial Woodland, Riparian, Valley Oak Savannah, and Blue Oak Woodland.

All overwinter sites contained at least some leaf litter, and in many cases (11 of $15,73.3 \%$ ) leaf litter was abundant. Dried grass, or thatch, was noticeably present at 6 of the 15 sites (40\%), and 4 of the $15(26.6 \%)$ had more thatch than leaf litter.

Twelve sites (80\%) had a southern aspect (south, southwest, southeast; Figure 21a). Six of fifteen sites ( $40 \%)$ were on slopes of 40 degrees or more and six others (40\%) were on slopes of 20 degrees or less, including two (13.3\%) on level ground (Figure 21b). 


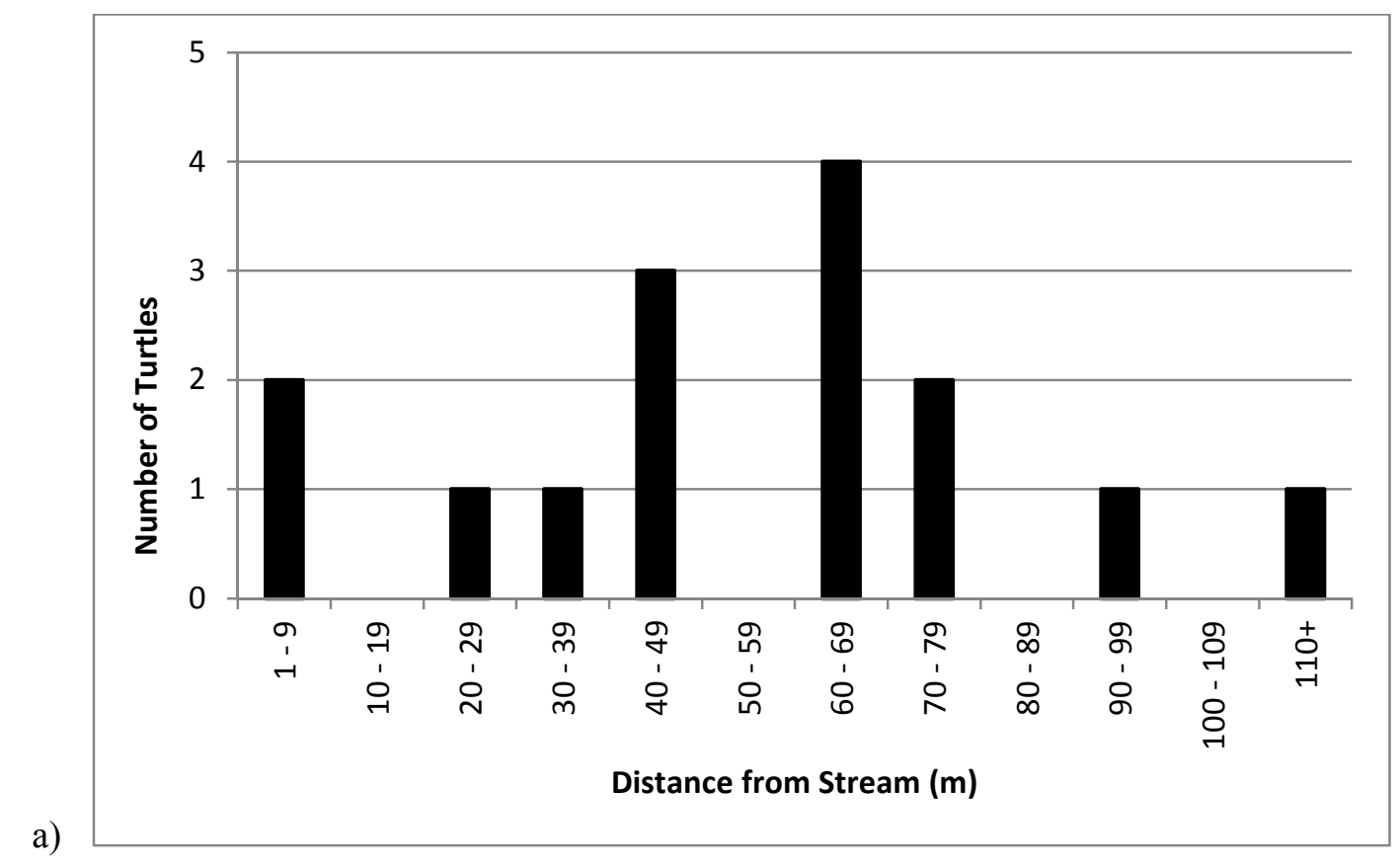

a)

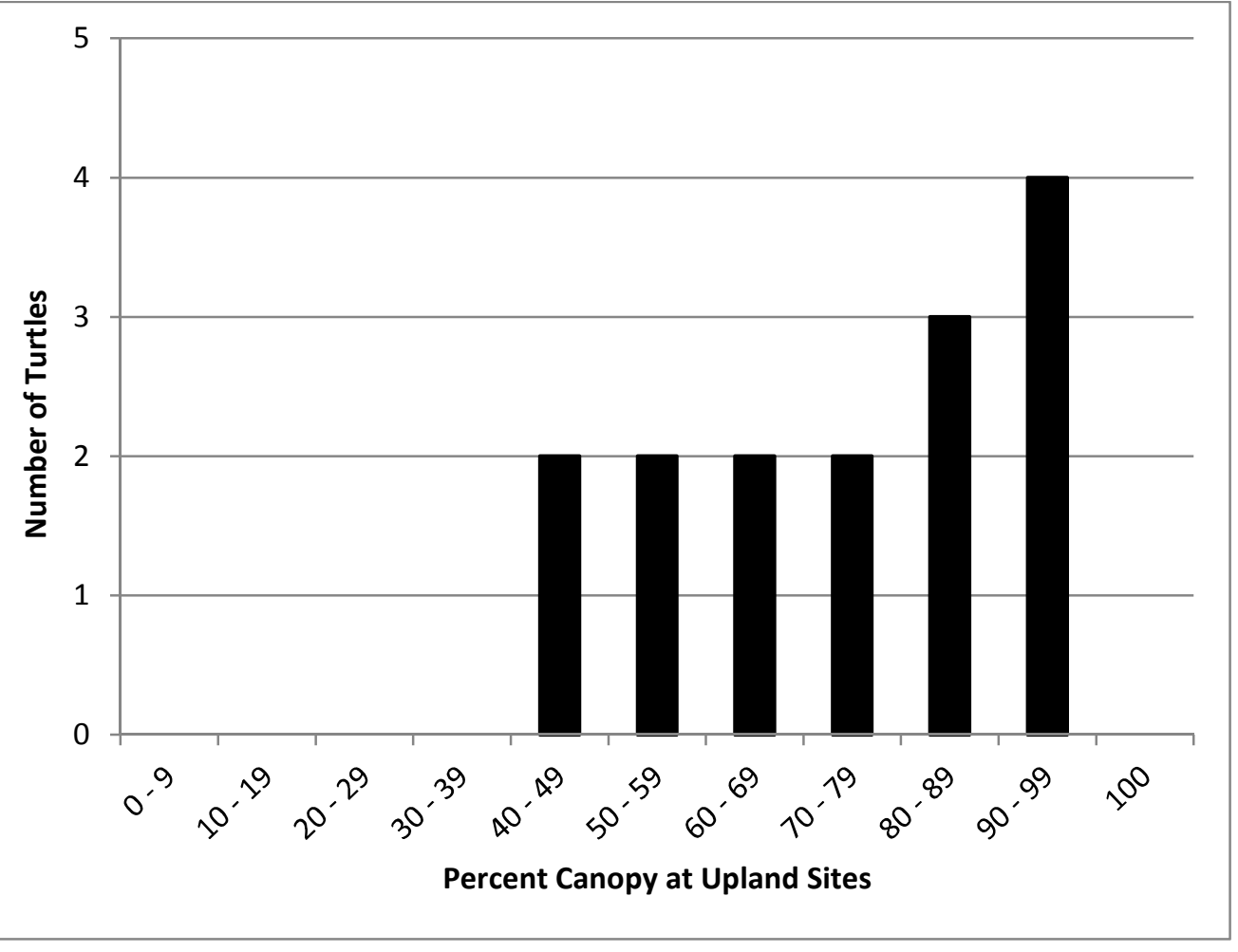

Figure 20. a) Distance from stream and b) percent canopy of upland sites used by Western Pond Turtles on upper Coyote Creek in summer 2011-spring 2012. 

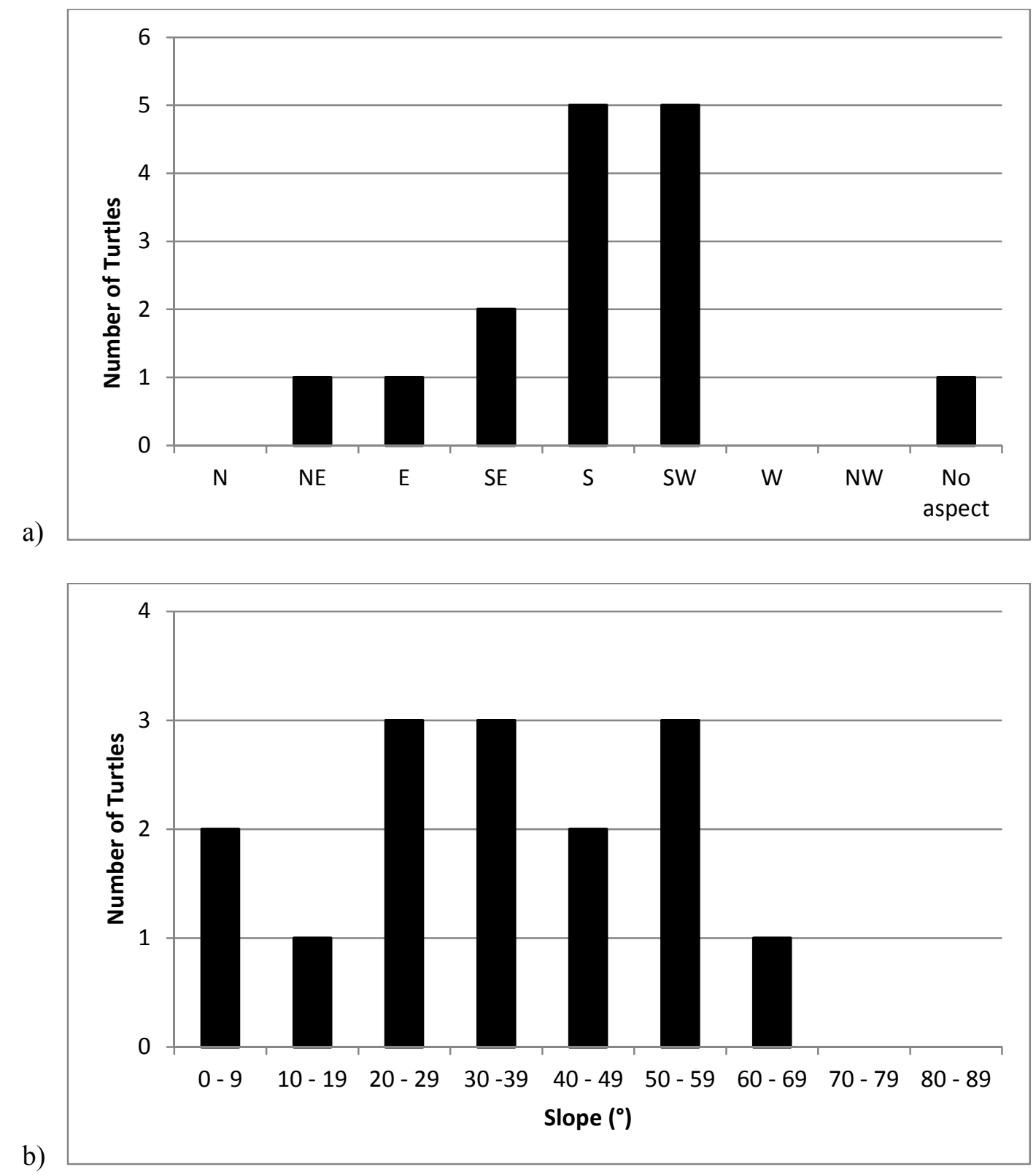

Figure 21. a) Aspect and b) slope of upland sites used by Western Pond Turtles on upper Coyote Creek in summer 2011-spring 2012. 


\section{DISCUSSION}

\section{Population Demographics}

In 2011 and 2012, 160 turtles were caught in the intensively trapped $3.8 \mathrm{~km}$ reach between Pools \#-5 and 25. The apparent density of $42 / \mathrm{km}$ is somewhat inflated because some of the mobile male turtles were tracked within an additional $4 \mathrm{~km}$ (Pools \#-10 to 44), and one marked male turtle was recaptured at the upper site (after being marked in Pool \#17). Even so, the density appears surprisingly high considering that much of the intermittent habitat was available only through early- to mid-summer. The density was probably similar to that along San Simeon Creek on the central California coast, where Rathbun et al. (1992) estimated a population of 150-180 along a $6.2 \mathrm{~km}$ stretch of lagoon and stream (24.2-29 per km). Bury (1972) recorded a much higher density, 578 along a $3.5 \mathrm{~km}$ section of small perennial stream in northern California (165.1 per km).

The male/female gender ratio in this study (2.8:1) appears heavily skewed toward males. While some studies have reported equal gender ratios (Goodman 1997, Lovich and Meyer 2002), most others have found populations composed of more males than females. Cook and Martini-Lamb (2004) found a slight male bias (1.3:1), while Bury found a more pronounced example (1.7:1). Both Davis (1998) and Abel (2010) found ratios of 2:1 in the Waddell Creek drainage along the coast south of San Francisco, while Spinks et al. (2003) reported a similar ratio of 1.9:1 in Davis, CA. The most extreme instance of male bias was found by Germano and Rathbun (2008), who reported a ratio of 4.9:1 in pond habitat near Lompoc, CA. Lubcke and Wilson (2007) found divergent ratios among different habitat types in the northern Sacramento Valley: 2.3:1 in canals, 
1.5:1 in sloughs, and an atypical example of females outnumbering males $0.7: 1$ in creeks. Bury et al. (2010) studied four sites in northern California and southern Oregon, and found gender ratios ranging from even to female biased.

Our trapping may have resulted in a skewed gender ratio in cases where a female in April or May entered the trap and her presence attracted a group of males. This may have contributed to a higher male count; however, captured males outnumbered captured females throughout the year. Other possible reasons for the male bias in this study might include increased predation risk associated with nesting forays and the apparent tendency of females to delay upland movements in drying reaches. Increased predation risk to females has been suggested by others (Holland 1994, Ernst and Lovich 2009).

Our initial captures consisted of only 14.5\% juveniles (1-5 yrs.), although unsexed individuals 6-8 years old and less than $120 \mathrm{~mm}$ CL accounted for an additional 12.1\%. Only 10 turtles aged 11-15 were captured, but 71 had worn shells and could not be aged. It is likely that most turtles older than 10 years had worn shells as a result of the rocky stream substrate. Turtles older than 10 years or with worn shells accounted for $46.8 \%$ of captured turtles. The percentage of juveniles $(26.6 \%)$ captured appears to be similar to results from the relatively few studies containing age data for WPT. Juveniles comprised $40.8 \%$ of the population studied by Germano and Rathbun (2008) along the central California coast, while Germano (2010) had Central Valley figures of $25-31 \%$ for fastgrowing populations at sewage treatment ponds in Fresno and Hanford, CA. Cook and Martini-Lamb (2004) reported 26.9\% juveniles in the population along the Russian River 
in northern California. Germano and Bury (2009) reported 32.2\% juveniles in an Oregon population.

\section{Size and Growth Rate}

The mean CL for adult turtles in this study was approximately $140 \mathrm{~mm}$, and only 11 of $128(8.6 \%)$ grew to lengths of $160 \mathrm{~mm}$ or more. The size range for adults, according to Bury and Germano (2008) lies between 140-190 mm. The largest turtle measured along UCC was $174 \mathrm{~mm}$, spent most of its time in a stock pond, and was the only turtle over $165 \mathrm{~mm}$, far short of the upper limits of $216 \mathrm{~mm}$ delineated by Stebbins (2003), $230 \mathrm{~mm}$ described by St. John (2002), and the record length of $241 \mathrm{~mm}$ (Ernst and Lovich 2009). By comparison, a population along the Russian River in Sonoma County studied by Cook and Martini-Lamb (2004) had a mean CL of approximately 170 $\mathrm{mm}$.

The relatively small size of most adult UCC turtles may be a product of environmental conditions. Large size and rapid growth rates are associated with warm air and water temperatures, as well as eutrophic conditions in which food and nutrients are abundant (Germano and Bury 2001). It appeared that UCC contained an adequate food supply of algae and invertebrates, though likely less than in many eutrophic pond environments. However, the ephemeral nature of the stream means that the creek can only be used for no more than six months in favorable years, and perhaps as few as three in drought years. Because WPTs must enter water in order to feed, UCC turtles can only feed between 3-6 months annually, and fat reserves must sustain them through an extensive upland period. In 2013 through 2015 (J. Smith, pers. comm., 2015), several 
turtles failed to show growth rings following the severe drought years 2012, 2013, and 2014, which affected apparent growth rate and may have affected our age estimates. Holland (1994) calculated an average length of seven years for WPT to reach $120 \mathrm{~mm}$, the size associated with sexual maturity, but the species shows much variation in growth rate from site to site and region to region, probably due to differences in temperature and food availability. Germano (2010) found turtles reaching $120 \mathrm{~mm}$ lengths in just two years in sewage treatment ponds in the San Joaquin Valley, in four years along the central California coast, and between 5-9 years in sites within the Klamath-Siskiyou region of northern California and southern Oregon.

UCC turtles appear to fall within the normal range. Seven year old turtles showed a mean CL of $119.1 \mathrm{~mm}$, virtually identical to the $120 \mathrm{~mm}$ norm projected by Holland (1994), but with a surprisingly wide range, between 92-146 mm. Ten year old turtles had a mean CL of $143.6 \mathrm{~mm}$, similar to Ernst and Barbour (1972), who estimated it typically takes 10 years for WPTs to reach a length of $140 \mathrm{~mm}$ CL.

\section{Reproduction}

UCC data on reproduction were similar to those found in other studies. During his three year study in southern California, Goodman (1997) found that not all adult females bred every year, with an annual rate at $50 \%$ or less. Germano and Rathbun (2009) found 12 of $18(66.7 \%)$ adult females to be gravid, while our study found 9 of 17 (52.9\%) gravid in 2011 and 4 of 16 (25\%) gravid in 2012. However, UCC percentages were probably biased low because turtles were captured opportunistically and many were checked only once. In 2011, of the seven checked once, only one was gravid, but of 
those checked two or more times, $8(80 \%)$ were gravid on at least one occasion. In 2012 none of the nine checked only once were gravid, while four of seven $(57.1 \%)$ checked more than once were gravid. Had all turtles been checked multiple times the percentages of gravid turtles would likely have been markedly higher.

In 2011, following a wetter than average winter, four cases of double clutching were documented among UCC turtles, and possibly a fifth. Double clutching may not be unusual for the species, as Germano and Rathbun (2008) cite four examples of double clutching discovered by other researchers. Double clutching was not confirmed among UCC turtles in 2012, when streambed drying occurred earlier than average. It may even be that dry conditions such as those following the winters of 2012-2013 or 2013-2014 may preclude breeding even once for many turtles. If that is the case, environmental conditions which either reduce the amount of water entering the system (precipitation decreases), or increase the rate of evaporation (air temperature increases) could result in reduced reproductive success for turtles.

The size range for UCC gravid turtles (131-161 mm CL) is in line with other studies such as Lovich and Meyer (2002) along the Mojave River, whose gravid turtles ranged from 133-160 mm CL. However, Goodman (1997) recorded a gravid individual $110 \mathrm{~mm}$ CL, well below the lowest figure on UCC. UCC turtles under $120 \mathrm{~mm}$ CL were rarely checked for eggs, and in most cases turtles smaller than that were not able to be sexed with confidence. However, one female $120 \mathrm{~mm} \mathrm{CL}$ was captured in a trap with five males, so she apparently was reproductively mature. 


\section{Home Range}

UCC male turtles had larger home ranges and undertook more extensive movements than females. It appears well established that male WPT range farther than females, as similar findings were reported by Bury (1972), Reese (1996), and Bondi (2009). Male turtles in this study had mean home ranges of approximately $2500 \mathrm{~m}$, and the largest was $5483 \mathrm{~m}$, among the largest yet recorded for the species. Much of the movement occurred in April and May, when breeding was taking place, and the large movements were apparently undertaken to increase encounters with receptive females. During that period, trapped females nearly always shared the trap with numerous males. Goodman and Stewart (2003) noted that turtles in intermittent streams had larger home ranges than those in perennial streams, although their study was restricted to female turtles. Bondi (2009) examined movements of turtles within a river system with both habitat types and also found more movement among turtles in intermittent reaches than in those inhabiting perennial waters. Therefore, the ephemeral nature of UCC may explain the large home ranges documented, although not all UCC male turtles moved extensively. A male tracked in both 2011 and 2012 exhibited a total range of $636 \mathrm{~m}$, and several other males showed limited movement as well. Those with less movement were located in the more perennial core of the study area where feeding and breeding opportunities may have been best.

While most UCC males moved extensively, most females did not. Limited female movement might also be understood within the context of breeding. With males moving and seeking out females, there is little need for females to expend energy seeking 
mates. Thus, female movements may be influenced by other factors such as finding food, predator avoidance, seasonal reach changes in stream flow, and particularly for traveling from foraging areas to adequate nesting sites.

Along UCC, mean home ranges for female turtles were much lower than those for males and similar to those documented by other researchers. However, other studies have included examples of individual females traveling greater distances than any recorded along UCC. Cook and Martini-Lamb (2004) reported a female with a range of $2309 \mathrm{~m}$, Goodman and Stewart (2000) documented a female with a range of $4263 \mathrm{~m}$, and Abel (2010) noted a case where a gravid female had traveled $5000 \mathrm{~m}$, apparently scouting nesting sites. In contrast, the largest home range for radio-tracked females along UCC was $810 \mathrm{~m}$, although a non-tracked female was recaptured over $1000 \mathrm{~m}$ from its original capture site, making her the widest-ranging female detected in this study. Limited female movement along UCC might be due to the relative abundance of suitable nesting habitat in the vicinity, for much of the study area consists of grassy uplands. With no shortage of areas with friable soils and open areas with plenty of solar exposure, female turtles may not need to travel far to nest. Subsequent tracking in 2013 confirmed a female traveling from Pool \#6 to a stock pond on private property adjacent to Pool \#-5, an estimated distance of $1700 \mathrm{~m}$; the turtle was first captured at the pond in 2011. Thus, it appears that at least some females in UCC may have ranges substantially larger than those detected in 2011-2012.

Recaptured turtles also provided data on home range. Overall, 82 turtles that had not received transmitters were recaptured during the course of this study, but $41(50 \%)$ 
were recaptured only once, providing a minimal data set of two locations for home range determination. However, recapture data provided at least some information on the movement and ranges of juvenile turtles $(n=27)$, which, with the exception of a single large (103 mm CL) juvenile, were not radio-tracked. Juvenile turtles along UCC had limited ranges similar to those of adult females. Bury (1972) came to the same conclusion in a study that involved radio-tracking. Without the need to breed, juveniles have no need to travel as far as do adult males. However, the only juvenile I radiotracked traveled from Pool \#1 to Coyote Reservoir, in excess of $3000 \mathrm{~m}$. This seven year old turtle may have been a male entering breeding age.

WPT are capable of undertaking extensive movements surprisingly quickly. Rathbun et al. (1992) recorded a turtle moving $700 \mathrm{~m}$ in four days; Bury and Germano (2008) had one move $1.5 \mathrm{~km}$ in 2 weeks, while Cook and Martini-Lamb (2004) had a turtle move $762 \mathrm{~m}$ in 19 hours, and $1241 \mathrm{~m}$ in 4 days. Such intense short term movements were common among male turtles in UCC, especially in spring. I recorded 24 cases of turtles moving $1000 \mathrm{~m}$ or more between weekly tracking efforts. The most extreme example was of a male that traveled $4100 \mathrm{~m}(4.1 \mathrm{~km})$ in six days.

\section{Seasonal Activity}

There have been relatively few studies documenting dates of return to the stream for turtles emerging from winter upland sites. Davis (1998) found that turtles along Waddell Creek, a perennial stream along the coast just south of San Francisco, began returning to water in April. Reese and Welsh (1997) recorded a wide spectrum of return dates ranging from February to late June along the Trinity River, also a perennial system. 
Bondi (2009) found turtles returning earlier (all by 20 April) to an intermittent stretch of the Mad River than to a perennial stretch (all by 13 May). Along UCC, return dates for 15 turtles ( 8 male, 7 female) ranged from the 29 January to 27 April. This wide range of dates is somewhat similar to that of Reese and Welsh (1997) but earlier than those reported by Davis (1998) and Bondi (2009). The early return dates exhibited by the UCC turtles are probably a product of the generally warmer inland environment compared to the other three sites, and possibly to the intermittent status of the stream. A late January date appears to be risky. While the stream is likely flowing by then, it is cold, and feeding is limited. In addition, January, February, and March are usually months of heavy rainfall and possible flood conditions which can pose a threat to stream-dwelling turtles. In the winter/spring 2011-2012, significant rainfall did not occur until mid-March (Figure 5), so the early return may have been atypical. However, all but four of the turtles tracked during the March and April storms remained in stream under banks or in stream bank or riparian vegetation during the peak flows. Yet WPT exhibit a great deal of flexibility regarding seasonal activity patterns. Some populations, such as that studied by Lovich and Meyer (2002) along the Mojave River, are apparently active all winter. It is possible that turtles inhabiting Coyote Reservoir just downstream of the study site and those in large ponds along the UCC drainage are active year round as well, since I have seen turtles in those still water habitats active on mild days in December and early January. Bondi (2009) noted that many turtles made short rest stops at backwater pools before returning to the main river. This behavior was also displayed by the first two turtles I found returning to UCC, on 29 January and 3 February. The backwater pools 
probably provide a refuge from flood hazards and offer more food resources than the main stream early in the year.

The latest recorded return date, 27 April, would appear too late for UCC, despite its similarity to the results from other sites. Typically, by late April, stream flows along UCC have long since been restored, air and water temperatures are increasing, food resources are increasing, and turtles returning to UCC may have a very limited amount of time in which stream conditions allow them to feed and breed. It is likely that most UCC turtles alter their movements to and from the water as weather conditions dictate. By April, the threat of flooding has greatly subsided, although a large mid-April storm occurred in 2012 (Figure 5) that caused some turtles to return upland.

After turtles returned to the stream, they resumed movement gradually, showing increased movements in March and major movements in April and May. Heavy April/May movement was also noted by Bondi (2009), especially among males. In UCC, the six weekly tracking periods that showed the most extensive movement were in May $(n=2)$ 2011, and April/ May (n=4) 2012, and all eight instances in which individual turtles moved over $2000 \mathrm{~m}$ weekly took place in either April or May. Since I did not begin tracking until May, the month of April 2011 was surely under-represented. The comparably modest movements observed for March 2012 may have been due to cooler air and water temperatures, or the need to spend some time feeding before undertaking long movements following an extended period of fasting upland.

The months of June and July saw a reduction in movement compared to April and May, but although this trend was similar in both 2011 and 2012, the results were a study 
in contrasts. In 2011, June/July movement was much greater than in 2012, and that difference must have been the result of substantially reduced stream flow in 2012 (Figure $6)$.

Turtles in UCC departed the stream for upland sites in early to late summer, associated with loss of flow continuity between pools and eventual pool drying. As a species, WPTs show a high degree of behavioral flexibility regarding the use of upland sites. In pond habitats, some remain active all year, some leave for upland sites, and some spend winter buried in the mud beneath the bottom of the water (Ernst and Lovich 2009). The situation is equally complex for turtles occupying stream habitats. Although Lovich and Meyer (2002) studied a population along the Mojave River which did not leave the stream, most studied populations departed the stream at some point to spend at least the winter upland. In general, turtles living in perennial stream habitats leave the stream for upland habitat in fall or early winter, apparently in response to heavy stream flows and flood conditions from winter storms. Reese and Welsh (1997) found turtles leaving the Trinity River in September, Rathbun et al. (2002) found turtles leaving four streams along the central California coast from October to early January, and Davis (1998) recorded turtles leaving her Waddell Creek site along the central California coast in late November and December with the first substantial rains. Bondi (2009) discovered behavioral differences between turtles in perennial habitat and intermittent habitat within the Mad River. Those in perennial habitat left in October, while those in intermittent habitat left between mid- July and late August. Bondi interpreted the results as a response to cool temperatures and increased stream flow in perennial habitat, and to 
decreased water levels in intermittent habitat. Those turtles in the intermittent habitat had a mean stream departure date of 8 August in 2007 and 12 August in 2008. UCC turtles persist in an intermittent stream environment similar to the population along the intermittent reach studied by Bondi. I recorded mean departure dates of 16 August in 2011, 20 July in 2012, and 28 June in 2013, with a range of dates in 2011 from 17 July to 3 October, in 2012 from 1 July to 2 September, and in 2013 from 18 May to 10 August. Much of the variation in each year reflected differences in the timing of drying in reaches within the study area. The earlier dates in 2012 and 2013 resulted from early stream drying following progressively drier rainy seasons. Comparing mean stream departure dates for 2011 (16 August) and 2013 (28 June), a 50-day difference, shows the difference between a moderate winter and a very dry one. Turtles were not tracked in 2014, but conditions were even drier with most surface flow ceasing in May (J. Smith, pers. comm., 2015); it is likely most turtles were upland by June.

The 18 May stream departure date observed in 2013 may be the earliest documented for the species, but that may simply be due to the fact that many WPT studies did not include stream departure data, and those that did studied populations in perennial stream habitat, where turtles typically wait until the approach of winter to leave the stream.

I collected stream departure data for ten turtles in both 2011 and 2012, and it is not surprising, given the drier stream conditions, that eight left earlier in 2012. The most extreme example is that of a turtle that left 72 days earlier in 2012 than in 2011 . In addition to variation and flexibility at the species level, it seems that WPTs may also 
exhibit such traits on an individual level as well. What seems strange is that two turtles left later in 2012 despite the earlier drying. Conditions in 2013 were even drier than in 2012, and only one of eight turtles tracked in both years left the stream later in 2013, and that by just four days.

With some stretches of UCC drying earlier than others, I expected turtles to move and concentrate in areas with the most ample water, Pools \#1 through \#5, but most radiotracked turtles showed no such tendency. In addition, turtles in Pools \#1-5 opted to head upland when pool \#4 maintained water in all 3 years. With extensive areas of water over $1 \mathrm{~m}$ in depth, some complex cover, steep banks, shady areas but not complete canopy cover, and boulders for emergent basking, Pool \#4 appeared to be the kind of habitat turtles could occupy throughout the summer and well into fall, perhaps leaving with the onset of winter. Rather than migrate to pools with substantial water, UCC turtles chose to move upland instead. While turtles in early-drying pools went upland early, some turtles inhabiting pools with ample water left early as well. One of the first turtles leaving the stream in 2011 did so while at the persistent Pool \#4.

Once upland, no turtle selected a site and remained there until re-emerging the next year, although one selected a site and made only two micro-movements of less than $5 \mathrm{~m}$ before settling in for good until returning to the water the next year. Most UCC turtles moved farther and more frequently once in upland habitat, although their movements were not nearly as extensive as those made within the stream environment. Few studies have examined the nature of upland movement in WPT. Reese and Welsh (1997) recorded turtles changing upland sites as many as 4 times, while 22 of 43 (51.1\%) 
turtles tracked by Rathbun et al. (2002) moved only once or not at all after initially heading upland from coastal creeks. They also recorded an individual using a total of nine upland sites. We found UCC turtles moving anywhere from 2-18 times, although only 1 turtle moved more than 10 times. With a mean figure of 5.8 moves per turtle, UCC turtles appeared to have been more active upland than those in the other studies.

The most extensive upland movements on UCC occurred in September (lengthiest movements) and October (most movements). The relatively frequent movements of upland UCC turtles may have been due to the early warm season movement upland. The warm air temperature may be conducive to activity, and may represent searching for better microhabitats. In addition, some UCC turtles returned to the stream shortly after having moved upland. Most that did return did so for only a short duration (less than a week). However, one male left an upland site and traveled upstream through a dry creek bed over $300 \mathrm{~m}$ to reach a remnant pool (pool \#44), where he stayed for nearly a month before returning to his original upland site. No turtle returned to the stream between late October and late January, even though Pools \#4 and \#5 persisted and water levels in UCC increased in late November with rainfall and cooler temperatures. A similar pattern was noted by Bondi (2009), who observed that resumption of stream flow late in the year did not entice upland turtles back to stream habitats.

By November, upland turtle movements along UCC were reduced in both frequency and distance, and intensified during the winter months of December and January, when turtle activity was at its nadir. UCC turtles were typically inactive, unalert, and hidden beneath a cover of dried leaves, twigs, and thatch. This winter 
reduction in activity is almost certainly due to the cold air and water temperatures, and has been documented throughout the range of the WPT, except in areas with very mild winters (Ernst and Lovich 2009). The amount of time that WPT spend annually in upland habitats has received relatively little scrutiny. Rathbun et al. (2002) found turtles along the central Coast spending an average of 111 days upland, with a wide range from 34-191 days. Reese and Welsh (1997) found turtles spending seven months per year upland along the Trinity River, while Bondi's (2009) population along the Mad River showed substantial differences between turtles in perennial habitat and turtles in intermittent habitat. Those in the perennial section averaged 207 days upland, while those in the intermittent reach averaged 241 days upland. Bondi (2009) had extreme examples of 287 days for a female and 310 days for a male, perhaps the lengthiest upland duration yet documented.

Along UCC, I found a fairly lengthy period of upland habitat use, a mean upland duration of 201 days in 2011-2012, similar to the findings of Reese and Welsh (1997). Like those studied by Rathbun et al. (2002), UCC turtles showed a wide range of variation in the time spent upland, from 151-274 days. The Rathbun et al. (2002) study was significant in that it documented upland habitat use over a 3-year period and showed that individual turtles varied in both their stream departure dates as well as the duration of time spent upland each year. I collected such data for only one year (late 2011 early 2012), but had I continued into the subsequent drier years I might have found lengthier upland durations approaching those documented by Bondi (2009). Because stream flow conditions and water levels along UCC were higher in 2011, turtles remained in the 
stream longer and probably spent less time upland. In 2012, turtles left the stream earlier due to overall drier conditions. If they had returned to the stream in 2013 at the same time as in 2012, they would have averaged about 220 days upland. It is also likely that during the even drier conditions in 2013-2014 some turtles could have spent in excess of 300 days upland.

The amount of time spent by WPTs in upland habitats could have profound physiological and ecological implications. Since WPTs feed only when in water, time spent upland is spent fasting. It may be that turtles spending much of the year upland do not grow as large or as quickly as those that spend little or no time upland annually; the lack of new plastron annuli in 2013 and 2015 support this. Turtles that grow slowly likely experience delayed maturity compared to turtles growing at a rapid rate. Slowgrowing turtles spend additional years in adolescence, and they run the risk of dying before breeding, thus having a lower reproductive output than turtles that grow quickly.

\section{Spring/Summer Aquatic Habitat Use}

During the in-stream period I tracked turtles to within $2 \mathrm{~m}$ of precise locations 602 times, and found them in water on $534(88.7 \%)$ occasions. Of the remaining 68, most (58) were on land along the stream terrace, adjacent to the stream, while the rest (10) were upland. I noted but did not analyze the exact locations and activities of turtles tracked to water. In many instances, turtles could not be seen due to depth, flowing water, or the fact that turtles were often hidden beneath rocks, root wads, or leaves. Bury and Germano (2008) also noted that WPTs often seek protected areas when resting under water. Given the predominantly shallow waters of UCC, it is not surprising that UCC 
turtles seek out such retreats. I sometimes observed turtles moving along the bottom, but more often than not, turtles were sedentary. Although I occasionally observed distant turtles basking on emergent objects such as boulders, I never confirmed a tracked turtle doing so, probably because basking turtles usually take to water long before the approach of a human. While I occasionally observed basking turtles at a distance in spring, such observations declined in summer with warmer air and water temperatures. Besides emergent basking, I also observed turtles submerged in shallow ( $<10 \mathrm{~cm}$ deep) water beneath algae mats on numerous occasions. Bury and Germano (2008) noted that WPTs utilize algal mats for basking. Besides retaining heat and providing a warmer microhabitat, algae also provides a protective cover where turtles can remain undetected by predators. These sub-algal observations were more frequent in late spring and summer, when warm air and water were more conducive to extensive algal growth.

Bury (1972) listed three components constituting good WPT habitat along streams and rivers: 1) abundant basking sites, 2) underwater refugia, 3) slow or still water. My results were similar, although with the warm conditions, basking was probably less important than in cooler habitats such as coastal streams (Abel 2010).

The pools used most often by UCC turtles were those with complex cover and depth. These were favored over shallow, simple pools or those that were deep but simple or shallow and complex (Figure 19). Pool \#6 had the highest number of trackings (70). It is a large pool, much of which is between $0.5-1 \mathrm{~m}$ deep, with boulders, overhanging vegetation, and a downed log: all providing habitat complexity. Tracked turtles were usually found within this cover. While generally open, a narrow band of trees along the 
right bank and a fortified earthen wall along the left bank adjacent to Roop Road provide ample shading in the afternoon. Shallow sections at the head and tail of the pool supported extensive algal mats which turtles often utilized.

Similarly, Pool \#11 (64 trackings) is large and contains numerous cover and basking features. The left bank contains a number of boulders and concrete rip-rap which serve as both emergent basking areas and subaquatic retreats. At the middle of the pool along the right bank is a large sycamore with a scour pool (roughly $1.5 \mathrm{~m}$ deep), and a root wad complex occasionally used by turtles. At the tail of the pool there is a deep backwater along the left bank shaded beneath the canopy of a large oak. That backwater was frequently occupied by tracked turtles. Despite several sections of deep water, Pool \#11 dries earlier in the year than some pools in entrenched channels downstream, and ceases to be important in-stream habitat as the year progresses. Turtles were rarely tracked to the shallower and simpler pools $(\# 9, \# 10, \# 12, \# 13)$ immediately up and downstream from heavily-used Pool \#11.

Two other pools with numerous trackings include Pool \#5 (52) and Pool \#8 (50). Both were smaller than Pools \#6 and \#11, yet still attractive to turtles. Pool \#5 includes a fairly deep $(1.5 \mathrm{~m})$ scour hole that is completely shaded by a dense overhanging willow thicket. The water in this section remains year round, while willow branches provide protective aquatic cover and safe basking sites.

Pool \#8 lacked both heavy shading and deep water, yet it contained several habitat features attractive to turtles. The right bank of Pool \#8 had sections over $0.5 \mathrm{~m}$ deep that sit below an extensive stand of mule fat hanging over the bank. Mats of algae provided 
further protective cover, and turtles were frequently tracked to this area where they were found along the bottom and along the bank, hidden among the submerged root-wads of mule fat. The mule fat habitat is thick and extends up onto a terrace island that exists between the main channel and a smaller, shaded secondary channel. This island habitat was also used often by turtles, for the dense mule fat affords additional protection from predators as well as a degree of shade. Turtles tracked here were often found resting at the base of a mule fat bush, immobile but alert. The shade provided by mule fat may also allow turtles to bask there in lieu of emergent basking sites, which were lacking at Pool $\# 8$.

Pool \#7 represented an enigma. More individual turtles (14) were tracked there than in any other location, yet the total number of trackings (15) was far less than the number recorded at Pools \#6 and \#11. Pool \#7 appeared to be an area where turtles passed through between perennial Pools \#5 and \#6 and Pool \#11 and early-drying habitats upstream of Pool \#11 but did not remain long. While not large, it had several features attractive to turtles: deep water along the right bank, and several small boulders for basking. Pool \#7 was a productive trapping site, especially early in spring when turtle movements were more pronounced. Juvenile turtles were frequently captured there.

The more perennial habitats between Pools \#1-4 were generally less frequently used. Pool \#1 (28 trackings) and Pool \#4 (37 trackings) are both large and deep, with a combination of open areas and shaded canopy, with sections of overhanging willows as cover and boulders for basking. While both pools were used fairly regularly by turtles, 
both possessed the high quality habitat features that should have resulted in more trackings.

Besides pools, there are a number of runs along UCC, and some were frequented more often than others. Those most used by tracked turtles $\left(7+, 6+, 5+,-1+, 18^{+}, 8^{+}\right)$ were complex and featured thick stands of mule fat along one or both banks and were

generally adjacent to heavily-used pools. Meanwhile, runs where I never recorded turtles $\left(12+, 13^{+}, 14^{+}, 15^{+}\right)$were simpler, with sparse or no mule fat growth along the banks and were not near heavily-used pools.

\section{Overwintering Sites}

Final overwintering sites of UCC turtles ranged from 9-110 m beyond the edge of the stream, and had a mean distance of $54 \mathrm{~m}$. Rathbun et al. (2002) found overwintering sites ranging from 8-280 $\mathrm{m}$ from water with a mean distance of $50 \mathrm{~m}$. Bondi (2009) found most turtles overwintering 90-120 m from water, while Reese and Welsh (1997) documented a mean distance of $203 \mathrm{~m}$, well beyond not only the UCC mean but also the maximum figure as well. Reese and Welsh (1997) also recorded 2 of 12 turtles overwintering beneath the mud at the bottom of pools along the river, a behavior more readily associated with turtles in pond or lake habitats.

Few studies have documented the plant communities at WPT upland overwinter sites. Rathbun et al. (2002) analyzed 28 overwinter sites along 4 central California coast streams near San Simeon and found the majority $(\mathrm{n}=18,64 \%)$ associated with riparian vegetation. Along UCC, 6 different plant communities were represented within the 15 overwinter sites: coast live oak woodland, Diablan (coastal) Sage Scrub, Sycamore 
Alluvial Woodland, Riparian, Valley Oak Woodland, and Blue Oak Woodland. However, only one community, Coast Live Oak Woodland, was associated with more than two sites. Coast Live Oak Woodland was noted at or adjacent to 14 of the 15 final overwinter sites. Another plant community, grassland, was occasionally used by UCC turtles in the transition between going upland and selecting a final overwinter site, but no tracked turtles utilized grasslands as a final overwinter site. The low incidence of Riparian plant community use may be because UCC was mostly intermittent and thus contained relatively sparse riparian vegetation. Within the study area, a dense riparian border existed only between Pools \#1-\#5. The heavy use of Coast Live Oak woodland for overwintering habitat was likely due to the overall abundance of that community in the uplands of the watershed.

While WPT may not depend upon the presence of Coast Live Oak Woodlands for overwinter sites, they do seem to rely heavily on dense vegetative cover and associated understory and leaf litter. Reese and Welsh (1997) found all ten of their upland turtles overwintering beneath leaf litter (two others overwintered in the mud beneath pools and never headed upland). Rathbun et al. (2002) also found overwintering turtles associated with leaf litter, buried 5-10 cm deep. Turtles along UCC behaved similarly, but with some slight differences. All 15 overwintering sites had leaf litter, but grass thatch was present at six sites and was more prominent than leaf litter at four of those. The exact nature of the plant material probably matters less than the quantity of vegetation under which turtles can hide. Extent of burial also probably depends on what is available. UCC turtles were found often at depths less than those found by Rathbun et al. (2002), 
and I often saw turtles partially exposed on the surface. Likewise, I saw little or no evidence of turtles burying themselves into the soil, possibly because the dry soil was hard during late summer and fall, when most turtles settled upland.

Overwintering turtles were also associated with moderate to heavy canopy cover. All 15 sites had a canopy cover of $40 \%$ or more, while nearly half $(n=7,46.7 \%)$ had $80 \%$ or greater canopy cover. I suspect the strong correlation with canopy cover is primarily due to the abundance of dry leaves, twigs, and understory vegetation under the canopy rather than the presence of shade.

Twelve of 15 overwintering sites had a southern aspect (S, SE, SW). Because of the heavy presence of canopy at overwinter sites this may not reflect a preference for maximum solar exposure during winter. Instead, it may have represented conditions on the closely adjacent slopes used. Some overwintering sites $(n=6)$ were on level ground $\left(<20^{\circ}\right)$, but most were located on hillsides with slopes in excess of 30-40 degrees, and some $(n=6)$ were on even steeper slopes. While it is understandable that turtles would seek sites above the relatively level flood zone, some went well beyond that, selecting sites over $30 \mathrm{~m}$ above the stream. Perhaps steep slopes lessen the likelihood of falling victim to predators.

\section{Status}

Given that the WPT has experienced range contraction and general population decline throughout its range (Stebbins 1985; Ernst and Lovich 2009) and has been petitioned for listing under the Endangered Species Act of 1973 (Ernst and Lovich 2009), it would be prudent to assess the status of as many known populations as possible. 
Unfortunately, a short term study of an apparently robust population such as this reveals little in the way of population trends. However, observations made during the course of this study may provide insight into potential threats to the UCC turtle population.

Currently, the UCC population seems safe from the large-scale urban, suburban, and agricultural developments that have ravaged WPT populations throughout California. Although Roop Road runs roughly parallel to the stream for several kilometers, in the two plus years of this study I walked and drove along the road extensively and saw no evidence of road kill. Much of the land within the UCC watershed, including most of the study area, was purchased and has been managed by the Santa Clara County Open Space Authority. The area has been closed to the general public and receives little visitation. If in the future these lands are opened to the public, that could result in some negative impacts on the turtle population, although I suspect that effect would be slight. The development of facilities necessary for public visitation would be limited but could result in some habitat loss, especially in upland areas. There is a potential for nesting to be disturbed or otherwise negatively impacted, especially if dogs are permitted. Another threat, illegal collecting, might increase.

Additional land management decisions that could negatively impact WPTs here include livestock grazing and prescribed burning. Over the course of this study, a small herd of cattle occupied the study site on a seasonal if not year-round basis. While cattle grazing may be benign in habitats such as non-native grasslands, it provides no benefit to stream environments. Cattle degrade streams with their droppings, erode and damage banks, and strip away vegetation in and around the stream bed. All of these actions 
degrade habitat for turtles as well as several other sensitive species. Increased numbers of cattle also heighten the risk of mortality through accidental trampling, which could victimize both individual turtles and nests. The threat posed by cattle is negligible upstream in Coe Park, where no grazing program exists. Open Space Authority lands have a more flexible policy toward cattle grazing. I recommend installing exclusionary fencing along the creek to keep cattle out of sensitive stream habitats.

Another land management action that could potentially pose a threat to UCC turtles is prescribed burning, which is part of the management plan upstream within Coe Park. Since many prescribed burns are conducted in fall, a time of year when turtles are vulnerable in upland environments, it is possible that some turtles and nests could be lost due to this practice if such a program were implemented on Open Space Authority lands. The intermittent stream habitat is largely responsible for protecting UCC turtles from a host of non-native, invasive species that could otherwise pose a threat to turtles. Non-native fish such as bass could consume hatchlings and juvenile turtles but cannot establish populations in UCC due to extensive stream drying. Bullfrogs are another aggressive non-native species that may consume hatchlings and young juveniles, and although they are present in numerous stock ponds throughout the watershed, their presence within the stream system is limited, for their tadpoles require year round water in order to transform. Finally, at least several species of non-native turtles are occasionally released into outdoor environments when their former owners no longer can or will take care of them (Stebbins and McGinnis 2012). Such turtles may pose a threat to WPTs through both competition for resources and disease transmission (Spinks et al. 
2002). Yet non-native turtles would have a difficult time establishing populations along UCC, for they did not evolve in, and could not likely adapt to, an aquatic environment which dries for half a year or more annually.

Another looming threat is that posed by global warming. Future temperature increases and/or a decline in precipitation threaten to reduce water levels and stream flow throughout the UCC watershed, perhaps similar to the drought conditions seen in 20122015. If severe enough, the less-than-optimal conditions now faced by turtles could degrade further, to the point where water levels become too meager to support the species. Rising temperatures could also influence reproduction, for WPT eggs are temperature-dependent for gender determination (Ewert et al. 1994; Geist et al. 2015). Higher temperatures produce an increase in female hatchlings (Geist et al. 2015), so the male bias presently observed at UCC could be replaced by a more balanced gender ratio, which could be an improvement over current conditions.

A final concern regarding the long term future for turtles in UCC involves genetic variability and the idea of a minimum viable population size. The present population is probably large enough and the habitat sufficiently connected to maintain genetic diversity. Upstream of the study area, the watershed continues for slightly over $10 \mathrm{~km}$, and there is evidence of movement between the study site and turtle concentrations upstream. However, any set of conditions which result in a substantial population decline or fragmentation of populations by drying could be disastrous, because other WPT populations downstream of Coyote Reservoir or in the Pacheco Creek drainage are not likely sources of connectivity. 
While this study has revealed much about the UCC turtle population, so much more remains to be discovered. Among the many potential topics are nesting and reproduction, and the effects of Coyote Reservoir on the UCC turtle population. Do some turtles regularly go back and forth between the creek and the reservoir? Does the reservoir have its own population that rarely, if ever, uses the creek?

Perhaps of even greater interest is the extent to which turtles use the many stock ponds that exist within the watershed. Some, such as Tule Pond and Rodeo Pond in Coe Park, are situated over $2 \mathrm{~km}$ from the creek on ridges over $400 \mathrm{~m}$ above the creek. If the turtles currently found there came from UCC, what accounts for such movement, especially since most long distance movements were made by males? Turtles have been reported in ponds near the study area, and landowners suggested movement between the creek and those ponds. This study found only one turtle that did so. Do turtles regularly trek back and forth between ponds and the creek, or do such "pond" turtles, particularly those frequenting larger, permanent ponds, remain sedentary? If they stay at ponds year round, do they exhibit different physiological and behavioral characteristics than "creek" turtles? For example, do "pond" turtles head upland in summer, or, with permanent water, do they do so in winter? Do they even have an inactive period? I have seen turtles basking on cool sunny days in early January in ponds at Coe Park at a time when UCC turtles are buried beneath leaf litter. Do "pond" turtles attain larger sizes, grow faster, and reproduce earlier than "creek" turtles due to the presence of year round water and food availability? If there truly are turtles in the UCC watershed that remain all year in pond habitats, and if they exhibit physiological and/or behavioral differences from those 
that inhabit the stream system, those could be significant discoveries. They could be examples of flexibility, variation, and adaptability not merely within a species but within a population. I hope some of those questions will be addressed in the future, and I hope that this work will motivate others to appreciate, preserve and protect the Western Pond Turtle, as well as the habitat and landscapes in which it evolved. 


\section{REFERENCES}

Abel, J. 2010. Western Pond Turtle summer habitat use in a coastal watershed. Master's thesis. San José State University, San José, California.

Ashton, D. T., H. H. Welsh, and J. B. Bettaso. 2006. Influence of altered thermal regime on body size and age of maturation on Western Pond Turtles (Clemmys marmorata) in Trinity County, California. Northwestern Naturalist 87:155.

Bondi, C. A. 2009. A comparison of Western Pond Turtle (Actinemys marmorata) movements in perennial and intermittent portions of a northwestern California river system. Master's thesis. Humboldt State University, Arcata, California.

Bousman, W. G. 2007. Breeding bird atlas of Santa Clara County, California. Santa Clara Valley Audubon Society, Cupertino, California.

Brattstrom, B. H. 1988. Habitat destruction in California with special reference to Clemmys marmorata: A perspective, p. 13-24. In H. F. De Lisle, P. R. Brown, B. Kaufman, and B. M. McGurty (eds.), Proceedings of the Conference on California Herpetology. Southwest. Herpetol. Soc., Van Nuys, California.

Brattstrom, B. H., and A. Sturn. 1959. A new species of fossil turtle from the Pliocene of Oregon, with notes on other fossil Clemmys from western North America. Bulletin of the Southern California Academy of Sciences 58:65-71.

Bury, R. B. 1972. Habits and home range of the Pacific Pond Turtle, Clemmys marmorata, in a stream community. Ph.D. dissertation, University of California, Berkeley.

Bury, R. B. 1979. Population ecology of freshwater turtles, p. 571-602. In M. Harless and H. Morlock (eds.), Turtles: Perspectives and Research. John Wiley and Sons, New York.

Bury, R. B. 1986. Feeding ecology of the turtle Clemmys marmorata. Journal of Herpetology 20:515-521. 
Bury, R. B., and D. J. Germano. 1998. Annual deposition of scute rings in the Western Pond Turtle, Clemmys marmorata. Chelonian Conservation and Biology 3:108109.

Bury, R. B., and D. J. Germano. 2008. Actinemys marmorata (Baird and Girard 1952)Western Pond Turtle, Pacific Pond Turtle, p. 001.1-001.9. In: The Conservation Biology of Freshwater Turtles and Tortoises. A. G. J. Rhodin, P. C. H. Pritchard, P. P. van Dijk, R. A. Saumure, K. A. Buhlman, and J. B. Iverson (eds.). A Compilation Project of the IUCN/SSC Tortoise and Freshwater Turtle Specialist Group. Chelonian Research Monographs 5.

Bury, R. B., D. J. Germano, and G. W. Bury. 2010. Population structure and growth of the turtle Actinemys marmorata from the Klamath-Siskiyou ecoregion: age, not size, matters. Copeia. No. 3:443-451.

Bury, R. B., H. H. Welsh, Jr., D. J. Germano, D. T. Ashton (eds.). 2012. Northwest fauna- a monograph of vertebrate biology, number 7. Western Pond Turtle: biology, sampling techniques, inventory and monitoring, conservation, and management. The Society for Northwestern Vertebrate Biology. Olympia, Washington.

Buskirk, J. R. 1991. An overview of the Western Pond Turtle, Clemmys marmorata, p. 16-23. In K. R. Beaman, F. Caporaso, S. McKeown, and M. D. Graff (eds.), Proceedings of the First International Symposium on Turtles and Tortoises: Conservation and CaptiveHusbandry. Chapman University, Orange, California.

Cagle, F. R. 1939. A system for marking turtles for future identification. Copeia 1939: $170-173$.

Cook, D., and J. Martini-Lamb. 2004. Distribution and habitat use of Western Pond Turtles in a seasonal impounded river. Sonoma County Water Agency, Santa Rosa, California.

Davis, C. 1998. Western Pond Turtle (Clemmys marmorata pallida) winter habitat use and behavior. Master's thesis. San José State University, San José, California.

Ernst, C. H., and R. B. Barbour. 1972. Turtles of the United States. University Press Kentucky, Lexington. 
Ernst, C. H., and J. E. Lovich. 2009. Turtles of the United States and Canada. The John Hopkins University Press, Baltimore, Maryland.

Geist, N. R., Z. Dallara, and R. Gordon. 2015. The role of incubation temperature and clutch effects in development and phenotype of head-started Western Pond Turtles (Emys marmorata). Herpetological Conservation and Biology 10 (Symposium):489-503.

Germano, D. J. 2010. Ecology of Western Pond Turtles (Actinemys marmorata) at sewage-treatment facilities in the San Joaquin Valley of California. The Southwestern Naturalist 55:89-97.

Germano, D. J., and R. B. Bury. 1998. Age determination in turtles: evidence of annual deposition of scute rings. Chelonian Conservation and Biology 3:123-132.

Germano, D. J., and R. B. Bury. 2001. Western Pond Turtles (Clemmys marmorata) in the central valley of California: status and population structure. Transactions of the Western Section of The Wildlife Society 37:22-36.

Germano, D. J., and R. B. Bury. 2009. Variation in body size, growth, and population structure of Actinemys marmorata from lentic and lotic habitats in southern Oregon. Journal of Herpetology 43:510-520.

Germano, D. J., and G. B. Rathbun. 2008. Growth, population structure, and reproduction of Western Pond Turtles (Actinemys marmorata) on the central coast of California. Chelonian Conservation and Biology 7:188-194.

Gonsolin, E. 2001. Ecology of Foothill Yellow-legged Frogs in upper Coyote Creek, Santa Clara County, CA. Master's thesis, San José State University, San José, California.

Goodman, R. H., Jr. 1997a. The biology of the Southwestern Pond Turtle (Clemmys marmorata pallida) in the Chino Hills State Park and the West Fork of the San Gabriel River. Master's thesis. California State Polytechnical University, Pomona.

Goodman, R. H., Jr. 1997b. Occurrence of double clutching in the Southwestern Pond Turtle, Clemmysmarmorata pallida, in the Los Angeles Basin. Chelonian Conservation and Biology 2:419-420. 
Goodman, R. H. Jr., and G. R. Stewart. 2000. Aquatic home ranges of female Western Pond Turtles, Clemmys marmorata, at two sites in southern California. Chelonian Conservation and Biology 3:743-745.

Goodrich, T. 2005. Names on the land: a history of Henry W. Coe State Park. Pine Ridge Association, Morgan Hill, California.

Hill, P. M. 2006. Actinemys marmorata (Pacific Pond Turtle): Neonates. Herpetological Review 37:215.

Holland, D. C. 1985. Clemmys marmorata (Western Pond Turtle): Feeding. Herpetological Review 19:112-113.

Holland, D. C. 1984. The Western Pond Turtle: Habitat and history. Final Rep. U. S. Dept. Energy, Bonneville Power Administration Project 92-068, Contract DEBI79-92B62137.

Janzen, F. J., S. L. Hoover, and H. B. Shaffer. 1997. Molecular phylogeography of the Western Pond Turtle (Clemmys marmorata): Preliminary results. Linnaeus fund research report. Chelonian Conservation and Biology 2:623-626.

Lovich, J., and K. Meyer. 2002. The Western Pond Turtle (Clemmys marmorata) in the Mojave River, California, U.S.A.: highly adapted survivor or tenuous relict? Journal of Zoology, London 256:537-545.

Lubcke, G. M., and D. Wilson. 2006. Actinemys marmorata (Pacific Pond Turtle): Size. Herpetological Review 37:339.

Lubcke, G. M., and D. Wilson. 2007. Variation in shell morphology of the Western Pond Turtle (Actinemys marmorata) from three aquatic habitats in northern California. Journal of Herpetology 41:107-114.

Pine Ridge Association. 1997. A resource inventory of the Redfern Addition to Henry W. Coe State Park.

Rathbun, G. B., N. J. Scott Jr., and T. G. Murphey. 2002. Terrestrial habitat use by Pacific Pond Turtles in a Mediterranean climate. Southwestern Naturalist 47:225235. 
Reese, D. A. 1996. Comparative demography and habitat use of Western Pond Turtles in northern California: The effects of damming and related alterations. Ph.D. dissertation, University of California, Berkeley.

Reese, D. A., and H. H. Welsh Jr. 1997. Use of terrestrial habitat by Western Pond Turtles, Clemmys marmorata: Implications for management, p. 352-357. In J. Van Abbema (ed.), Proceedings: Conservation, Restoration, and Management of Tortoises and Turtles- An International Conference. New York Tortoise Society, New York.

Reese, D. A., and H. H. Welsh Jr. 1998. Habitat use by Western Pond Turtles in the Trinity River, California. Journal of Wildlife Management 62:842-843.

Scott, N. J., G. B. Rathbun, T. G. Murphey, and M. B. Harker. 2008. Reproduction of Pacific Pond Turtles (Actinemys marmorata) in coastal streams of central California. Herpetological Conservation and Biology 3:143-148.

Spinks, P. Q., G. B. Pauly, J. J. Crayon, and H. B. Shaffer. 2003. Survival of the Western Pond Turtle (Emys marmorata) in an urban California environment. Biological Conservation 113:257-267.

Spinks, P. Q., and H. B. Shaffer. 2005. Range-wide molecular analysis of the Western Pond Turtle (Emys marmorata): Cryptic variation, isolation by distance, and their conservation implications. Molecular Ecology 14:2,047-2,064.

St. John, A. D. Reptiles of the Northwest: California to Alaska; Rockies to the Coast. Lone Pine, Auburn, Washington.

Stebbins, R. C. 2003. A field guide to western reptiles and amphibians. Houghton Mifflin, Boston.

Stebbins, R. C., and S. M. McGinness. 2012. Field guide to reptiles and amphibians of California. University of California Press, Berkeley.

Storer, T. I. 1930. Notes on the range and life-history of the Pacific fresh-water turtle, Clemmys marmorata. University of California Publications in Zoology 32:429441. 